\title{
Canadian guidelines for the management of acute exacerbations of chronic bronchitis
}

\author{
Meyer S Balter MD FRCPC ${ }^{1}$, Jacques La Forge MD FRCPC CSPQ ${ }^{2}$, Donald E Low MD FRCPC 1,3 , \\ Lionel Mandell MD FRCPC ${ }^{4}$, Ronald F Grossman MD FRCPC FACP 1 and the Chronic Bronchitis Working Group ${ }^{5}$ \\ on behalf of the Canadian Thoracic Society and the Canadian Infectious Disease Society
}

\begin{abstract}
MS Balter, J La Forge, DE Low, L Mandell, RF Grossman, and the Chronic Bronchitis Working Group on behalf of the Canadian Thoracic Society and the Canadian Infectious Disease Society. Canadian guidelines for the management of acute exacerbations of chronic bronchitis. Can Respir J 2003;10(Suppl B):3B-32B.
\end{abstract}

Acute exacerbations of chronic bronchitis (AECB) account for over 1.5 million physician visits annually in Canada and are a cause of significant morbidity and mortality. This document represents a joint effort between respirologists, microbiologists, infectious disease specialists and family physicians to update the Canadian AECB guidelines published in 1994. Treatment recommendations are graded on the strength of evidence in the published literature where possible. The role for oral corticosteroid therapy in preventing treatment failures, speeding up recovery and delaying the time to next exacerbation is discussed. Risk factors for treatment failure were used to stratify patients into risk groups to help guide antibiotic treatment recommendations. The importance of emerging antimicrobial resistance to current antibiotics is reviewed and strategies to prevent future AECB episodes are suggested.

Key Words: Chronic bronchitis, Exacerbations, Antibiotics, Risk Stratification

\section{Lignes directrices canadiennes sur le traite- ment des exacerbations aiguës de bronchite chronique}

Les exacerbations aiguës de bronchite chronique (EABC) motivent plus 1,5 million de consultations médicales chaque année, au Canada et sont cause d'une morbidité et d'une mortalité importantes. Le présent document est le fruit du travail de collaboration entre les pneumologues, les microbiologistes, les infectiologues et les omnipraticiens visant à actual iser les lignes directrices canadiennes en matière d'EABC, publiées en 1994. Les recommandations relatives au traitement ont été cotées, dans la mesure du possible, en fonction du degré de fiabilité des données trouvées dans la documentation. On y traite du rôle de la corticothérapie orale pour éviter les échecs de traitement, accélérer le rétablissement et repousser la prochaine exacerbation. Les facteurs de risque d'échec de traitement ont servi de critère à la classification des patients en groupes de risque pour aider à orienter les recommandations quant à l'antibiothérapie. Il est également question de l'importance d'un phénomène nouveau, soit de la résistance des bactéries aux antibiotiques actuels, et de stratégies pour prévenir les futurs épisodes d’EABC.

\begin{abstract}
A cute exacerbations of chronic bronchitis (AECB) account for over 1.5 million physician visits annually in Canada and are a cause of significant morbidity and mortality. Canadian guidelines for the management of chronic bronchitis were published in 1994 (1). In that document, the pathophysiology of chronic bronchitis and emphysema and the pathology, risk factors, diagnosis and treatment of chronic bronchitis were discussed. AECB were dealt with in the major section of the document. A stratification system comprising five different patient groups was proposed, with antimicrobial recommendations made for each group. Many recent developments have forced a re-examination of these recommendations with respect to the risk stratification process and the specific antimicrobial recommendations. This document is an update from our original guidelines and is a joint effort by the Canadian Thoracic Society (CTS) and the Canadian Infectious Disease Society (CIDS).
\end{abstract}

\section{METHODS}

A needs assessment survey was sent out with the 1994 guidelines to representative family physicians across Canada early in 1999. The purpose was to obtain insight into the major challenges they faced in diagnosing and managing AECB. A committee was established that was composed of members from both the CTS and the CIDS, as well as two family physicians with strong interests in continuing medical education and AECB. The committee members were divided into four teams, each of which was responsible for one of four sections. These sections were as follows: epidemiology, risk factors, pathogenesis and pathophysiology; diagnosis and therapy excluding antibiotics; antimicrobial therapy; and resistance. The committee met for one day in Toronto, Ontario, in May 1999 to discuss key areas of interest and controversy. Subsequently, each team developed a draft of its section. These drafts were then circulated among all committee members and revised a number of times based on comments from committee members and outside reviewers.

${ }^{1}$ University of Toronto, Mount Sinai Hospital, Toronto, Ontario; ${ }^{2}$ Laval University, Hôpital Laval, Ste-Foy, Quebec; ${ }^{3}$ The Toronto Hospital, Toronto Medical Laboratories, Toronto, Ontario; ${ }^{4}$ McMaster University, Henderson General Hospital, Hamilton, Ontario; ${ }^{5}$ See appendix Correspondence: Dr Meyer Balter, 640-600 University Avenue, Toronto, Ontario M5G 1X5. Telephone 416-586-4663, fax 416-586-4736, e-mailmbalter@mtsinai.on.ca

Reprints: Core Health Services Inc, 1800 Steeles Avenue West, Second Floor, Concord, Ontario L4K 2P3 


\section{COPYRIGHT PULSUS GROUP INC, - DO NOT COPY}

Relevant articles published between 1966 and July 1, 2002, were retrieved from Medline using the index terms 'chronic obstructive pulmonary disease', 'chronic bronchitis' combined with 'acute exacerbations', as well as specific terms relating to various interventions such as 'steroids', 'bronchodilators', 'anticholinergics', 'antibiotics' and 'mucolytics'. Articles published before 1966 were retrieved from the reference lists of later papers. The Cochrane control trials register until the end of the year 2001 was also searched. In addition, abstracts from the American Thoracic Society, American College of Chest Physicians, European Respiratory Society and International Conference on Antimicrobial Agents in Chemotherapy meetings from 1999 to 2002 were reviewed.

Treatment recommendations were graded on the strength of evidence similar to those used for the Canadian guidelines for the initial management of community-acquired pneumonia (2). Wellconducted, randomized, controlled trials constitute strong or Level I evidence; well-designed controlled trials without randomization including cohort and case-control studies constitute Level II or fair evidence; and expert opinion, case studies, and before and after studies are Level III or weak evidence. These ratings appear as roman numerals in parentheses after each recommendation in these guidelines.

\section{EPIDEMIOLOGY AND RISK FACTORS}

Chronic obstructive pulmonary disease (COPD) is now the fifth leading cause of death in Canada and the prevalence is increasing (3). There have been several attempts in recent years to define COPD $(4,5)$. Most definitions consider COPD to be a disease state characterized by air flow limitation that is not fully reversible. The air flow limitation is usually progressive and associated with an abnormal inflammatory response of the lungs to inhaled particles or gases. It is an umbrella term that includes the entities of chronic bronchitis and emphysema when associated with air flow limitation. Ordinarily, asthma, cystic fibrosis, bronchiectasis and bronchiolitis obliterans are excluded from this definition.

Chronic bronchitis can be defined clinically as a disorder with expectoration of sputum on most days during at least three consecutive months for more than two successive years, other causes of cough and sputum having been excluded (6). Chronic bronchitis is present in approximately $85 \%$ of patients with COPD. Chronic bronchitis frequently coexists with emphysema and small airways disease, the degree of each varying from person to person. It is essential to recognize that chronic bronchitis often occurs without airway obstruction; only a minority of patients with chronic bronchitis have evidence of COPD (7).

\section{Epidemiology}

Between 1951 and 1984, the mortality from COPD in Canada increased in both sexes, and by the mid 1980s, COPD was the sixth leading cause of death in men and the eighth leading cause of death in women (8). By 1995, COPD was the fifth leading cause of death in Canada and there had been an increase in total deaths from 4438 in 1980 to 8583 in 1995. During this period, the age-standardized mortality in men remained stable (around 45 per 100,000 population) while it doubled in women (8.3 per 100,000 in 1980 to 17.3 per 100,000 in 1995) (9). Review of data from the 1994 to 1995 Canadian National Health Survey indicated that about 750,000 Canadians had chronic bronchitis or emphysema diagnosed by a health professional. The prevalence of COPD in Canada has been estimated to be about $5 \%$ in adults between the ages of 55 and 75 and approximately $7 \%$ in the over 75 age group. In 1993 to 1994, there were 55,782 hospital separations in which COPD was the primary discharge diagnosis; this was increased from 42,102 in 1981 to 1982 . The average in-hospital length of stay for patients admitted with COPD was 9.6 days in 1981 to 1982 and 8.3 days in 1993 to 1994 (9). These data clearly demonstrate that COPD is a disorder with enormous morbidity and mortality, and puts a very significant burden on health care resources.

COPD appears to have a similar prevalence in other Western countries. The Cardiovascular Health Study (10) in the United States, in which spirometry was performed on 5201 elderly individuals, demonstrated that $5 \%$ of adults over the age of 65 reported a diagnosis of one of the COPDs (asthma, chronic bronchitis and emphysema). In this study, undiagnosed airway obstruction was noted in $7 \%$ of individuals and was most likely to occur in current and former smokers, women, lower income groups and individuals with chronic cough. This still may be an underestimate with reports of as many as $20 \%$ of the population having COPD in the United States, where it is the fourth leading cause of death $(11,12)$. The prevalence of COPD in Europe varies from approximately $4 \%$ in Denmark and Norway $(13,14)$, to $6 \%$ in Spain and Sweden $(15,16)$. Data from the Asia Pacific area appear to be in the same range (17). In some communities, the prevalence of chronic bronchitis is much higher, and this may reflect the local environment and smoking habits. In Nepal, the prevalence of chronic bronchitis is $18 \%$ with similar frequency in men and women, and this may relate to exposure to wood smoke for cooking with inadequate or absent ventilation (18).

\section{Risk factors}

Smoking, some occupational exposures and alpha-1 antitrypsin deficiency are well-established risk factors for the development of COPD. There is good evidence that a number of other risk factors are also important including air pollution, environmental tobacco smoke, respiratory infections, airway hyperresponsiveness and genetic factors.

Cigarette smoking is undoubtedly the most common cause of chronic bronchitis, and there is well-established evidence that cigarette smoking is associated with increased mortality from COPD, increased prevalence of symptoms of COPD and increased prevalence of lung function abnormalities. The degree of abnormality is proportional to the amount smoked and is not specific for cigarettes, because both pipe and cigar smokers also have an increased morbidity and mortality from COPD. Although many smokers have some degree of cough and sputum production, only approximately $15 \%$ will develop significant COPD (19-21). In Western society, cigarette smoking accounts for $80 \%$ to $90 \%$ of the overall COPD burden (22).

A number of occupations have been associated with the development of COPD, and there is good evidence that chronic exposure to cadmium, silica, minerals and grain dusts can result in the development of airway disease. Workers involved in mining, furnace work, farming, metal work, wood and paper work, and cement workers are all at increased risk. Grain workers and cotton workers also have an increased risk of COPD $(23,24)$.

Alpha-1 antitrypsin deficiency is a well-recognized cause of COPD but is responsible for less than $1 \%$ of all cases. Only a 


\section{COPYRIGHT PULSUS GROUP INC, " DO NOT COPY}

few nonsmokers with alpha-1 antitrypsin deficiency develop emphysema; most never develop symptoms. Some alpha-1 antitrypsin-deficient smokers never develop obstruction (25). Some families appear to have an increased risk of COPD and it is probable that other genetic factors may increase susceptibility to COPD (26).

Individuals with increased airway hyperresponsiveness who smoke appear to be at increased risk for the development of COPD. It is difficult to determine whether bronchial hyperresponsiveness is a true risk factor for COPD or whether it follows as a result of the development of smoking-related airway disease and the decrease in lung function. The Lung Health Study demonstrated a strong correlation between increased bronchial hyperresponsiveness and accelerated decline in forced expiratory volume in one second $\left(\mathrm{FEV}_{1}\right)(27)$. This finding confirmed earlier work that showed that both smokers and exsmokers with less nonspecific hyperreactivity had a slower decline in $\mathrm{FEV}_{1}$ (28).

Ongoing exposure to environmental tobacco smoke and secondhand smoke appears to be a risk factor for the subsequent development of chronic bronchitis (29); 4197 never smokers aged between 18 and 60 years in eight separate geographic areas of Switzerland were surveyed and it was found that there was an increased prevalence of respiratory symptoms that was directly proportional to the increased dose and duration of exposure to secondhand cigarette smoke (30).

There appears to be a causal relationship between early childhood infections and respiratory symptoms and reduced lung function in adult life. Over 800 children in East Boston were observed for 13 years, and it was found that respiratory illness before two years of age and two or more lower respiratory tract illnesses during a single surveillance year were associated with lowered lung function in adulthood (31). The causal relationship between pneumonia in early childhood and COPD in late adult life has been further supported in a study of 618 subjects with a mean age of 70 years in whom parish records were available for their first two years of life. It was found that pneumonia before the age of two was associated with a lower FEV in late adult life (32). Adenoviral infections are responsible for many childhood respiratory illnesses and the adenovirus is known to persist in a latent form. Latent adenoviral DNA was more commonly found in individuals with COPD than in those without (33). These data suggest that the developing airways are vulnerable to the effects of infection, and that latent adenoviral infections may contribute to the pathogenesis of COPD in adults. The role of acute respiratory infections in adults is less clear, although there is a good theoretical argument to support the "vicious circle" hypothesis of Cole and Wilson (34) that ongoing chronic bacterial infection may result in ongoing airway damage.

Air pollution appears to be a significant risk factor for COPD. The risk appears to be related to the nature and intensity of the air pollution. Exposure to particulates less than 10 microns was strongly correlated with the development of cough and sputum production and mortality in the Utah valley (35). More recently, a direct association between exposure to particulates in the air in Switzerland and symptoms of chronic phlegm production and cough was demonstrated in a large population study (36). Levels of air pollution have fallen considerably in most developed countries but are still high in many cities in developing countries, and levels of indoor air pollution can be very high in these countries - in particular, where wood is burned to cook and heat the home. A recent case-control study in Colombia found wood smoke to be more highly associated with the development of COPD in women than either tobacco use or passive smoking (37).

There is currently no good evidence that race, socioeconomic class, education and dietary factors can be linked definitively as independent risk factors to the development of COPD. Recent data suggest that female sex may be an independent risk factor, although this has not been clearly established (38). It appears that women have a higher prevalence of airway hyperreactivity than men (39). Whether this alone explains their apparent increased susceptibility to the harmful effects of cigarette smoking remains to be determined.

\section{PATHOGENESIS, PATHOLOGY AND PATHOPHYSIOLOGY}

The past few years have brought with them new interest into the basic mechanisms contributing to chronic bronchitis. A detailed review of this topic is outside the scope of these guidelines and the interested reader is referred elsewhere $(40,41)$. This section reviews some basic tenets regarding the pathogenesis, pathology and pathophysiology of chronic bronchitis, particularly as it relates to acute exacerbations of the disease.

The pathological lesions of chronic bronchitis involve both the large and the small airways. The walls of the airways of affected patients contain a prominent inflammatory cell infiltrate. In the large airways, this inflammatory process is associated with metaplasia of both the columnar and the goblet cells lining the epithelium, an increase in the size of the mucoussecreting glands (42), an increase in the amount of smooth muscle and connective tissue in the bronchial wall (43) and degeneration of the airway cartilage (44). The Reid index, a ratio of gland to bronchial wall thickness, is the pathological marker of the excess cough and sputum production that defines the disease (39). However, there is no relation between this index and the degree of air flow obstruction, which appears to correlate better with the presence of inflammation in the small airways (45). Smooth muscle hyperplasia in chronic bronchitis is not related to bronchodilator responsiveness or bronchial hyperreactivity as occurs in asthma. However, bronchial hyperreactivity can be seen in up to $50 \%$ of patients with chronic bronchitis, occasionally making it difficult to exclude an asthmatic component to the illness. Part of the reason for the finding of bronchial hyperreactivity in chronic bronchitis may be due to the fact that these patients are starting with a lower $\mathrm{FEV}_{1}$. The lower the $\mathrm{FEV}_{1}$, the greater the response to an inhaled bronchoconstrictor. Therefore, the relevance of this finding remains unclear.

Two separate hypotheses have been put forward to explain the pathogenesis of chronic bronchitis and COPD. The "Dutch hypothesis" (46) postulated that airway hyperresponsiveness and atopy were markers of a basic genetic disturbance predisposing to the development of chronic lung disease characterized by the presence of cough, sputum production and air flow limitation. This suggests that asthma and chronic bronchitis are variations of the same disease. The "British hypothesis" $(47,48)$ proposed that chronic obstructive bronchitis develops as a result of bronchial irritation and subsequent hypertrophy of mucous-secreting glands due to smoking, pollution and recurrent infections. The development of cough was hypothesized to lead to progressive airway obstruction, disability and death. A major criticism of this hypothesis was the 


\section{COPYRIGHT PULSUS GROUP INC, - DO NOT COPY}

lack of evidence linking chronic cough and sputum production to progressive air flow limitation (49-51). However, recent studies have shown a consistent association between chronic mucous hypersecretion and both an accelerated decline in $\mathrm{FEV}_{1}$ and an increased risk of subsequent hospitalization (52-54). In addition, exacerbation frequently appears to be correlated with $\mathrm{FEV}_{1}$ decline (55), particularly in patients who continue to smoke (56). Thus, it appears that components of both of these hypotheses are likely to be correct. This would make it easier to explain the pathogenesis of such a heterogeneous disease.

The inflammatory cell infiltrate affects both the central airways and the peripheral airways, the sites responsible for the air flow limitation in smokers. So called 'small airways disease', a chronic inflammatory process of the small airways, has been demonstrated in virtually all young smokers (57). In addition, increased peripheral airway inflammation distinguishes the airways of smokers with obstruction from those without obstruction (58). However, only $15 \%$ to $20 \%$ of heavy smokers go on to develop clinically significant or measurable airway obstruction $(48,59)$. Therefore, factors other then cigarette smoking alone must contribute to the development of air flow obstruction. There are most likely genetic factors influencing the susceptibility to the effects of cigarette smoking or the development of the airway inflammatory response to various stimuli $(60,61)$. The association of mucous gland enlargement and goblet cell hyperplasia with the intensity of the inflammatory cell infiltrate in airway walls also suggests that inflammation is of central importance in the pathogenesis of chronic bronchitis. However, the cells, cytokines and mediators involved in the airway inflammation of chronic bronchitis are quite different from those found in asthmatic airways, perhaps explaining the differences in clinical presentation and responses to treatment of these diseases.

The neutrophil is the predominant cell found in the airways of patients with chronic bronchitis. Bronchial lavage fluid from patients with chronic bronchitis contains a significantly higher percentage of neutrophils than lavage fluid from asymptomatic smokers or normal control subjects (62). In addition, the potent neutrophil chemotactic factors, interleukin (IL)-8 and leukotriene B4 (LTB4), and the neutrophil activation products myeloperoxidase (MPO) and elastase, are elevated in chronic bronchitis (63-65). There is evidence that the bacteria that colonize the airways of patients with chronic bronchitis and that are involved in many of the exacerbations of the disease secrete products that contribute to this neutrophil-driven inflammation (66). A higher percentage of neutrophils was found in the airways of smokers who developed airway obstruction over a 15-year period than those who did not (67). In addition, the annual decline in $\mathrm{FEV}_{1}$ over the15-year period was related to the degree of induced sputum neutrophilia implying cause and effect (68). Patients with more severe air flow obstruction have a higher percentage of neutrophils in both induced sputum and bronchial lavage $(62,68,69)$. Finally, neutrophils in induced sputum are higher in COPD patients with severe air flow obstruction than nonobstructed smokers, nonsmoking control subjects and asthmatics (69).

Macrophages and activated $\mathrm{T}$ lymphocytes are also increased in the airways of patients with chronic bronchitis (70). The T cells are of the $\mathrm{CD}^{+}$variety, differentiating the type of inflammation from that seen in asthma (71). Eosinophils, which are the predominant inflammatory cells in the airways of asthmatics, do not seem to play a prominent role in the stable chronic bronchitic patient, although there have been reports of elevated bronchial lavage and biopsy eosinophils in some studies $(64,65,72)$. The eosinophil may have a more prominent role in the pathogenesis of acute exacerbations (73).

\section{Airway inflammation during AECB}

Patients with chronic bronchitis are prone to recurrent exacerbations of their disease. Evidence is beginning to emerge that these exacerbations are associated with increased airway inflammation. In addition, there appears to be an association between the degree of inflammation and the severity and frequency of the exacerbations. Both the absolute number and the proportion of neutrophils in bronchoalveolar lavage (BAL) increase during AECB (74). In addition, cytokines and mediators known to reflect neutrophil infiltration and activation rise during AECB. Levels of IL-8, MPO and LTB4 in induced sputum all rise during AECB (75-78). Patients with higher baseline cytokine levels have more frequent exacerbations (76). Patients with severe AECB requiring hospitalization have evidence of more severe neutrophilic inflammation during exacerbations (75).

Eosinophils, which do not appear to play a significant role in the pathogenesis of chronic bronchitis, may be important during AECB. There are increased numbers of eosinophils in induced sputum and BAL during AECB (74). In addition, bronchial biopsies taken from the airways of mild chronic bronchitics during an acute exacerbation have revealed marked increases in mucosal and submucosal eosinophils, as well as evidence of increased cellular activation $(73,79)$.

\section{Role of bacteria in chronic bronchitis and AECB}

The normal tracheobronchial tree is sterile. In patients with chronic bronchitis, the lower airways are chronically colonized with bacteria, predominantly Haemophilus influenzae, Moraxella catarrhalis and Streptococcus pneumoniae (80-82). The role that these bacteria play in causing progressive lung disease remains controversial, but a clearer understanding of their interaction with damaged airways is emerging.

Cigarette smoking leads to the loss of ciliated epithelium and more viscous airway secretions, compromising the local defenses of the respiratory tract. The delay in mucociliary clearance allows inhaled bacteria to colonize the normally sterile airways (83). Once bacteria adhere to mucin or epithelial cells in the lower airway, they persist by further impairing mucociliary clearance. There are several mechanisms whereby bacteria may damage the lower airways. $H$ influenzae, $S$ pneumoniae and Pseudomonas aeruginosa have all been shown to stimulate mucus secretion (84). These same bacteria produce substances that impair ciliary function $(85,86)$. In addition, there is some evidence that $H$ influenzae can directly cause airway epithelial injury (87). Finally, bacteria residing in the lower airway secrete enzymes that break down local immunoglobulins, and also demonstrate antigenic heterogeneity to avoid immune surveillance and can form microcolonies surrounded by polysaccharide gel to decrease their clearance (88).

It is becoming clear that bacteria colonizing the lower airways of patients with chronic bronchitis are capable of stimulating the secretion of various inflammatory mediators and cytokines that contribute to airway inflammation. Lipopolysaccharide (LPS) is the major glycolipid in the outer 
membrane of Gram-negative bacteria. Bacteria colonizing the airways are in a constant state of turnover to avoid recognition by the host inflammatory response. As they turn over, bacteria release extracellular products as well as LPS from their cell walls. LPS is a very potent inflammatory stimulus. H influenzae expresses an LPS molecule that lacks the long repeating polysaccharide side chains that are typical of this molecule in other Gram-negative bacteria. Therefore, the endotoxin of $\mathrm{H}$ influenzae is more commonly referred to as a lipo-oligosaccharide (LOS). LOS is a potent secretagogue for a variety of inflammatory mediators. It can increase epithelial cell permeability and can lead to the release of IL-6, IL-8 and tumour necrosis factor (TNF) (89).

Evidence has accumulated suggesting a correlation between levels of inflammatory mediators and cytokines and bacterial colonization of the lower airways. Soler et al (90) performed BAL and compared quantitative cultures of bacteria in the lower airways with the levels of various cytokines. They demonstrated that bacterial colonization of the lower airways was associated with significantly more neutrophils and TNFalpha when compared with airways that did not have significant amounts of bacteria. In addition, there was a trend toward higher levels of IL-8 in the BAL of patients colonized with bacteria. Interestingly, bacterial colonization and increased inflammatory cells and cytokines occurred in patients with chronic bronchitis whether or not they had associated air flow obstruction. Bresser et al (91) performed similar experiments using expectorated sputum in patients with both obstructive and nonobstructive chronic bronchitis. They found similar correlations between the levels of certain cytokines and infection with $\mathrm{H}$ influenzae. Of interest, they also found differences in levels of TNF-alpha in patients with obstructive lung disease when compared with patients with nonobstructive chronic bronchitis. This is of interest because the TNF-alpha has been implicated in the pathogenesis of chronic airway obstruction $(69,92)$.

To summarize, initial damage to the airways, most commonly caused by cigarette smoking, impairs mucociliary clearance and weakens host defences, allowing the normal steril airways to become colonized with bacteria. Once the bacteria colonize the airways, they contribute to the airway inflammation and impaired mucociliary clearance allowing their persistence in the airways and, perhaps, contributing to progressive airway obstruction. This is referred to as the "vicious circle" hypothesis (Figure 1) (34,93).

Lower airway bacterial colonization during the stable state Initial studies examined the presence of bacteria in the sputum of patients with stable chronic bronchitis. H influenzae was present in the sputum of up to $60 \%$ of such patients (94). More recently, bronchoscopic techniques have been used to examine pathogens residing in the airways during stable chronic bronchitis. Cabello et al (95) found colonization of the lower airways in $83 \%$ of COPD patients. They claimed that only a minority of these bacteria were potentially pathogenic. However, nonpotentially pathogenic bacteria may still contribute to lower airway inflammation and risk of recurrent infections with other species. In addition, our view as to what is a pathogenic microorganism changes with time. For example, $\mathrm{M}$ catarrhalis was considered a commensal for many years but is now thought to be a pathogenic species in AECB. A similar debate revolves around Haemophilus parainfluenzae (96). Zalacain et al (97), using a protected specimen brush, found

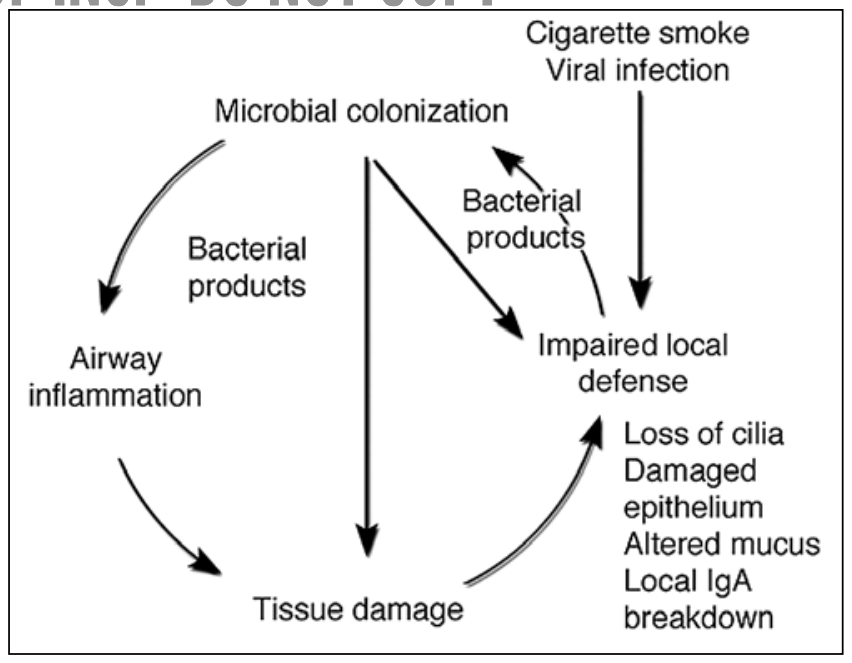

Figure 1) The role of cigarette smoke and viral infection in initializing and perpetuating the "vicious circle" of impaired local defenses. IgA Immunoglobulin A Source: Recommendations on the Management of Chronic Bronchitis: A Practical Guide for Canadian Physicians. Reprinted from Supplement to CMAJ 15 November 1994; 151:7-23 by permission of the publisher, (C) 1994 Canadian Medical Association (1)

significant bacterial growth in $40 \%$ of patients with stable COPD and in none of the control subjects. Monso et al (98) found significant bacterial growth in $22 \%$ of patients with stable COPD using similar methods. Nontypeable $H$ influenzae was the most common isolate in both studies, which is consistent with virtually all studies done using sputum from patients with chronic bronchitis. Monso et al (98) reported that current smoking was the most important predictor of bacterial colonization, whereas Zalacain et al (97) determined that air flow obstruction and smoking were independent predictors of airway bacterial colonization. Recent studies have confirmed the association between the degree of air flow obstruction and the type of bacteria colonizing the lower airways. Individuals with chronic bronchitis and an $\mathrm{FEV}_{1}$ less than $50 \%$ of predicted have a six-fold higher risk of being colonized by virulent Gram-negative bacteria such as $P$ aeruginosa and Enterobacteriaceae species than do patients with an $\mathrm{FEV}_{1}$ above $50 \%$ of predicted $(99,100)$. Whether this is an effect of worsening air flow obstruction or, more likely, an effect of more frequent episodes of AECB with subsequent use of antibiotic therapy in patients with poor lung function remains to be determined.

The location of bacteria within the airways may be important in terms of both inducing inflammatory responses and protecting the bacteria from local defense mechanisms. Nontypeable $H$ influenzae not only binds to human epithelial cells in the airways but is able to penetrate the epithelial cell layer where they may be protected from both antibiotics and antibody mediated bactericidal activity $(101,102)$. Moller and colleagues (103) found H influenzae not only in the epithelium and submucosa of the bronchi, but also in the interstitium and alveolar epithelium of patients with end-stage lung disease undergoing lung transplantation. These bacteria residing in tissues may act as a reservoir for recurrent infections or induce chronic low-grade infection that continues to enhance the host inflammatory response as described by the vicious circle 
TABLE 1

COPYRIGHT PULSUS GROUP INC. DO NOT COPY

Prevalence of bacterial pathogens from sputum in acute exacerbations of chronic bronchitis

\begin{tabular}{|c|c|c|c|c|c|c|c|c|c|}
\hline & $\begin{array}{l}\text { Fogarty } \\
\text { et al (106) }\end{array}$ & $\begin{array}{l}\text { Eller et al } \\
(99)\end{array}$ & $\begin{array}{l}\text { Wilson et al } \\
(107)\end{array}$ & $\begin{array}{c}\text { Shah et al } \\
(108)\end{array}$ & $\begin{array}{l}\text { Langan et al } \\
(109)\end{array}$ & $\begin{array}{c}\text { Georgopoulos } \\
\text { et al (110) }\end{array}$ & $\begin{array}{c}\text { Habib } \\
\text { et al (111) }\end{array}$ & $\begin{array}{l}\text { Chodosh } \\
\text { et al (112) }\end{array}$ & $\begin{array}{l}\text { DeAbate } \\
\text { et al (113) }\end{array}$ \\
\hline Year & 2000 & 1998 & 1999 & 1999 & 1999 & 2001 & 1998 & 1998 & 1997 \\
\hline Patients, $\mathrm{n}$ & 548 & 211 & 750 & 832 & 802 & 395 & 373 & 624 & 492 \\
\hline Patients with isolates, $n$ & 403 & 112 & 287 & 547 & 400 & 219 & 192 & 290 & 301 \\
\hline Total isolates, $\mathrm{n}$ & 498 & 150 & 342 & 577 & 513 & 275 & 181 & 379 & 346 \\
\hline \multicolumn{10}{|l|}{ Bacterial isolates, \% } \\
\hline Haemophilus influenzae & 18 & 14 & 31 & 36 & 36 & 35 & 25 & 18 & 17 \\
\hline Moraxella catarrhalis & 9 & 7 & 15 & 16 & 12 & 13 & 14 & 21 & 14 \\
\hline Streptococcus pneumoniae & 5 & 17 & 25 & 18 & 11 & 3 & 8 & 7 & 6 \\
\hline Staphylococcus aureus & 13 & 13 & 5 & 3 & 9 & 3 & 7 & 20 & 10 \\
\hline Pseudomonas species & NR & 15 & 1 & 8 & NR & 3 & 13 & NR & 5 \\
\hline Haemophilus parainfluenzae & 28 & NR & 5 & 2 & 27 & NR & 12 & 6 & 15 \\
\hline Enterobacteriaceae species & $S \quad N R$ & 25 & 5 & 5 & NR & 33 & 19 & NR & 8 \\
\hline
\end{tabular}

NR Not reported

hypothesis. Finally, there is evidence that there may be antigenic drift in nontypeable $H$ influenzae species so that recurrent infections may actually be by new strains of the bacteria in some individuals $(102,104,105)$.

\section{Isolation of bacteria during an AECB}

Bacteria have been isolated from sputum in up to $60 \%$ of AECB. The most common organism isolated include $H$ influenzae, $H$ parainfluenzae, $S$ pneumoniae, and $M$ catarrhalis (Table 1) (99,106-113). Some studies have found higher numbers of Staphylococcus aureus, Pseudomonas species and members of the Enterobacteriaceae family. It is not always clear whether these more virulent organisms are found in patients with more severe air flow obstruction, more frequent exacerbations treated with antibiotics, or are due to different culture techniques. Finding a bacterial pathogen within the airways of somebody during an AECB does not necessarily implicate that species as the trigger for the exacerbation. A number of studies have shown a similar incidence of bacterial isolation from sputum during periods of clinical stability and AECB (114,115). More recently, investigators have turned toward the use of bronchoscopy using protected specimen brushes or BAL sampling of the lower airways with subsequent quantitative cultures to determine the importance of bacteria during episodes of AECB. Four studies have now been published using these methods and all have shown evidence for significant bacterial infection of the distal airways in approximately $50 \%$ of patients experiencing an AECB $(116-119)$. Two of these studies were performed in outpatients and demonstrated significant bacterial growth more frequently in patients during an episode of AECB than at baseline $(117,119)$. Although many of the bacteria found in the airways were similar during periods of clinical stability and exacerbations, the colony counts were significantly elevated during episodes of AECB.

Sputum, bronchial washings and bronchial brushings may underestimate the presence of bacteria, particularly if the latter have penetrated the epithelial cell layer. Bandi et al (102) found nontypeable $H$ influenzae in only $26 \%$ of bronchial washings or brushings from clinically stable patients with chronic bronchitis, and in only $7 \%$ of patients with AECB. However, intracellular nontypeable $H$ influenzae were demonstrated in bronchial biopsies from $87 \%$ of patients with AECB, 33\% of stable patients with chronic bronchitis and from no healthy controls.

Sethi and colleagues (46) used molecular typing to identify new strains within a bacterial species in sputum isolates collected during an AECB. Exacerbations were associated with 33\% of visits in which new strains were identified, versus only $15 \%$ of visits in which no new strains were found $(\mathrm{P}<0.001)$. These findings support an important role for bacteria in AECB.

If bacteria are important in inducing exacerbations and contributing to worsening airway inflammation, there should be a correlation between measures of airway inflammation and sputum culture results during an episode of AECB. Sethi et al (77) followed a group of COPD patients at regular intervals and cultured either spontaneously expectorated or induced sputum from individuals who had evidence of an AECB. The sputum specimens were also assayed for IL-8, TNF-alpha and neutrophil elastase, which were used as surrogate markers for neutrophilic inflammatory responses to acute bacterial infection in the airways. These investigators showed that there were significantly higher levels of markers of airway inflammation in pathogenpositive exacerbations than in pathogen-negative exacerbations, supporting a role for these pathogens in AECB.

One of the arguments against the importance of bacteria in AECB has been that many patients recover without antibiotic therapy. Up to this point, there have been no characteristic markers separating a bacterial exacerbation from a nonbacterial exacerbation, making the study of potential beneficial effects of antibiotics in AECB very difficult. Anthonisen et al (120) suggested that antibiotics benefit patients with AECB who have a triad of increased sputum volume, sputum purulence and worsening dyspnea. It was only in patients with all three of these symptoms that antibiotics seemed to have a statistically significant and clinically relevant advantage over placebo. Some studies purporting to show no additional benefits of antibiotics compared with oral corticosteroids alone included many patients who had underlying asthma, and no effort was made to document the presence of bacterial infection (121). More recently, Stockley et al (122) compared the presence of purulent sputum with the results of bacterial cultures. During periods of exacerbation, a positive bacterial culture was obtained from $84 \%$ of patients if their sputum was purulent, whereas positive cultures were obtained in only $38 \%$ of patients with mucoid sputum. In addition, when the patients 


\section{COPYRIGHT PULSUS GROUP ING, - DO NOT COPY}

were restudied in a stable state between exacerbations, the incidence of a positive bacterial culture was similar in both groups, approximating 40\%. Overall, they felt that the presence of purulent sputum was $94.4 \%$ sensitive and $77 \%$ specific in predicting the yield of a high bacterial load in culture and in identifying the group most likely to benefit from antibiotic therapy. In a follow-up to this study, the same authors correlated the presence of sputum purulence with the levels of certain inflammatory markers including MPO, IL-8 and LTB4 $(123,124)$.

The role of viruses and atypical organisms, such as Mycoplasma and Chlamydia species, is becoming clearer. There are three separate mechanisms whereby these organisms may have a role in COPD and AECB. First, infection with certain agents at a young age may make airways more susceptible to the effects of cigarette smoking and increase the risk of chronic bronchitis later in life. This has been suggested both with adenoviral infections in childhood (33) and with Chlamydia pneumoniae infection (125). Second, these organisms can cause AECB in their own right. $\mathrm{Up}$ to one-third of $\mathrm{AECB}$ are related to viral or Mycoplasma infections $(82,114,126-128)$. C pneumoniae is thought to account for only $5 \%$ to $10 \%$ of acute exacerbations of COPD $(129,130)$, although one recent study suggested that it may be involved either alone or as a cofactor in up to $22 \%$ of AECB (131). The third mechanism whereby viruses and atypical organisms may be involved in AECB would be by causing a primary infection that worsens lower airway inflammation, which enables a secondary increase in bacterial proliferation that would then play a role in the exacerbation $(131,132)$. There is evidence that respiratory virus infections are associated with more severe and frequent $\mathrm{AECB}$ and may contribute to chronic infection in COPD (128). Rhinovirus infection had been shown to be involved in precipitating AECB (133) and a recent study suggests that rhinovirus infection leads to an elevation of lower airway IL-6 levels (134). This worsening of lower airway inflammation may theoretically enhance bacterial proliferation, leading to secondary bacterial involvement in these episodes of AECB as well.

\footnotetext{
AECB

Like the disease itself, exacerbations of chronic bronchitis are defined clinically. It has become traditional to use some combination of the following three criteria originally described by Anthonisen and colleagues (120) to define AECB: increased cough and sputum, sputum purulence and increased dyspnea over baseline. Unfortunately, there are no characteristic laboratory or radiographic tests to make the diagnosis of AECB, so the definition of an exacerbation remains problematic. Seemungal and colleagues (134) have proposed major and minor criteria to define an exacerbation. The major criteria are the three proposed by Anthonisen. Minor criteria include wheezing, sore throat, cough and symptoms of a common cold such as nasal congestion or discharge. They defined an exacerbation as the presence of at least two major symptoms, or one major and one minor symptom, for at least two consecutive days. It is clear that the incidence of $A E C B$ will vary depending on which definition is used. Using the Anthonisen criteria, the typical patient with COPD will average two to three AECB episodes annually. Other causes of deterioration include congestive heart failure, pneumonia, pulmonary emboli, pneumothorax, inappropriate oxygen administration and drugs such as tranquilizers.
}

Approximately $50 \%$ of exacerbations, particularly those meeting the Anthonisen criteria, are believed to result from infection, but exposure to allergens, pollutants or irritants (cigarette smoke, dust) may all precipitate a worsening of chronic bronchitis. Exacerbation rates are an important determinant of disease-specific health status as measured by a standard quality of life questionnaire (135). Exacerbations may lead to hospitalization, which carries with it a $4 \%$ short term mortality rate for patients with mild to moderate disease (136), but as high as $24 \%$ if admitted to an intensive care unit with respiratory failure (137-140). This latter group of patients with severe disease have one-year mortality rates of up to 46\% (137-139). Many patients requiring hospitalization for $\mathrm{AECB}$ will require subsequent readmissions because of persistent symptoms $(137,140,141)$. In addition, they will experience at least a temporary decrease in their functional abilities (142).

There are no characteristic physical findings in AECB. Although some authors have suggested that severe exacerbations of chronic bronchitis are associated with a body temperature of higher than $38.5^{\circ} \mathrm{C}(143)$, this idea is not widely accepted. In fact, a study of patients hospitalized because of a severe $\mathrm{AECB}$ found that the mean temperature on admission was $36.4^{\circ} \mathrm{C}(137)$. The presence of an elevated body temperature should suggest a viral infection (128) or underlying pneumonia as a cause of an AECB. The lack of a clear definition of AECB has hampered investigation into appropriate therapy of the disorder.

Chest roentgenograms are not helpful in making the diagnosis of AECB, although they should be considered if there is a possibility of pneumonia or congestive heart failure contributing to the presentation. An exception to this general rule should be made for patients seen in emergency rooms or admitted to hospital. In these settings, routine chest roentgenograms have been shown to reveal abnormalities that lead to changes in management in $16 \%$ to $21 \%$ of patients (144-146).

Sputum Gram-stain and culture have a very limited role in the investigation of the etiology of AECB because, for reasons discussed above, the airways of patients with chronic bronchitis are chronically colonized with bacteria. Therefore, the finding of a particular organism does not necessarily imply a causal relationship to the AECB. Sputum analysis should be reserved for patients with frequent exacerbations or chronic purulent sputum in whom the presence of more virulent and/or resistant bacteria is more likely (Level III evidence).

Objective measurements of lung function are necessary to confirm the presence of air flow obstruction. There is a poor correlation between chronic symptoms of dyspnea and measurement of $\mathrm{FEV}_{1}$ (147). In addition, there is a very poor correlation between the amount of sputum produced and the degree of air flow limitation $(43,148)$. However, $\mathrm{FEV}_{1}$ remains the best predictor of mortality (149) and has been shown to be important in predicting need for admission to the intensive care unit (150). There is also evidence that $\mathrm{FEV}_{1}$ is highly predictive of clinical outcomes during AECB (151). Despite this there is continued evidence that spirometry is being underutilized in the patient group at risk of developing chronic bronchitis (152154). The continued reliance on clinical indicators as a basis for obtaining spirometry leads to the underdiagnosis of COPD and other causes of air flow obstruction. Despite this, strong argument in favor of screening spirometry in high-risk individuals, there is little evidence to suggest that spirometry has a role in evaluating an $\mathrm{AECB}$. Measurement of $\mathrm{FEV}_{1}$ may not be possible 


\section{COPYRIGHT PULSUS GROUP INC, - DO NOT COPY}

in a patient with a severe AECB. In addition, it is not clear that there is a correlation between transient falls in lung function and the severity of the exacerbation as defined by the Anthonisen criteria (120). Therefore, although it is helpful to know the premorbid $\mathrm{FEV}_{1}$ as a predictor of adverse outcome during an AECB, it is not necessary that spirometry be performed during the actual exacerbation (Level III evidence). However, the development of an AECB should be a motivating factor to obtain objective measurements of pulmonary function after recovery in patients who had not previously had spirometry (Level III evidence). The use of peak expiratory flow rates (PEFR) is not recommended as a substitute for spirometry because it is much more effort-dependant, has not been demonstrated to predict outcome in COPD and should not show variability in a disease defined as having fixed air flow obstruction.

\section{Management of AECB}

Chronic bronchitis is a clinical entity related to chronic/ intermittent mucous hypersecretion. It represents a diagnostic category within the spectrum of COPD in which chronic air flow limitation may or may not be present. AECB are by definition associated with increases in the quantity and/or purulence of the sputum, with or without increased dyspnea. The large body of literature focusing on the treatment of AECB is, in most cases, focused on antimicrobial therapy.

The phrase 'exacerbation of COPD', on the other hand, typically refers to increases in dyspnea in association with increases in the degree of air flow limitation, with or without clinical manifestations of respiratory infection. Increased sputum volume and/or purulence may be present, but are not necessary for the diagnosis of COPD exacerbation.

The problem that becomes apparent in reviewing the COPD literature is that the majority of studies regarding treatment of exacerbations beyond antibiotics (oxygen, bronchodilators, corticosteroids, etc) are focused on exacerbations of COPD; hence, results are generally extrapolated, perhaps inappropriately, to the management of AECB.

Treatment of AECB should provide symptomatic relief, prevent transient loss of pulmonary function that may lead to hospitalization and lead to a re-evaluation of the disease in a particular patient to determine if the risk of future exacerbations can be reduced. Patients should be removed from any source of irritants that may worsen lower airway inflammation, including dust, pollutants and first- and second-hand smoke. Pharmacological therapy aims at decreasing the work of breathing, reducing airway inflammation, reducing the bacterial burden in the lower airways and treating any accompanying hypoxemia.

\section{Bronchodilator therapy}

Bronchodilator therapy should be employed for the treatment of dyspnea accompanying an exacerbation. The majority of the studies examining the role for inhaled bronchodilators in exacerbations of COPD have been done in patients presenting to the emergency room or hospitalized because of the exacerbation. Therefore, it is not clear whether the results of these studies are applicable to the much larger population of AECB patients treated at home. In addition, the endpoint most commonly measured is $\mathrm{FEV}_{1}$, and this may not be the most relevant parameter because it may not change much in a single AECB episode. Some of the studies comparing anticholinergics to short-acting beta-agonists have combined asthmatics with
COPD patients. Nonetheless, certain general statements can be made based on the available literature (155).

Most studies comparing short-acting beta-agonists with inhaled anticholinergic agents show no appreciable difference between the two in terms of effects on pulmonary function (156-159). There may be fewer side effects with ipratropium than salbutamol (160). Most studies examining the effects of combination therapy do not report any added benefit of adding a second agent (156,160-162). One study demonstrated a greater improvement in $\mathrm{FEV}_{1}$ with combination therapy than with a beta-agonist alone (163), while another showed shorter emergency room stays for the group on combination therapy (164). None of these studies are well standardized in terms of dose of medication or dosing frequency. Therefore, it is difficult to make specific recommendations. Some patients clearly benefit from combination bronchodilator therapy and there does not appear to be a significant increase in side effects with this combination (Level III evidence). Although there has been recent interest in the role of long-acting beta-agonists in the chronic therapy of COPD, these agents have not been studied in AECB and are not recommended for treatment of this condition at the present time. A number of studies have compared the use of metered dose inhalers (MDIs) to nebulized bronchodilators. These studies are occasionally flawed by using much larger doses of nebulized medications. Nonetheless, as supported by a meta-analysis of studies in patients with either asthma or COPD, there does not appear to be any difference in pulmonary function outcomes between delivery systems (165). Therefore, the choice of delivery system should be based on cost and the patient's ability to use MDIs with a spacer. In most situations, MDIs with an appropriate spacer would be preferred (Level II evidence).

There does not appear to be a role for the initiation of therapy with methylxanthines in AECB. The addition of aminophylline to inhaled bronchodilators has not been shown to lead to improved $\mathrm{FEV}_{1}$ but does increase frequency of side effects $(166,167)$. For patients who are already on an oral methylxanthine product, it is reasonable to continue the medication during an AECB. However, one must keep in mind possible drug interactions with antibiotics (eg, ciprofloxacin, clarithromycin) and adjust the dose accordingly (Level III evidence).

\section{Oxygen therapy}

Patients with chronic bronchitis are at risk of developing hypoxemia during an exacerbation. This can lead to hypoxic pulmonary vasoconstriction with subsequent right heart strain and possible cor pulmonale. In addition, hypoxemia can increase the risk of myocardial ischemia in the elderly COPD population and can have neuropsychiatric side effects. Low-flow oxygen should be administered if hypoxemia is present (168-171). Excess use of oxygen should be avoided as this may lead to progressive hypercapnia, either by decreasing hypoxic ventilatory drive or by worsening ventilation-perfusion mismatching within the lung $(172,173)$. The goal of therapy with supplemental oxygen should be to maintain a partial pressure of oxygen in arterial gas at or just above $60 \mathrm{mmHg}$. Decisions regarding long term need for supplemental oxygen should not be made during an AECB, because up to $50 \%$ of patients requiring oxygen during an exacerbation will no longer meet the criteria for home use if reassessed one to three months later (174-176). 


\section{COPYRIGHT PULSUS GROUP ING. " DO NOT COPY}

TABLE 2

Randomized trials of corticosteroids in chronic obstructive pulmonary disease exacerbations

\begin{tabular}{|c|c|c|c|c|c|}
\hline Study (Reference) & Year & Sample size & Intervention & Outcomes & $\mathbf{P}^{*}$ \\
\hline \multirow[t]{2}{*}{ Emerman et al (190) } & 1989 & 96 & Methylprednisolone $100 \mathrm{mg} \times 1$ dose & $\mathrm{FEV}_{1}$ at 3 and $5 \mathrm{~h}$ & NS \\
\hline & & & & Admission & NS \\
\hline \multirow[t]{2}{*}{ Albert et al (371) } & 1980 & 44 & Methylprednisolone & Pre- and postbronchodilator & $<0.001$ \\
\hline & & & $0.5 \mathrm{mg} / \mathrm{kg} \mathrm{q} 6 \mathrm{~h} \times 72 \mathrm{~h}$ & $\mathrm{FEV}_{1}$ tid $\times 72 \mathrm{~h}$ & \\
\hline \multirow[t]{3}{*}{ Thompson et al (191) } & 1996 & 27 & Prednisone $30 \mathrm{mg} \times 3$ days, & Improvement in $\mathrm{PO}_{2}$ & 0.002 \\
\hline & & & $40 \mathrm{mg} \times 3$ days, $20 \mathrm{mg} \times 3$ days & Improvement $\mathrm{FEV}_{1}$ & 0.006 \\
\hline & & & & Decreased treatment failures & 0.002 \\
\hline \multirow[t]{2}{*}{ Davies et al (192) } & 1999 & 56 & Prednisolone $30 \mathrm{mg}$ od $\times 2$ weeks & $\mathrm{FEV}_{1}$ postbronchodilator & $<0.0001$ \\
\hline & & & & Length of hospitalization & 0.027 \\
\hline \multirow[t]{3}{*}{ Niewoehner et al (193) } & 1999 & 271 & Methylprednisolone $125 \mathrm{mg} \mathrm{q6h} \times 72 \mathrm{~h}$ & Treatment failure & 0.04 \\
\hline & & & followed by prednisone $60 \mathrm{mg}$ od $\times 4$ days & Length of hospitalization & 0.03 \\
\hline & & & tapered over 2 versus 6 weeks & Increased $\mathrm{FEV}_{1}$ days 1-3 & $<0.05$ \\
\hline \multirow[t]{3}{*}{ Maltais et al (201) } & 2002 & 199 & Prednisolone $30 \mathrm{mg} \mathrm{q} 12 \mathrm{~h} \times 3$ days & Postbronchodilator FEV 1 & $<0.05$ versus placebo \\
\hline & & & Budesonide $2 \mathrm{mg} q 6 \mathrm{~h} \times 3$ days & & NS budesonide \\
\hline & & & & & versus prednisolone \\
\hline
\end{tabular}

*Steroids versus placebo. FEV ${ }_{1}$ Forced expiratory volume in $1 \mathrm{~s}$; NS Not significant; $\mathrm{PO}_{2}$ Partial pressure of oxygen

\section{Mucous clearing strategies}

Expectorants or cough suppressants are not effective during exacerbations of chronic bronchitis. Pharmacological therapy to enhance mucous clearance has not been shown to improve lung function or hasten the clinical recovery in AECB (177-179), although it may produce a subjective improvement (177). There is no beneficial effect of chest physiotherapy on the time to recover from an AECB $(180,181)$. There is even some suggestion of worsening pulmonary function and gas exchange with this form of therapy $(182,183)$. Therefore, we do not endorse the use of mucolytic agents or chest physiotherapy during AECB (Level II evidence). Patients should be kept adequately hydrated to prevent excessive mucous viscosity but increased fluid intake should be avoided except by patients who are clearly dehydrated (Level II evidence).

\section{Miscellaneous therapies}

At this point, there is no evidence supporting the use of leukotriene receptor antagonists in AECB.

The use of noninvasive ventilation (NIV) in acute exacerbations of COPD has been demonstrated to reduce mortality and decrease the need for intubation and mechanical ventilation $(184,185)$ (Level I evidence). Overall, NIV also reduces morbidity and hospital or intensive care unit length of stay (186). Factors predicting success include good level of consciousness at the start of the trial, higher $\mathrm{pH}$ and lower partial pressure of carbon dioxide in arterial gas $\left(\mathrm{PaCO}_{2}\right)$, and improvements in $\mathrm{pH}$ and $\mathrm{PaCO}_{2}$ within $1 \mathrm{~h}$ of $\mathrm{NIV}$ initiation (187-189). Poor outcomes are associated with decreased adherence to NIV protocol, presence of pneumonia and poor nutritional status.

\section{Corticosteroid therapy}

Since our first set of guidelines was published in 1994, a number of randomized, placebo-controlled trials have been published confirming the value of oral and/or parenteral corticosteroids in the therapy of AECB. These trials are summarized in Table 2. These studies demonstrate that systemic steroids lead to a faster improvement in pre- and postbronchodilator $\mathrm{FEV}_{1}$, more rapid recovery of partial pressure of oxygen, decreased treatment failures and shorter hospitalization rates. The one study that failed to show a benefit of parenteral steroids during an exacerbation of COPD used only a single dose of methylprednisolone 100

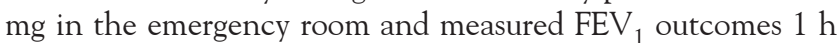
and $3 \mathrm{~h}$ following this bolus (190). The follow-up interval may not have been sufficient to detect a significant improvement because it is generally felt that steroids take at least $6 \mathrm{~h}$ to have a beneficial effect.

There are a number of limitations to these trials. All but one study (191) were performed in emergency rooms or hospital wards, so that the results may not be applicable to outpatient populations. The severity of the underlying lung disease was quite variable, although the majority of patients enrolled had moderate to severe underlying disease. Finally, the dose and duration of corticosteroid therapy varied widely among studies, making it virtually impossible to provide specific treatment recommendations. One must carefully weigh the pros and cons of higher dose and more prolonged corticosteroid therapy in this elderly group of individuals. In the studies quoted, the major side effect in the steroid-treated group was hyperglycemia $(192,193)$.

Systemic therapy may have additional beneficial effects aside from speeding up recovery from an AECB. A retrospective study performed in an emergency room setting demonstrated that steroid-treated individuals had a significantly reduced likelihood of relapse compared with the group not getting steroids (194). Seemungal and colleagues (134) followed a cohort of 101 COPD outpatients over 2.5 years during which a total of 504 exacerbations were recorded. It was up to the individual treating physician to choose whether to add steroids to the treatment plan for any patient. Patients receiving prednisolone had more severe exacerbations as reflected by larger falls in PEFR and a longer recovery time for symptoms and PEFR. However, the rate of recovery of PEFR was faster in the group given prednisolone. Of greater interest, steroids prolonged the time to the next exacerbation from a median of 60 days in the group not receiving prednisolone to 84 days in the treated group $(\mathrm{P}=0.037)$. In contrast, antibiotic therapy had no effect on recovery time or time to next exacerbation.

The mechanism(s) through which corticosteroids speed up recovery in AECB remain(s) unclear. Steroids are effective in terms of reducing airway edema and mucus hypersecretion, 


\section{COPYRIGHT PULSUS GROUP ING. " DO NOT COPY}

both of which play a role in the pathogenesis of AECB. Airway eosinophilia and activation have been demonstrated in some patients with $\operatorname{AECB}(79,134)$ and steroids are very effective at reducing eosinophil migration into the airways and preventing degranulation. Steroids are capable of increasing secretory leukoproteinase inhibitor (SLPI) in airway epithelial cells in vitro and in airway secretions measured in induced sputum $(195,196)$. SLPI has antiviral and antibacterial activity (197) and sputum SLPI levels are lower in COPD patients with more frequent exacerbations (124). Therefore, their effect on reducing the frequency of exacerbations may be on the basis of both decreased airway inflammatory effects and decreased risk of mucosal infections. However, this hypothesis will need to be tested in the future.

There is good evidence to support the use of oral or parenteral steroids for most patients with moderate to severe AECB (Level I evidence). The exact dose and duration of therapy should be individualized and more specific recommendations must await further evidence. It appears that 10 days of therapy is more effective than three days, but no other comparisons have been made (198). We recommend treatment for periods of five to 14 days (Level III evidence). Whether patients with mild disease $\left(\mathrm{FEV}_{1} 60 \%\right.$ to $70 \%$ greater than predicted) also benefit from a course of oral steroids during AECB is unknown at the present time. There are significant health consequences to the use of continuous oral corticosteroids in COPD and similar deleterious effects may occur in patients treated with frequent short courses (199).

The role for inhaled steroids in AECB has not yet been defined. Although some studies have failed to demonstrate a role for inhaled steroids in speeding up symptom resolution in AECB, these trials have not been designed to answer this question (200). A recently published prospective, randomized trial comparing high dose nebulized budesonide ( 2 mg every $6 \mathrm{~h}$ for $72 \mathrm{~h}$ ) versus prednisone ( $30 \mathrm{mg}$ twice daily for $72 \mathrm{~h}$ ) demonstrated no difference between active treatments, with both being superior to placebo in terms of recovery of $\mathrm{FEV}_{1}$ (201).

\section{ANTIBIOTIC THERAPY}

Despite many decades of therapeutic trials, the role for antimicrobial therapy in AECB treatment remains controversial. There are a number of reasons for this. Most comparative antimicrobial trials demonstrate equivalence (1). These trials are mainly performed for registration purposes. Accordingly, they are powered to demonstrate equivalence only as required by the licensing authorities, and intrinsic superiority such as improved in vitro activity or excellent pharmacokinetics and/or pharmacodynamics cannot be demonstrated. Complicated patients with pretreatment-resistant pathogens or with comorbid conditions that might interfere with the activity or assessment of the antimicrobial agent are usually systematically excluded. Most clinical studies do not capture subtle outcome differences between agents such as speed of recovery, microbiological eradication rates and time to next occurrence. As currently designed, these studies demonstrate the efficacy of the antimicrobial but cannot demonstrate effectiveness (performance in real life circumstances). This part of the document will emphasize data supporting the use of antibiotics in AECB. Emerging concepts regarding antimicrobial resistance will be discussed. Finally, the data to support a simpler risk stratification scheme will be presented and specific antimicrobial recommendations for each risk category will be offered.
The controversial role of antibiotics has been somewhat clarified by more recent studies. Randomized, placebocontrolled antimicrobial trials conducted in previous decades were inconclusive (202-207) (Table 3). Many of the earlier studies were not powered to reach a definitive conclusion, but more recent well-designed studies have concluded that antibiotics are effective. Anthonisen and coworkers (120), in a landmark study, developed a classification system to identify patients likely to be infected with bacterial pathogens based on presenting clinical symptoms. A type I exacerbation was defined as a patient presenting with increased dyspnea, increased sputum volume and sputum purulence. A type II exacerbation referred to a patient with two of these symptoms, while a type III exacerbation occurred when a patient had only one symptom. Patients exhibiting a type I or type II exacerbation had a demonstrable benefit from antimicrobial therapy (more likely to resolve in 21 days, more rapid recovery of peak flow, shorter clinical illness, fewer patients exhibiting deterioration after the first $72 \mathrm{~h}$ ) implying a bacterial etiology, while those with a type III exacerbation did not differ from patients receiving placebo. Allegra and coworkers (208), in another well-designed, randomized trial involving a large number of patients, demonstrated the superiority of amoxicillin/ clavulanate to placebo. A more recent randomized, doubleblind, placebo-controlled study in 93 mechanically ventilated patients with an exacerbation demonstrated that the use of fluoroquinolones compared with placebo was associated with a reduction in mortality, duration of hospital stay and time on mechanical ventilation, and a decrease in the need for additional antibiotics (209). A conflicting study purporting to show no benefit of antibiotic therapy is flawed by including patients with relatively mild disease and/or asthma, with the latter group undoubtedly improving due to the oral steroids that the patients were given (121).

Although the Anthonisen classification is helpful in predicting an antimicrobial response, it had only a sensitivity of $59 \%$ and a specificity of $60 \%$ in predicting a bacterial exacerbation (210). While this is an improvement, this would suggest that this particular classification system is only moderately successful in predicting a bacterial etiology and confirming the role of antimicrobials. The presence of green (purulent) secretions in a patient with a history of COPD was $99.4 \%$ sensitive and $77.0 \%$ specific for the yield of high bacterial load, and may identify a clear subset of patients likely to benefit from antibiotic therapy (122). It should be pointed out that the patients in this study all had increased dyspnea, so that they were all at least Anthonisen Type II. In a meta-analysis examining placebo-controlled trials in AECB, antibiotic therapy improved clinical outcomes and hastened clinical and physiological recovery (211).

Traditionally, older antibiotics such as ampicillin, tetracycline or trimethoprim/sulfamethoxazole (TMP/SMX), have been the standard treatment choices for AECB. The development of resistance of primary respiratory pathogens to these antibiotics, the recognition of more virulent Gram-negative organisms especially among patients with significant impairment of lung function, and the development of more potent, broad spectrum agents with improved coverage of the major respiratory pathogens has forced a re-examination of antimicrobial choices.

A failure rate that varies from $13 \%$ to $25 \%$ can be expected after treatment with traditional first-line antibiotics 
TABLE 3

\section{COPYRIGHT PULSUS GROUP INC, D DO NOT COPY}

Randomized trials of antibiotics in acute exacerbations of chronic bronchitis

\begin{tabular}{|c|c|c|c|}
\hline Comparators & $\begin{array}{l}\text { Patients } \\
\text { (n/n) }\end{array}$ & Outcome of therapy & Reference \\
\hline Placebo versus oxytetracycline & $37 / 37$ & $\begin{array}{l}\text { Treated patients lost half as much time from work } \\
\text { and exacerbations were shorter }\end{array}$ & Elmes et al, 1957 (202) \\
\hline Placebo versus oxytetracycline & $27 / 26$ & Treated patients recovered sooner and deteriorated less often & Berry et al, 1960 (203) \\
\hline Placebo versus ampicillin & $28 / 28$ & No significant difference in clinical response & Elmes et al, 1965 (204) \\
\hline $\begin{array}{l}\text { Placebo versus physiotherapy } \\
\text { versus chloramphenicol }\end{array}$ & $10 / 10 / 9$ & No significant differences & Peterson et al, 1967 (205) \\
\hline $\begin{array}{l}\text { Placebo versus chloramphenicol } \\
\text { versus tetracycline }\end{array}$ & $86 / 84 / 89$ & $\begin{array}{l}\text { Antibiotic therapy superior to placebo but } \\
\text { no differences between antibiotics }\end{array}$ & Pines et al, 1972 (206) \\
\hline Placebo versus tetracycline & $20 / 20$ & $100 \%$ versus $100 \%$ clinical response & Nicotra et al, 1982 (207) \\
\hline $\begin{array}{l}\text { Placebo versus either co-trimoxazole, } \\
\text { amoxicillin or doxycycline }\end{array}$ & $180 / 182$ & $55 \%$ versus $68 \%$ success $(P<0.01)$ & Anthonisen et al, 1987 (120) \\
\hline Placebo versus co-amoxiclav & $179 / 190$ & $50.3 \%$ versus $86.4 \%$ success $(P<0.01)$ & Allegra et al, 1991(208) \\
\hline Placebo versus ofloxacin & $47 / 46$ & $\begin{array}{l}\text { Absolute risk reduction of } 45.9 \text { in death or need for additional } \\
\text { antibiotics in ventilated patients }(P<0.0001)\end{array}$ & Nouira et al, 2001(209) \\
\hline
\end{tabular}

(amoxicillin, TMP/SMX, tetracycline, erythromycin) (212214). This initial treatment failure may be associated with enormous additional expenditures, especially among patients with significant compromise of lung function. These patients may require hospitalization and are at risk for the development of respiratory failure (214). Resistance to $\beta$-lactam antibiotics such as ampicillin can be expected in $20 \%$ to $40 \%$ of isolated strains of $\mathrm{H}$ influenzae and in greater than $90 \%$ of strains of $\mathrm{M}$ catarrhalis $(215,216)$. There are no clinical features that can predict the presence of $\beta$-lactamase-producing bacteria, except that patients with these organisms tend to have more courses of antibiotics (217). Penicillin resistance is now found in greater than $35 \%$ of S pneumoniae isolates in some studies and is increasing worldwide (218). Penicillin resistance in Canada has been reported as high as 30\% (216). Penicillin resistance is also a marker for resistance to other classes of antibiotics including the cephalosporins, macrolides, $\beta$-lactam $/ \beta$-lactamase inhibitors, TMP/SMX and tetracyclines (219). Whereas antibiotic resistance and widespread clinical failure in lower respiratory tract infections have not been linked at this time, this may only be a reflection of the rapidly changing antimicrobial environment. Most 'resistant' organisms demonstrate low levels of penicillin resistance (minimal inhibitory concentration [MIC] of $2 \mu \mathrm{g} / \mathrm{ml}$ or less). Because the doses of $\beta$-lactams usually prescribed achieve high levels in blood, these levels of resistance may be overcome. If levels of resistance continue to increase, however, the value of many classes of antibiotics including $\beta$-lactams, cephalosporins, macrolides, tetracyclines and trimethoprim-sulfonomide combinations may diminish. Antibiotic overprescribing for nonbacterial infections is a major factor in the emergence of bacterial resistance. Attention must be paid to improving antibiotic use as well as to identifying those patients who would benefit from aggressive broad spectrum therapy. One advantage of a risk stratification system is that patients not requiring antimicrobial therapy can be identified as well as those requiring more aggressive therapy.

$\boldsymbol{\beta}$-Lactam resistance: There are three major mechanisms of $\beta$-lactam resistance: alteration of the antibiotic target sites (penicillin binding proteins [PBPs]), inactivation of the drug by enzymes produced by the bacteria ( $\beta$-lactamases), and reduction of drug permeability into or out of the cell (220). Efflux and bypassing a blocked pathway do not play a role in this class. Target modification: Target modification is the only mechanism of resistance of $S$ pneumoniae to $\beta$-lactams. Reduced susceptibility of $S$ pneumoniae to the $\beta$-lactams has been the result of the remodelling of the PBPs so that there is decreased binding affinity. Pneumococci for which the MIC of penicillin is less than $0.1 \mu \mathrm{g} / \mathrm{ml}$ are defined as penicillin-susceptible, those for which the MIC is $0.1 \mu \mathrm{g} / \mathrm{mL}$ to $1.0 \mu \mathrm{g} / \mathrm{mL}$ are defined as penicillin-intermediately resistant and those for which the $\mathrm{MIC}$ is greater than $1.0 \mu \mathrm{g} / \mathrm{mL}$ are defined as penicillin-resistant (221) (Table 4). Penicillin-nonsusceptible $S$ pneumoniae (PNSP) are those that have an MIC of $0.1 \mu \mathrm{g} / \mathrm{mL}$ or greater.

Resistance trends and clinical significance: The prevalence of PNSP continues to increase worldwide. Rates of resistance vary from $20 \%$ to $80 \%(216,222-228)$. Jacobs et al $(225)$ in a United States surveillance study found that penicillin-resistant strains were more frequent than intermediately resistant ones (32.5\% versus $18 \%)$. Zhanel et al (223) found in a crossCanada surveillance study that penicillin-intermediately resistant and resistant strains occurred at rates of $14.8 \%$ and $6.4 \%$, respectively.

Despite the widespread prevalence of nonsusceptible pneumococci, the clinical impact of using a b-lactam to treat a patient with a respiratory tract infection due to such a strain is uncertain (229-231). The S pneumoniae breakpoints for penicillin were established to predict efficacy in infections such as meningitis, where levels might barely reach the $2 \mu \mathrm{g} / \mathrm{mL}$ level established for penicillin resistance. In contrast to antibiotic concentrations in the cerebrospinal fluid (CSF), peak serum and tissue concentrations of intravenously administered b-lactam antimicrobials may be considerably higher than the MICs of intermediate or resistant pneumococci. In the setting of pneumococcal bacteremia and/or pneumonia, current levels of penicillin resistance have not had any significant impact on mortality in adults. Pharmacokinetic/pharmacodynamic data suggests that bacteremic and respiratory tract infections due to pneumococci will only result in clinical failures when treated with a b-lactam when the penicillin MIC is $4 \mu \mathrm{g} / \mathrm{mL}$ or higher (230). Less than $2 \%$ of pneumococcal isolates have MICs of $4 \mu \mathrm{g} / \mathrm{mL}$ or higher (Table 4) (232).

The increasing prevalence of penicillin-resistant pneumococci may have a greater impact on the activity of the oral 
TABLE 4 COPYRIGHT PULSUS GROUP ING. " DO NOT COPY

In vitro activities of 16 antimicrobials against 2245 isolates of Streptococcus pneumoniae collected from across Canada during 2000 (372)

\begin{tabular}{|c|c|c|c|c|c|c|c|c|c|c|c|c|c|c|c|}
\hline \multirow[b]{2}{*}{ Antimicrobial } & \multirow[b]{2}{*}{0.007} & \multirow[b]{2}{*}{0.015} & \multicolumn{13}{|c|}{ Minimal inhibitory concentration ( $\mu \mathrm{g} / \mathrm{mL})$} \\
\hline & & & 0.03 & 0.06 & 0.12 & 0.25 & 0.5 & 1 & 2 & 4 & 8 & 16 & 32 & 64 & 128 \\
\hline Penicillin & & $586^{*}$ & 1233 & 147 & $75^{\dagger}$ & $18^{\dagger}$ & $18^{\dagger}$ & $38^{\dagger}$ & 92 & 38 & - & & & & \\
\hline Amoxicillin & & $84^{*}$ & 1153 & 734 & 73 & 37 & 46 & 74 & 33 & $10^{\dagger}$ & 1 & & & & \\
\hline Ceftriaxone & & & $1824^{*}$ & 60 & 41 & 40 & 126 & $109^{\dagger}$ & 43 & 1 & 1 & & & & \\
\hline Ciprofloxacin & & & & & $2^{*}$ & 63 & 892 & 1188 & $68^{\dagger}$ & 7 & 7 & 6 & 9 & $3^{\ddagger}$ & \\
\hline Levofloxacin & & & & & $1^{*}$ & 19 & 832 & 1355 & 16 & $2^{\dagger}$ & 5 & 12 & 3 & & \\
\hline Gatifloxacin & & & $1^{*}$ & 19 & 548 & 1612 & 40 & 4 & $3^{\dagger}$ & 14 & 3 & 1 & & & \\
\hline Moxifloxacin & & & $25^{*}$ & 449 & 1675 & 74 & 1 & 0 & $12^{\dagger}$ & 8 & 1 & & & & \\
\hline BMS-284756 & $44^{*}$ & 294 & 1533 & 344 & 9 & 4 & 10 & 6 & 1 & & & & & & \\
\hline Gemifloxacin & $588^{*}$ & 1214 & 401 & 20 & 3 & 11 & 6 & 1 & 1 & & & & & & \\
\hline Doxycycline§ & & & & & & & & $1960^{*}$ & 10 & 91 & 72 & 10 & - & & \\
\hline Chloramphenicol & & & & & & & & & & $2198^{*}$ & 2 & $45^{\ddagger}$ & & & \\
\hline Erythromycin & & & & & $1984^{*}$ & 9 & $3^{\dagger}$ & 10 & 28 & 42 & 28 & 18 & 12 & 24 & $87^{\ddagger}$ \\
\hline Clindamycin & & & & & & $2118^{*}$ & $3^{\dagger}$ & 0 & 4 & 4 & 2 & 5 & 6 & 13 & $90^{\ddagger}$ \\
\hline Telithromycin & & $2016^{*}$ & 59 & 49 & 37 & 23 & 40 & 19 & 2 & - & & & & & \\
\hline ABT-773 & & $2102^{*}$ & 49 & 40 & 39 & 12 & 2 & 1 & - & & & & & & \\
\hline Linezolid§ & & & & & - & 29 & 966 & 1054 & 94 & - & & & & & \\
\hline Trimethoprim/sulf & ole & & & & & $1501^{*}$ & 254 & $149^{\dagger}$ & $87^{\dagger}$ & 85 & 144 & 24 & 0 & 0 & $1 \ddagger$ \\
\hline
\end{tabular}

*Less than or equal to; †Intermediate category where applicable; ¥Greater than or equal to; §Only 2143 isolates tested

cephalosporins. Oral cephalosporins have a disproportionate loss of activity against strains of PNSP. Therefore, as penicillin resistance rates increase, not only do the rates of cephalosporin resistance increase, but also the degree of resistance increases. Reports of clinical failures of cephalosporin treatment of pneumococcal infections caused by strains of $S$ pneumoniae highly resistant to penicillins are rare. However, the numbers of penicillin-resistant pneumococci causing disease in prospective studies designed to evaluate the impact of resistance have been small (229).

In January 2002, the NCCLS published new susceptibility interpretive criteria for cefotaxime and ceftriaxone for nonmeningeal isolates of S pneumoniae (233). Previously susceptibility interpretive breakpoints were less than or equal to $0.5 /$ equal to $1 /$ greater than or equal to $2 \mu \mathrm{g} / \mathrm{mL}$ for susceptible/intermediate/resistant, respectively. However, these breakpoints were derived largely from considerations in the treatement of meningitis. The Subcommittee on Antimicrobial Susceptibility Testing of NCCLS reviewed surveillance susceptibility data, pharmacokinetic-pharmacodynamic data in animal models of infection, clinical data and a simulated trial evaluating the probability of attaining target serum levels relative to various MICs. As a result of this review, the NCCLS has agreed to publish new interpretive criteria for nonmeningeal isolates of $S$ pneumoniae. The changes are largely designed to clarify the efficacy of these drugs in nonmeningeal infections due to $S$ pneumoniae strains with MICs of $1 \mu \mathrm{g} / \mathrm{mL}$ or less. Thus, new interpretive criteria for susceptibility of cefotaxime and ceftriaxone for $S$ pneumoniae in nonmeningitis are less than or equal to 1 /equal to $2 /$ greater than or equal to $4 \mu \mathrm{g} / \mathrm{mL}$ for susceptible/intermediate/resistant, respectively (233).

Previous interpretive standards for cefuroxime categorized isolates of pneumococci with a cefuroxime MIC of $2 \mu \mathrm{g} / \mathrm{mL}$ or greater as resistant (221). However, pharmacokinetic/ pharmacodynamic data based on a dose of cefuroxime of
$15 \mathrm{mg} / \mathrm{kg}$ twice a day suggests that pneumococcal MICs of $4 \mu \mathrm{g} / \mathrm{mL}$ or greater may be required before clinical failures occur. The most recent NCCLS guidelines categorize isolates of pneumococci with a cefuroxime MIC of $4 \mu \mathrm{g} / \mathrm{mL}$ or greater as resistant (233). Using breakpoints, which were the same as those in the new NCCLS guidelines, Doern et al (216) found that of the 41\% of pneumococci that were PNSP, in a 1997 North American antimicrobial resistance surveillance program, $61 \%$ and $41 \%$ were resistant to cefixime and cepodoxime, respectively. As the prevalence of PNSP continues to increase, we may see an increase in the number of clinical failures associated with oral cephalosporin therapy of pneumococcal respiratory tract infections.

\section{Antimicrobial inactivation}

$\beta$-lactamase destroys penicillins and cephalosporins by hydrolysis and is the single greatest cause of resistance to these antimicrobials. $\beta$-lactamases account for greater than $99 \%$ of $\beta$-lactam resistance in $H$ influenzae and $M$ catarrhalis $(224,234)$. Among the various $\beta$-lactamase enzymes, the TEM-1 and TEM-2 enzymes, which hydrolyze ampicillin and amoxicillin, are the enzymes most commonly seen in $H$ influenzae (235). M catarrhalis produces ROB-1 and ROB-2 enzymes, which also hydrolyze ampicillin and amoxicillin, but have no effect on cephalosporins (236).

Studies done in the late 1990s have found rates of $\beta$-lactamase positivity in $H$ influenzae between $30 \%$ and $40 \%$ in North America and about 20\% in Europe (224,225,237-239). $\beta$-lactamase resistance in $M$ catarrhalis rose very rapidly to over $90 \%$ in most countries of the world and has remained stable at that rate $(224,225,237-239)$. Although there are no NCCLS breakpoints for $M$ catarrhalis, the degree of activity of all the antimicrobials used to treat AECB, with the exception of amoxicillin, have excellent activity against this pathogen (239). 


\section{COPYRIGHT PULSUS GROUP INC, D DO NOT COPY}

Despite the widespread prevalence of $\beta$-lactamase-positive $H$ influenzae and $M$ catarrhalis, the clinical impact of using a $\beta$-lactam such as amoxicillin to treat a patient with AECB due to such a strain is unknown.

\section{Macrolide resistance}

Resistance to the macrolide antibiotics occurs primarily by target site modification and active efflux (240-242). Acquired macrolide resistance has not been described in $\mathrm{H}$ influenzae and $\mathrm{M}$ catarrhalis. H influenzae appears to have inherent resistance to erythromycin. Azithromycin and clarithromycin are considerably more active (243). Clarithromycin is metabolized to $14-\mathrm{OH}$-clarithromycin, which is two to four times more active than clarithromycin itself; thus, in vitro susceptibility testing with only the parent drug inaccurately reflects in vivo sensitivity. Clarithromycin and 14-hydroxy-clarithromycin have additive effects against $82 \%$ of $H$ influenzae isolates and are synergistic against $8 \%$.

Target site modification: Resistance due to target site modification is mediated by one of a number of erm (erythromycin resistance methylase) genes that modify the ribosome target sites by methylation. The ensuing conformational change results in reduced affinity between the macrolides, clindamycin and streptogramin B antibiotics and the ribosome, thereby conferring the MLSB phenotype. This accounts for about $40 \%$ of the macrolide resistance in $S$ pneumoniae in North America (244). In S pneumoniae, the erm gene is usually constitutive $(244,245)$.

Resistance due to efflux has been described in S pneumoniae and is encoded for by the mefE gene (246). It confers erythromycin, clarithromycin and azithromycin resistance only (M phenotype) (242,247-249). Macrolide resistance due to efflux accounts for up to about $55 \%$ of the macrolide resistance of S pneumoniae (244).

Approximately $2 \%$ of pneumococcal isolates displaying macrolide resistance have both erm and mef genes. Approximately $1 \%$ to $2 \%$ of macrolide-resistant isolates have neither the erm nor the mef gene. A new mechanism of macrolide resistance has been described with structural changes that conceivably may become more common in the future (250).

Resistance trends and clinical significance: In the United States, resistance rates of pneumococci to the macrolides vary from $19 \%$ to $30 \%(225,251)$. In Canada, macrolide resistance rates have remained below $10 \%(216,223)$.

Resistance due to target site modification (RTSM) results in high levels of resistance to both clindamycin (MICs $8 \mu \mathrm{g} / \mathrm{mL}$ or greater) and erythromycin (MICs $64 \mu \mathrm{g} / \mathrm{mL}$ or greater). Strains resistant on the basis of efflux are susceptible to clindamycin (MICs $0.25 \mu \mathrm{g} / \mathrm{mL}$ or less) and typically have erythromycin MICs of 1 to $32 \mu \mathrm{g} / \mathrm{mL}$ (251). This has begged the question as to whether a patient infected with an efflux-mediated macrolide-resistant strain would more likely be successfully treated with a macrolide than if the infection was due to a strain that was macrolide-resistant on the basis of RTSM $(251,252)$. Currently, there are no clinical data to determine whether the type of macrolide resistance affects the outcome.

Despite widespread macrolide resistance in $S$ pneumoniae, there has been sparse clinical data to support that this correlates with clinical failure (253). A possible explanation may be the pharmacokinetic/pharmacodynamic properties of the macrolides (252). The concentrations of macrolides in the alveolar macrophages and extracellular lining fluid of the alveolus are several fold higher than the serum concentrations and the MICs of macrolide-resistant strains (254).

\section{Fluoroquinolone resistance}

Fluoroquinolones directly inhibit DNA synthesis. Inhibition appears to occur by interaction of the drug with complexes composed of DNA and either of the two target enzymes, DNA gyrase and topoisomerase IV. These enzymes are structurally related to each other, both being tetrameric with pairs of two different subunits. The GyrA and GyrB subunits of DNA gyrase are respectively homologous with the $\mathrm{ParC}$ and $\mathrm{ParE}$ subunits of topoisomerase IV. Both enzymes act by breaking both strands of DNA segment, passing another segment through the break, and then resealing the break. Fluoroquinolones appear to trap the enzyme on DNA during the topoisomerization.

Target modification: One mechanism of resistance is the alterations in target enzymes, which are generally localized to specific domains of each subunit type, the quinolone resistance determining region (QRDR). These alterations arise from spontaneous mutations in the genes encoding the enzyme subunits and, thus, can exist in small numbers ( 1 in 106 to 1 in 109 cells) in large bacterial populations.

Fluoroquinolone resistance has been associated most frequently with alterations in the gyrA and/or parC genes. In $S$ pneumoniae, low-level fluoroquinolone resistance to ciprofloxacin and levofloxacin has been associated with mutations in the QRDR of parC. However, high-level resistance requires additional mutations in the QRDR of gyrA (255-259). Decreased accumulation: Acquired fluoroquinolone resistance due to active efflux in S pneumoniae has been shown to be due to increased levels of expression of efflux pumps mediated by the pmrA gene (260). Efflux pumps of this type have broad substrate profiles and mediate resistance including chloramphenicol and hydrophilic quinolones such as ciprofloxacin, norfloxacin and ofloxacin. The activity of hydrophobic quinolones such as levofloxacin, gatifloxacin and moxifloxacin are less affected (260).

Resistance trends and clinical significance: Emergence of resistance to the fluoroquinolones has already been described in Canada, Spain, Hong Kong and Ireland. In Canada, Chen et al (261) found that the prevalence of ciprofloxacin-resistant pneumococci (MIC $4 \mathrm{\mu g} / \mathrm{mL}$ or greater) increased from $0 \%$ in 1993 to $1.7 \%$ in 1997 to 1998 ( $\mathrm{P}=0.01)$.

Reports of fluoroquinolone resistance in $\mathrm{H}$ influenzae and $M$ catarrhalis are rare (262-266). These have occurred in patients with chronic or recurrent respiratory infections, which emphasizes the risk of the development of fluoroquinolone resistance in this type of patient.

Despite the marginal activity of ciprofloxacin against $S$ pneumoniae, clinical failures of ciprofloxacin treatment of pneumococcal respiratory tract infections are rare $(223,269$. 270). This may be explained in part by the fact that fluoroquinolones, including ciprofloxacin, are relatively concentrated in lung tissue (lung concentrations exceed serum concentrations by 1.5 to four fold) $(271,272)$. Although there are no recommended ciprofloxacin susceptibility breakpoints for pneumococci, pharmacokinetic/pharmacodynamic data suggest that an isolate with a MIC of $2 \mu \mathrm{g} / \mathrm{mL}$ or greater should be considered resistant to ciprofloxacin used at a dose of $500 \mathrm{mg}$ twice a day $(273,274)$. Therefore, as resistance emerges 


\section{COPYRIGHT PULSUS GROUP INC, - DO NOT COPY}

and the MIC values increase above the MICs of wild type organisms, therapeutic levels of ciprofloxacin may not be achievable, even in the lung (275).

Reports of treatment failures in AECB due to ciprofloxacinresistant pneumococci have started to emerge (276).

\section{TMP/SMX resistance}

Biosynthesis of several amino acids and purines depends on the availability of tetrahydrofolic acid (THF). In addition, THF is a prerequisite cofactor for essential thymidylate synthesis. In contrast to human cells, which use dietary folates, most bacteria are unable to take up preformed folic acid derivatives and must synthesize THF. The sulfonamides and trimethoprim are structural analogues for intermediaries in THF synthesis.

Resistance to trimethoprim (TMP) and/or sulfamethoxazole (SMX) can be the result of chromosomal mutations or the acquisition of genetic elements, which bypass the TMP and/or SMX blockade $(277,278)$. This has been found in S pneumoniae and $H$ influenzae $(279,280)$. TMP/SMX resistance in pneumococci is now very high. More than $90 \%$ of TMP/SMX resistant isolates are also resistant to penicillin (281). Conversely, increasing levels of resistance to $\beta$-lactams corresponds with increasing resistance to TMP/SMX. For example, Thornsberry et al (224) found that $40 \%$ of pneumococci that were highly resistant to penicillin were resistant to TMP/SMX, whereas only $3 \%$ of penicillin-susceptible pneumococci were. Therefore, overall rates of TMP/SMX resistance will reflect the prevalence of PNSP.

Thornsberry et al (224) found that $16 \%$ of $\beta$-lactamasepositive $H$ influenzae were TMP/SMX resistant versus $7 \%$ of $\beta$-lactamase-negative isolates. In recent studies from North America, $10 \%$ to $16 \%$ of isolates of $H$ influenzae were TMP/SMX resistant (224,239). As noted previously, M catarrhalis remains fully susceptible to TMP/SMX (226,241). There are no clinical data to show that TMP/SMX resistance is associated with clinical failures.

\section{Tetracycline resistance}

The tetracycline group of antibiotics are either naturally occurring (tetracycline) or semisynthetic (doxycycline, minocycline) products. The bacteriostatic activity of tetracycline is associated with reversible inhibition of protein synthesis.

In both Gram-negative and Gram-positive bacteria, efflux of tetracycline is an important cause of high-level resistance. All efflux pumps confer resistance to tetracycline but not to minocycline (minocycline is much more hydrophobic than tetracycline).

A cytoplasmic protein produced by the resistant organism interacts or associates with the ribosome, making it insensitive to tetracycline inhibition (282). These ribosomal protection proteins, which are encoded by tet $\mathrm{M}, \mathrm{O}, \mathrm{P}, \mathrm{Q}$, and $\mathrm{S}$, protect the ribosome from the action of tetracycline, doxycycline and minocycline. Ribosomal protection is the only mechanism of tetracycline resistance found in S pneumoniae (283).

Thornsberry et al (224) found that $51 \%$ of penicillin-highly resistant pneumococci were resistant to tetracycline, whereas only $4 \%$ of penicillin-susceptible pneumococci were. In Canada, approximately $10 \%$ of pneumococci are tetracycline resistant, whereas in the United States, $17 \%$ are resistant $(223,224)$. Tetracycline resistance rates for both $H$ influenzae and $\mathrm{M}$ catarrhalis are less than $1 \%$.
There have been no clinical studies that have addressed the issue of the impact of tetracycline resistance on clinical outcome.

\section{Conclusion}

Despite the increasing prevalence of resistance in the most common respiratory pathogens responsible for AECB, there is very little published clinical information, showing that in vitro susceptibility results predict clinical outcome. This may be in part due to the fact that clinical trials carried out for registration purposes are designed to show equivalency and do not include patients that are infected with a pathogen that is resistant to the study drug. In addition, it is only recently that the prevalence and degree of resistance have increased dramatically. As the prevalence of more highly resistant strains increases, we are now seeing cases of clinical treatment failures (276) and we suspect that these will increase in frequency.

\section{RISK FACTORS FOR TREATMENT FAILURE}

Published failure and relapse rates for AECB in the literature vary from $17 \%$ to $32 \%$ depending on the definition used (Table 5). Identification of patients at risk of failing standard antimicrobial therapy with the usual first-line agents might lead to improved antimicrobial prescribing. Ball et al (212) enrolled 471 patients with AECB characterized by increased dyspnea, sputum volume and purulence. The median number of AECBs in the previous year was three, and one-third of the patients had cardiopulmonary disease (ischemic heart disease with/without cor pulmonale). Clinical features at presentation and antibiotic therapy did not predict recovery. However, an increased number of chest infections in the previous year and coexistent cardiopulmonary disease were predictors for returning to the physician with a chest problem. Patients with more than four treated exacerbations in the previous year were 2.11 times more likely to fail initial management than patients without this risk factor. The presence of coexistent cardiopulmonary disease increased the odds of failure by 2.3 times. The presence of cardiovascular comorbidity and more than four exacerbations in the previous year had a sensitivity of $75 \%$ and specificity of $47 \%$ in predicting return to the prescribing physician for further treatment.

In a retrospective study, Dewan and colleagues (284) reviewed the clinical experience with 107 patients in a University Veterans Administration clinic over a 24-month observation period. They observed a $14.7 \%$ failure rate within four weeks of observation among COPD patients mainly treated with first line antibiotics. More than one-half of the patients with exacerbations who failed initial treatment required hospitalization. Independent host factors that were associated with treatment failure included severe impairment of lung function, use of home oxygen, frequent exacerbations, history of previous pneumonia and use of maintenance corticosteroids. Using a stepwise logistic regression analysis, the necessity for home oxygen and frequent exacerbations correctly classified failures in $83 \%$ of the patients. In this study, age, the presence of comorbidity, and the choice of antibiotics did not affect treatment outcome.

In another restrospective study, Miravitlles and colleagues (285) identified risk factors for relapse after ambulatory therapy of AECB. Baseline characteristics of coexisting ischemic heart disease, degree of dyspnea and frequency of visits to the family physician for respiratory problems in the past year were strongly 
related to risk of relapse. The severity of AECB, as measured by the Anthonisen criteria, was not a risk factor for relapse. It appears that the Anthonisen criteria help to predict outcome in placebo-controlled trials (120) but not in trials where the majority of patients are given antibiotics $(212,284-286)$.

\section{RISK FACTORS FOR HOSPITALIZATION}

Patients are admitted to hospital following an inadequate response to outpatient management, an inability to perform the activities of daily living due to increased dyspnea or the development of respiratory failure, often in association with comorbidities or inadequate home care resources. Knowledge of risk factors for hospitalization might allow interventions to prevent this and other unfortunate outcomes (Table 6).

Ball and colleagues (212) demonstrated that the presence of significant ischemic heart disease or cor pulmonale was the only predictor of referral to hospital for further management of AECB. Patients suffering from chronic bronchitis for a greater number of years were less likely to be referred to hospital. This is in contrast to the findings of Grossman et al (287), who determined that severity of underlying COPD (using $\mathrm{FEV}_{1}$ criteria) and duration of disease were the best predictors of hospitalization. Patients with severe chronic bronchitis were more than four times more likely to be admitted to hospital than patients with mild to moderate disease and the risk was similar for patients with disease for more than 10 years. If both risk factors were present, the risk of hospitalization increased almost 20-fold. Kessler et al (288) identified low body mass, a limited six-minute walk test, significant gas exchange impairment and pulmonary hemodynamic worsening as predictors of hospitalization. Multivariate analysis indicated that carbon dioxide retention $\left(\mathrm{PaCO}_{2}\right.$ higher than $44 \mathrm{mmHg}$ ) and pulmonary hypertension (mean pulmonary artery pressure at rest higher than $20 \mathrm{mmHg}$ ) were the best predictors of hospitalization. Age, comorbidity and smoking habit were not predictive of hospitalization. Vestbo and colleagues (52) demonstrated in the Copenhagen City Heart Study that chronic mucous hypersecretion was associated with an excess decline in $\mathrm{FEV}_{1}$ and an increased risk of subsequent hospitalization because of COPD. This relationship continued to be significant even after adjusting for age, smoking and $\mathrm{FEV}_{1}$. Garcia-Aymerich and colleagues (289) found that after adjusting for a wide range of potential risk factors, only three or more admissions in the previous year, lower $\mathrm{FEV}_{1}$ and underprescription of long term oxygen therapy were independently associated with a higher risk of admission for COPD exacerbation.

Miravitlles and colleagues (290) found that the presence of ischemic heart disease, frequent exacerbations, chronic mucous hypersecretion, severe impairment of lung function and advanced age were all risk factors for hospitalization. Antonelli-Incalzi et al (291) found that the presence of comorbidities and advanced age increased the risk of mortality during an exacerbation.

\section{RISK STRATIFICATION}

A group of high-risk patients in whom the cost of clinical treatment failure is high may be identified by simple clinical criteria. Patients with significant cardiac disease, frequent purulent exacerbations of COPD, generalized debility, malnutrition, chronic corticosteroid administration, use of supplemental oxygen, long duration of COPD, chronic mucous
TABLE 5

Risk factors for treatment failure

\begin{tabular}{ll}
\hline Risk factor & Reference \\
\hline Frequency of exacerbations & Ball et al, 1995 (212) \\
& Dewan et al, 2000 (284) \\
& Seemungal et al, 1998 (135) \\
& Miravitlles et al, 2001 (285) \\
Severity of FEV ${ }_{1}$ impairment & Dewan et al, 2000 (284) \\
Ischemic heart disease/congestive & Miravitlles et al, 2000 (290) \\
heart failure & Ball et al, 1995 (212) \\
Increasing age & Miravitlles et al, 2001 (285) \\
Maintenance steroids & Adams et al, $2000(286)$ \\
Use of home oxygen & Antonelli-Incalzi et al, 1997 (291) \\
Chronic mucous hypersecretion & Miravitlles et al, 1999 (100) \\
\hline
\end{tabular}

FEV 1 Forced expiratory volume in $1 \mathrm{~s}$

hypersecretion and severe underlying lung function abnormalities tend to fail therapy with usual antimicrobial therapy and have early relapse or hospitalization. These patients may be infected with difficult-to-treat organisms such as Klebsiella pneumoniae or $P$ aeruginosa, particularly in the presence of severe impairment of lung function (99). Frequent exacerbations, chronic use of oral steroids and poor underlying lung function increase the risk for pseudomonas infection $(99,100,118)$. Frequent courses of antibiotics increase the risk of infection with $\beta$-lactamase-producing bacteria (217). Treatment directed toward resistant pathogens with potent antimicrobial drugs might lead to improved clinical outcomes and overall lower costs, particularly if hospital admissions and respiratory failure can be prevented. Therapeutic failure leads to increased cost of care due to extra physician visits, further diagnostic tests and repeated courses of antibiotics. It may also lead to more hospitalization and prolonged absence from work. This greatly increases the cost of AECB treatment (292,293). Stratification of patients into risk categories may allow the physician to select targeted antimicrobial therapy to prevent some of these consequences.

Our proposed, simplified classification system divides patients into four groups (Table 7). It is important to point out that this stratification scheme has not been prospectively validated and represents a consensus from our group based on the evidence available (Level III evidence).

Group 0 patients present with the acute onset of cough associated with sputum production often in association with a preceding coryzal illness and fever. While smokers may be included in this group, these patients have no underlying lung disease and do not meet the definition for chronic bronchitis. These patients have acute tracheobronchitis that is usually viral in origin. The presence of purulent sputum in this previously healthy group of patients is not predictive of a bacterial infection, unlike the evidence in patients with chronic bronchitis. Because there is no underlying lung disease in this group, the illness is usually self-limited and runs a benign course. Most placebo-controlled trials have failed to support a role for antibiotic therapy in this group of patients, although meta-analyses of these trials gave conflicting results (294-296). However, none of these meta-analyses demonstrated a positive impact of antibiotics on duration of illness, limitation of 
TABLE 6 COPYRIGHT PULSUS GROUP ING , DO NOT COPY

Risk factors for hospitalization

\begin{tabular}{|c|c|c|c|}
\hline Reference & Variable & Odds ratio & Confidence interval (95\%) \\
\hline Ball et al, 1995 (212) & Cardiopulmonary disease & 8.89 & $1.73-45.6$ \\
\hline \multirow[t]{2}{*}{ Kessler et al, 1999 (288) } & $\mathrm{PaCO}_{2}>44 \mathrm{mmHg}$ & 2.1 & $1.4-3.1$ \\
\hline & Ppa > 18 mmHg & 2 & $1.3-3.1$ \\
\hline \multirow[t]{3}{*}{ Grossman et al, 1998 (287) } & Duration of disease & 4.6 & $1.6-13.0$ \\
\hline & Severity of disease & 4.3 & $0.8-24.6$ \\
\hline & Duration and severity of disease & 19.8 & $3.2-120.8$ \\
\hline \multirow[t]{3}{*}{ Vestbo et al, 1996 (52) } & Mucous hypersecretion (men) & 2.4 & $1.3-4.5$ \\
\hline & Mucous hypersecretion (women) & 2.6 & $1.2-5.3$ \\
\hline & Ischemic heart disease & 1.97 & $1.25-3.14$ \\
\hline Miravitlles et al, 2000 (290) & $\mathrm{FEV}_{1}(\%$ predicted $)$ & 0.72 for each $10 \%$ drop & $0.58-0.888$ \\
\hline \multirow[t]{3}{*}{ Garcia-Aymerich et al, 2001 (289) } & COPD admissions $>3$ /past year & 6.21 & $1.60-24.07$ \\
\hline & $\mathrm{FEV}_{1}(\%$ predicted $)$ & 0.96 (per percentual unit) & $0.93-0.98$ \\
\hline & Underprescription of long term oxygen & 22.64 & $2.31-221.88$ \\
\hline
\end{tabular}

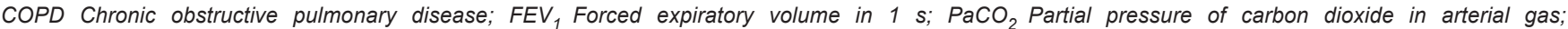
Ppa Pulmonary arterial pressure

activities or return to work. Therefore, the routine use of antibiotics in patients with uncomplicated acute tracheobronchitis is not justified (297). Antibiotic overprescribing for trivial illnesses is a major factor in the emergence of bacterial resistance. Therefore, efforts at decreasing the use of antibiotics in group 0 patients may have a positive societal effect. Giving patients a written leaflet explaining why they do not require an antibiotic has been shown to reduce use of antibiotics (298). Patients in group 0 might benefit from one to weeks of inhaled beta-agonist bronchodilator therapy to reduce the severity and duration of cough, particularly if wheezing is heard on physical examination (297).

A small number of patients have a more protracted course. Mycoplasma pneumoniae and $\mathrm{C}$ pneumoniae are known etiologic agents for acute tracheobronchitis and may be responsible for those patients not demonstrating a rapid clinical improvement. Treatment with a macrolide or doxycycline might be considered for patients in whom the cough does not improve after 10 to 14 days (Level III evidence). There is no evidence supporting a positive response to this therapy even in the presence of documented infection with an atypical organism. Up to $20 \%$ of adults with a cough lasting more then three weeks have serological evidence of pertussis. Unfortunately, there are no clinical features that predict infection aside from exposure to someone with documented pertussis.

Group I patients have chronic bronchitis defined as having chronic cough and sputum production for at least three months for two consecutive years. During an exacerbation of this illness, they demonstrate worsening cough and increased production of purulent sputum. However, in general, they have only mild to moderate impairment of lung function $\left(\mathrm{FEV}_{1}\right.$ greater than $50 \%$ predicted value), have less than four exacerbations per year and have no significant cardiac disease. In this group of patients, the usual pathogens including $H$ influenzae, S pneumoniae and M catarrhalis are present, although viral infection often precedes bacterial superinfection. Antibiotics have been demonstrated to shorten the clinical illness. Treatment with virtually any antibiotic is usually successful and the prognosis is excellent. Despite the presence of resistance to $\beta$-lactams, outcomes, in general, are acceptable. Until a prospective pharmacoeconomic or clinical study demonstrates some advantage for more potent agents among this group of patients, the recommendation for simple therapy such as an aminopenicillin, doxycycline or TMP/SMX is justified. However, the majority of studies showing beneficial results from the use of these agents were performed more than 10 years ago, before current concerns regarding emerging antimicrobial resistance. Given current knowledge about increasing $S$ pneumoniae and $H$ influenzae resistance to these older agents, therapy with selected second- or third-generation cephalosporins or a second-generation macrolide may be preferable (Level III evidence).

In the face of a treatment failure, alternative therapies such as a $\beta$-lactam $/ \beta$-lactamase inhibitor or fluoroquinolones can be used. However, there is no data demonstrating that these failures are due to resistant organisms or even due to antibiotic failure.

Group II patients have risk factors for treatment failure such as poor underlying lung function $\left(\mathrm{FEV}_{1}\right.$ less than $50 \%$ predicted). Alternatively, they may demonstrate only moderate impairment of lung function $\left(\mathrm{FEV}_{1}\right.$ between $50 \%$ and $65 \%$ predicted) but have significant comorbidity (ischemic heart disease, congestive heart failure) and/or experience four or more exacerbations per year. $H$ influenzae, $S$ pneumoniae and $M$ catarrhalis continue to be the predominant organisms. Several studies have indicated that, with declining lung function, enteric Gram-negative organisms may be isolated from pulmonary secretions. Treatment with medications directed at resistant organisms, such as a fluoroquinolone or amoxicillin-clavulanic acid should perform better than amoxicillin or other traditional first-line agents. In addition, there is increasing evidence suggesting that the enhanced bacterial eradication associated with fluoroquinolones leads to faster symptom resolution and results in more prolonged diseasefree intervals compared to cephalosporins and extended spectrum macrolides (Level II evidence) (vide infra).

It is unclear how group II patients who fail to respond to antimicrobial therapy or who quickly relapse should be treated. Again, it is unclear as to whether failures are due to antimicrobial failure or some other factor. It makes sense to treat therapeutic failures or recurrences within three months of antibiotic therapy with another class of antibiotic, but this has never been studied. A significant number of patients with an $\mathrm{FEV}_{1}$ less than $50 \%$ predicted are infected with Pseudomonas species $(99,100,118)$. Whether this occurs only 
TABLE 7

COPYRIGHT PULSUS GROUP ING. - DO NOT COPY

Risk classification and suggested antimicrobial therapy

\begin{tabular}{|c|c|c|c|c|c|}
\hline Group & Basic clinical state & Symptoms and risk factors & Probable pathogens & First choice & $\begin{array}{l}\text { Alternatives } \\
\text { for treatment failure }\end{array}$ \\
\hline 0 & Acute tracheobronchitis & $\begin{array}{l}\text { Cough and sputum without } \\
\text { previous pulmonary disease }\end{array}$ & Usually viral & $\begin{array}{l}\text { None unless symptoms } \\
\text { persist for }>10 \text { to } 14 \text { days }\end{array}$ & $\begin{array}{l}\text { Macrolide } \\
\text { or tetracycline }\end{array}$ \\
\hline I & $\begin{array}{l}\text { Chronic bronchitis } \\
\text { without risk factors } \\
\text { (simple) }\end{array}$ & $\begin{array}{l}\text { Increased cough and } \\
\text { sputum, sputum purulence } \\
\text { and increased dyspnea }\end{array}$ & $\begin{array}{l}\text { Haemophilus influenzae, } \\
\text { Haemophilus spp, } \\
\text { Moraxella catarrhalis, } \\
\text { Streptococcus pneumoniae }\end{array}$ & $\begin{array}{l}\text { Second-generation macrolide, } \\
\text { second- or third-generation } \\
\text { cephalosporin, amoxicillin, } \\
\text { doxycycline, trimethoprim/ } \\
\text { sulfamethoxazole }\end{array}$ & $\begin{array}{l}\text { Fluoroquinolone, } \\
\beta \text {-lactam/ } \beta \text {-lactamase } \\
\text { inhibitor }\end{array}$ \\
\hline II & $\begin{array}{l}\text { Chronic bronchitis } \\
\text { with risk factors } \\
\text { (complicated) }\end{array}$ & $\begin{array}{l}\text { As in group I plus } \\
\text { (at least one of): } \\
\mathrm{FEV}_{1}<50 \% \text { predicted } \\
>4 \text { exacerbations/year } \\
\text { Cardiac disease } \\
\text { Use of home oxygen } \\
\text { Chronic oral steroid use } \\
\text { Antibiotic use in the } \\
\text { past } 3 \text { months }\end{array}$ & $\begin{array}{l}\text { As in group I plus } \\
\text { Klebsiella spp + other } \\
\text { Gram-negatives } \\
\text { Increased probability } \\
\text { of } \beta \text {-lactam resistance }\end{array}$ & $\begin{array}{c}\text { Fluoroquinolone, } \beta \text {-lactam/ } \\
\beta \text {-lactamase inhibitor }\end{array}$ & $\begin{array}{l}\text { Consider referral } \\
\text { to a specialist } \\
\text { or hospital }\end{array}$ \\
\hline III & $\begin{array}{l}\text { Chronic suppurative } \\
\text { bronchitis }\end{array}$ & $\begin{array}{l}\text { As in group II with constant } \\
\text { purulent sputum; } \\
\text { Some have bronchiectasis } \\
\mathrm{FEV}_{1} \text {, usually } \\
\quad<35 \% \text { predicted, or } \\
\text { Multiple risk factors } \\
\text { (eg, frequent exacerbations } \\
\text { and } \mathrm{FEV}_{1}<50 \% \text { ) }\end{array}$ & $\begin{array}{l}\text { As in group II plus } \\
\text { Pseudomonas aeruginosa } \\
\text { and multi-resistant } \\
\text { Enterobacteriaceae }\end{array}$ & $\begin{array}{l}\text { Ambulatory patients: } \\
\text { Tailor treatment to airway patl } \\
P \text { aeruginosa common } \\
\text { (ciprofloxacin) } \\
\text { Hospitalized patients: } \\
\text { Parenteral therapy usually } \\
\text { required. }\end{array}$ & logen \\
\hline
\end{tabular}

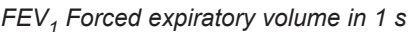

in the subset of patients with frequent exacerbations remains to be clarified. It is reasonable to get sputum samples, if possible, from these patients with multiple risk factors to help guide subsequent treatment.

Group III patients suffer from chronic bronchial infection with daily production of purulent secretions. They are subject to frequent exacerbations characterized by increased sputum production, increased sputum purulence, cough and worsening dyspnea often accompanied by hemoptysis. Some of these patients have bronchiectasis on high resolution computed tomography scanning. In addition to the usual respiratory organisms, other Gram-negative organisms including Enterobacteriaceae and Pseudomonas species should be considered as potential pathogens, particularly in patients treated chronically with oral steroids. Ciprofloxacin is the oral agent with the most activity against these species and should be considered the agent of choice when they are identified. As discussed in the previous paragraph, there is some overlap between patients in group II, with multiple risk factors, and those in group III.

\section{CLINICAL STUDIES}

The next section will summarize clinical studies demonstrating the efficacy of different classes of antimicrobial agents. The approach used will review studies with various study designs to develop definitive recommendations for antimicrobial therapy.

\section{Modelling studies}

Backhouse et al (299) used a decision analytic model, comparing amoxicillin, amoxicillin/clavulanic acid, ciprofloxacin and cefaclor, to determine the most cost effective therapy in highrisk patients with AECB. They concluded that the cheapest product is not always the most cost effective, and in their study, found amoxicillin/clavulanic acid to be the most cost effective. Clinical opinion was used to provide essential data regarding antimicrobial efficacy rates. They called for prospective clinical trials to reach a definitive answer.

Wool et al (300) compared four antibiotics amoxicillin/clavulanic acid, ciprofloxacin, clarithromycin and rufloxacin - in the management of AECB. They reviewed 19 published studies to calculate pathogen eradication rates and used Italian costing data to estimate overall costs. They concluded that amoxicillin/clavulanic acid had the lowest drug acquisition cost and rufloxacin had the highest efficacy rate. Less cost effectiveness was calculated for ciprofloxacin and clarithromycin.

In a similar decision analytic model, van Barlingen et al (301) compared macrolides, fluoroquinolones, penicillins and cephalosporins in the outpatient treatment of AECB. The key cost drivers were the clinical success and failure rates of firstline treatment and the cost of hospitalization. They divided their theoretical patient population into two groups - those with mild to moderate AECB and those with more severe disease. For patients with less severe disease, they concluded that the differences among the antibiotic classes were not great but slightly favoured the macrolides and fluoroquinolones. For patients with more severe AECB, they concluded that the fluoroquinolones were the most cost effective. The experts selected to adjudicate clinical success rates for the various classes of antibiotics did not include the penicillins as appropriate therapy for patients with a severe AECB.

Pechere and Lacey (302) reviewed 12 studies of patients with AECB and demonstrated a strong correlation $(r=0.91)$ 


\section{COPYRIGHT PULSUS GROUP INC. - DO NOT COPY}

between eradication failure rates and clinical failure rates following treatment with macrolides, penicillins, cephalosporins, TMP/SMX or fluoroquinolones.

These studies concluded that the antibiotic class with the lowest acquisition cost was not necessarily the most cost effective. First-line clinical success rate is the most important factor in reducing overall costs. The studies reached different conclusions regarding which class of antimicrobial was the most cost effective because of the different assumptions used to create the models.

\section{Database analysis}

LeLorier and Derderian (303) examined the role of ciprofloxacin in the treatment of serious lower respiratory tract infections. Following the introduction of ciprofloxacin in the province of Quebec, they noted a decrease in the rate of hospitalizations for asthmatic bronchitis. This association was not found in the province of Saskatchewan, where ciprofloxacin usage was severely restricted. There was a statistically significant correlation between increased ciprofloxacin prescriptions and the differences between predicted and observed hospitalization rates. However, ecological correlations are poor models to establish cause-effect relationships, so these results must be viewed with caution.

Adams et al (286) demonstrated that patients severe enough to present to an emergency department and subsequently treated with ampicillin had higher recurrence rates of COPD exacerbations than patients who received other antimicrobial therapies. The recurrence rate with ampicillin was $54 \%$, but was $13 \%$ if the patient received any other antibiotic from among choices that included cephalosporins, TMP/SMX, second-generation macrolides, ciprofloxacin or amoxicillin/ clavulanic acid $(\mathrm{P}<0.001)$. This would suggest that high-risk patients (presumably anyone requiring emergency department treatment for an AECB) benefit from aggressive therapy directed at resistant pathogens.

A retrospective study by Destache and colleagues (214) demonstrated that the use of newer antibiotics, when compared with the usual first-line antibiotics in the treatment of AECB, reduced both the hospitalization rate and the failure rate. While the acquisition cost of the newer antibiotics (cephalosporins, macrolides and fluoroquinolones) was higher, the overall costs of the treated patients given these drugs were lower. In particular, the group receiving amoxicillin/clavulanate, azithromycin or ciprofloxacin had the lowest hospitalization rate, lowest clinical failure rate and lowest costs compared with cephalosporins or first line therapy.

A recent population-based, retrospective cohort study was done in Ontario to determine the association between outpatient use of an oral antibiotic and 30-day all-cause mortality (304). In patients over 65 years of age hospitalized for COPD, the use of an antibiotic was associated with a significant reduction in short term mortality.

The previously discussed study by Adams and colleagues (286) also revealed a significant reduction in relapse rates for patients treated in the emergency room for AECB with antibiotics when compared with those not receiving antibiotics. This beneficial effect of antibiotics was not seen with amoxicillin.

In a retrospective analysis of their study that demonstrated a beneficial effect of amoxicillin/clavulanate versus placebo in AECB, Allegra and colleagues (305) demonstrated that patients with the greatest impairment in lung function and/or more frequent exacerbations benefited the most from antibiotic therapy.

\section{Prospective randomized trials}

The hypothesis that aggressive antibiotic therapy should be offered to high-risk patients was tested in a recent, prospective health economic study. Patients with at least three treated exacerbations in the past year were randomly assigned to receive either ciprofloxacin or any nonquinolone-based therapy for their next AECB (306). Clinical endpoints (days of illness, hospitalizations, time to next exacerbation) were blended with quality-of-life measurements (Nottingham Health Profile, St George's Hospital Respiratory Questionnaire, Health Utility Index) and total respiratory costs from a societal perspective. While the overall results indicated no preference for either treatment arm, in patients with multiple risk factors (severe underlying lung disease, more than four exacerbations/year, duration of bronchitis greater than 10 years, elderly, significant comorbid illness), the use of ciprofloxacin led to improved clinical outcome, higher quality of life and less costs. However, due to the smaller number of patients in this post hoc analysis, this improvement did not reach statistical significance.

In a series of double-blind crossover studies, Chodosh (309) determined that ampicillin $0.5 \mathrm{~g}$ to $1 \mathrm{~g}$ four times daily was associated with a low failure rate and an infection-free interval ranging from 117 to 302 days. These studies were conducted in the 1970s when there was no $\beta$-lactamase-producing $H$ influenzae or $M$ catarrhalis. Ciprofloxacin $750 \mathrm{mg}$ twice daily gave comparable results. Tetracyclines, TMP/SMX and especially cefaclor were associated with higher failure rates and a shorter infection-free interval. Two recently published studies compared ciprofloxacin $500 \mathrm{mg}$ twice daily with clarithromycin $500 \mathrm{mg}$ twice daily and cefuroxime axetil $500 \mathrm{mg}$ twice daily in group II patients $(307,308)$. These studies demonstrated similar clinical outcomes but ciprofloxacin had superior bacterial eradication rates. In addition, the time to the next exacerbation was shortest for clarithromycin (a poor outcome), although this did not reach statistical significance. A number of other studies have consistently demonstrated significantly superior bacterial eradication rates with fluoroquinolones compared to cefuroxime or clarithromycin (107-109).

In the recently completed GLOBE (Gemifloxacin Longterm Outcomes in Chronic Bronchitis) trial (309), gemifloxacin $320 \mathrm{mg}$ once daily for five days was compared with clarithromycin $500 \mathrm{mg}$ twice daily for seven days. While short term clinical outcomes were similar, gemifloxacin had a significantly better bacteriological eradication rate and demonstrated faster eradication of $H$ influenzae. Gemifloxacin was superior to clarithromycin in preventing further exacerbations $(71.0 \%$ versus $58.5 \%$ for no further exacerbations, $\mathrm{P}=0.016$ ) and reduced the number of patients hospitalized for respiratory tract infection over the next six months of follow-up $(0.023 \%$ versus $0.0625 \%, \mathrm{P}=0.059)$. This is the first well-designed clinical trial to demonstrate clinical superiority of a more potent antimicrobial on clinically relevant outcomes. In a more recent study comparing moxifloxacin with amoxicillin, clarithromycin or cefuroxime, use of the fluoroquinolone resulted in higher clinical and bacteriological success rates and a subsequent reduced need for additional antibiotics (310). 


\section{COPYRIGHT PULSUS GROUP INC, D DO NOT COPY}

Despite this preliminary evidence that fluoroquinolones may be a superior choice in terms of bacterial eradication and delaying time to next relapse, there is not enough evidence to warrant their use in all cases of AECB. One must carefully balance the potential benefits of these powerful antibiotics with the risk of developing resistance. There is recent evidence to suggest that frequent use of fluoroquinolones leads to the emergence of resistant strains and that COPD patients are a major reservoir for these resistant organisms (311).

\section{SUMMARY OF EVIDENCE REGARDING ANTIBIOTIC THERAPY FOR AECB}

1. Antimicrobial therapy is warranted for patients with an AECB if they fall into the Anthonisen type I or type II categories (Level I evidence, two randomized, large scale double-blind trials, one meta-analysis).

2. Antimicrobial therapy is not warranted for patients with a type III exacerbation (Level I evidence).

3. Patients can be stratified according to their risk of treatment failure (Level III evidence).

4. A high-risk group of patients can be identified on clinical grounds, and the major clinical features are significant impairment of lung function $\left(\mathrm{FEV}_{1} 50 \%\right.$ or lower than predicted), frequent exacerbations (four or more per year), long duration of disease, significant comorbidity, use of supplemental oxygen and chronic oral corticosteroid use (Level II evidence).

5. Risk group 0 patients (acute tracheobronchitis) should not be treated with antibiotics unless symptoms persist beyond 10 to 14 days (Level I evidence).

6. For risk group 0 patients with persistent symptoms, a macrolide or tetracycline is recommended since M pneumoniae, $\mathrm{C}$ pneumoniae, or Bordetella pertussis may be pathogens (Level III evidence).

7. Although resistant $H$ influenzae and $M$ catarrhalis may be pathogens, traditional 'first-line' agents (aminopenicillins, doxycycline, TMP/SMX) continue to be efficacious and are recommended for patients without risk factors for treatment failure (Level II evidence). Second-generation macrolides and some second- and third-generation cephalosporins (cefuroxime, cefprozil, cefixime) may be better choices given concerns regarding emerging antimicrobial resistance (Level III evidence).

8. There are no data to demonstrate that, among group I patients (low risk for treatment failure), there is any clinical or economic benefit derived from using more potent, broader spectrum agents (Level I evidence).

9. Broad spectrum potent agents such as fluoroquinolones or amoxicillin/clavulanate are recommended for group II patients (Level III evidence).
10. There is some evidence that fluoroquinolones perform better than other agents for group II patients (Level II evidence).

11. Group III patients at risk for P aeruginosa infection (frequent antimicrobials, structural lung damage and chronic corticosteroids) should be treated with an anti-pseudomonal agent (ciprofloxacin). Alternative agents currently must be given parenterally (Level III evidence).

12. Patients presenting with a relapse or recurrence of AECB, within three months of previous antibiotic therapy, should be treated with a different class of antibiotics (Level III evidence).

\section{PREVENTION OF AECB}

Cigarette smoking remains the primary risk factor for the development of chronic bronchitis. Although only $15 \%$ of smokers will develop air flow obstruction, more than one-half will develop chronic cough and sputum production with subsequent increased risk for bacterial colonization and recurrent episodes of AECB. Unfortunately, in 1999, there were slightly more than six million smokers in Canada, representing 25\% of the population age 15 years and older (312). Any intervention that slows the rate of decline in $\mathrm{FEV}_{1}$ is likely to have a major impact on survival in patients with chronic bronchitis. Smoking cessation has clearly been shown to reduce the rate of decline of $\mathrm{FEV}_{1}$ (313). The benefits in terms of decline of lung function are seen even in those over the age of 60 years (314). In addition, cessation of smoking has been shown to confer a survival advantage (Level II evidence) (315). Smoking cessation leads to dramatic symptomatic benefits for patients with chronic bronchitis (Level III evidence). Coughing stops in as many as $77 \%$ of patients who quit smoking and improves in another $17 \%$. When coughing stops, it does so within four weeks in $54 \%$ of patients (316). Evidence is lacking that this decrease in cough and sputum production will lead to a subsequent decline in the frequency of AECB. It is known that patients with chronic cough and sputum production have increased numbers of AECB episodes compared to similarly matched smoking control patients so the hope is that smoking cessation will lead to fewer exacerbations. Nonetheless, this enthusiasm must be tempered by the fact that there is evidence for ongoing airway inflammation even in patients with COPD who do not currently smoke $(317,318)$. A recent analysis of patients in the Lung Health Study (56) revealed that recurrent lower respiratory infections hastened the decline in $\mathrm{FEV}_{1}$ in current smokers but not in ex-smokers.

A detailed discussion of smoking cessation can be found elsewhere (319). No single technique to encourage smoking cessation is successful in all groups of patients; however, recent studies using a combination of behavioural counselling, nicotine replacement and pharmacological therapy to decrease the desire to smoke revealed one-year abstinence rates of as high as $35.5 \%$ (320). A discussion of smoking behaviour and the setting of a specific cessation date should be part of every physician-patient encounter (Level III evidence).

Patients with chronic lung disease have a higher risk for complications from influenza infection. By virtue of its ability 


\section{COPYRIGHT PULSUS GROUP INC, D DO NOT COPY}

to further damage airway epithelial cells, influenza infection can lead to secondary bacterial proliferation and an increase in the frequency of AECB. Serological evidence of influenza A or $B$ infection has been found in up to $28 \%$ of patients with AECB (126,321,322). In addition, COPD patients infected with influenza have a significant risk of requiring hospitalization (323). Perhaps this is related to the transient decline in pulmonary function caused by influenza in a group of patients with less pulmonary reserve (127). Annual influenza vaccination reduces morbidity and mortality of influenza in the elderly by $50 \%$. In addition, it reduced the incidence of hospitalization for acute and chronic respiratory conditions by as much as $39 \%(324,325)$. Therefore, the use of an annual influenza vaccine for all patients with chronic bronchitis is strongly recommended (Level II evidence). The role for either oral or inhaled neuraminidase inhibitors, which are effective against strains of both influenza $A$ and $B$, are currently being studied in terms of preventing AECB during influenza outbreaks in high-risk patients. Therefore, no current evidence-based recommendations can be made. However, high-risk patients who have not been vaccinated should receive prophylaxis during an outbreak (Level III evidence).

The value of pneumococcal vaccination in patients with chronic bronchitis is less well established. At least two metaanalyses looking at efficacy of a 17 -valent or less vaccine resulted in opposite conclusions (326,327). Since 1983, a 23 -valent vaccine has been available in Canada and this covers $85 \%$ of the serotypes responsible for invasive pneumococcal infection. Use of this vaccine in elderly patients with chronic lung disease revealed a significant lower risk for pneumonia, hospitalization and death, and direct medical care cost savings (329). However, AECB is a mucosal infection and it is unclear whether this vaccine can reduce the incidence of this complication of chronic bronchitis. Some reports state that the vaccine has up to a $65 \%$ efficacy in patients with COPD but do not specifically comment on AECB (329). It is generally agreed that pneumococcal vaccination is safe and can reduce invasive pneumococcal infection leading to current recommendations for vaccinations in all patients with COPD at least once in their lives. In addition, consideration should be given to repeating the vaccine in five to 10 years in high-risk patients (330) (Level III evidence).

Over the past two decades, attempts have been made to use oral administration of bacterial antigens in the hope of upregulating antigen-specific antibodies in the bronchial mucosa, thereby decreasing the frequency of AECB. Initial studies using an oral vaccine against $H$ influenzae revealed a decrease of approximately $50 \%$ in use of antibiotics and days lost from work in patients with chronic bronchitis (331). A recent meta-analysis of six trials using this vaccine showed a decrease in the number of episodes of bronchitis at both three and six months in treated patients and a decrease in antibiotic use at six months but not at three months in treated patients (332). Problems with this meta-analysis include the fact that some patients with recurrent episodes of acute bronchitis and without underlying chronic bronchitis were included. In addition, a six-month follow-up only was obtained, so it is unclear whether there will be a continued benefit at one or two years after vaccination. More recent studies have used a preparation called OM-85, which is a lyophilized powder made from cultures of eight different bacterial pathogens responsible for AECB (H influenzae, S pneumoniae, M catarrhalis, K pneumoniae,
Klebsiella ozaenae, S aureus, Streptococcus pyogenes and Streptococcus viridans). The use of this preparation in institutionalized elderly patients with chronic bronchitis led to a $30 \%$ reduction in respiratory tract infections (333). However, a more recent multicentre study failed to demonstrate any reduction in the frequency of AECB (334). Nonetheless, patients treated with the vaccine had a $30 \%$ reduction in hospitalization related to respiratory problems and a $55 \%$ reduction in total number of days in hospital. A more recent analysis of this study suggested that use of this oral immunostimulating agent was cost effective (335). If available in the future, the use of oral immunostimulating agents would be recommended in Canada (Level II evidence).

The use of inhaled corticosteroids in chronic bronchitis and COPD has been the subject of great interest over the past decade. There are two potential mechanisms whereby inhaled steroids might have a role in chronic bronchitis. First, by decreasing the annual rate of decline in $\mathrm{FEV}_{1}$ which is the major predictor of mortality from COPD. Second, by decreasing airway inflammation via an effect on either mucus hypersecretion or on inflammatory cytokines and mediators. Theoretically, this effect should decrease the risk of exacerbations. Studies examining the effects of inhaled steroids on airway inflammation have been conflicting. There is some evidence that therapy with higher doses of inhaled corticosteroids reduces visible bronchial inflammation and epithelial fluid albumin (336), airway neutrophilia (337) and markers of neutrophilic inflammation such as IL-8 and MPO (338). A similar number of studies failed to demonstrate any effect of inhaled steroids on airway neutrophilia, epithelial permeability or airway mediator and cytokine levels (339-341). Patients in studies showing a beneficial response tended to be treated for somewhat longer periods of time (six to eight weeks versus four weeks), but it is unclear whether this is a sufficient explanation for the different outcomes.

The past two years have brought with them the publication of long awaited trials of the effects of inhaled corticosteroids in slowing the rate of annual decline of $\mathrm{FEV}_{1}$ in patients with COPD. These studies examined the effects of different inhaled steroids (budesonide, fluticasone propionate, triamcinolone) versus placebo for 3 to 3.5 years with a total of over 3000 patients completing the trials (342-345). Overall, there was no benefit seen in terms of rate of decline in lung function in patients treated with inhaled steroids versus those getting placebo. In addition, patients receiving inhaled steroids had a higher percentage of skin bruising (342), a decrease in bone density of the lumbar spine and femur (345) and a small decrease in mean cortisol concentrations, although this was not associated with any clinical effects (344).

The Inhaled Steroids on Obstructive Lung Disease in Europe (ISOLDE) study (344) revealed a $25 \%$ reduction in the median exacerbation rate from 1.32 per year on placebo to 0.99 per year for patients on fluticasone propionate. Another study examining the effects of fluticasone $500 \mu \mathrm{g}$ twice daily versus placebo over the course of six months also showed a significant reduction in both moderate and severe exacerbations in the steroid-treated group compared with the placebo group ( $86 \%$ versus $60 \%, \mathrm{P}<0.001)$ (346). Available data do not allow specific recommendations to be made regarding the use of inhaled steroids in patients with COPD. The risks versus the benefits of this therapy must be individualized. Patients with severe impairment in $\mathrm{FEV}_{1}$ and those 


\section{COPYRIGHT PULSUS GROUP ING, " DO NOT COPY}

with frequent exacerbations requiring the use of oral corticosteroids should be considered for therapy with inhaled corticosteroids (Level III evidence). Supporting this recommendation is a recent cohort study performed in Ontario. Data were collected regarding filling of prescriptions for inhaled steroids in 22,620 patients over the age of 65 years hospitalized with COPD, and one-year prognosis was measured according to whether they received a prescription for an inhaled steroid within three months of their admission. Prescription of an inhaled steroid led to a $10 \%$ one-year reduction in readmission and/or death (347). After adjusting for age, sex, comorbid conditions, concomitant medications and visits for COPD in the preceding year, the reduction in mortality was $29 \%$ (95\% CI, $22 \%$ to $35 \%$ ) and reduction in risk of readmission was $24 \%$ (95\% CI, $22 \%$ to $29 \%$ ) (347).

There is little evidence to suggest a benefit of regular therapy with oral corticosteroids in patients with COPD. Although two retrospective, long term studies $(348,349)$ claimed to demonstrate a beneficial effect over 20 years in patients with COPD, this effect was most apparent in patients with the most rapid rate of decline in $\mathrm{FEV}_{1}$ and no comments were made on the frequency of AECB. The same group showed no benefit with the addition of $5 \mathrm{mg}$ of prednisolone daily to inhaled corticosteroids in patients with relatively mild COPD in terms of decreasing the frequency or duration of AECB over a twoyear period (350). This, combined with the recognition of the significant complications of chronic oral corticosteroid therapy $(351,352)$ including a dose-dependent increase in mortality (353), argues against chronic use of systemic steroids in COPD (Level II evidence). It appears that even patients on chronic oral corticosteroids can be weaned off this medication without any adverse effects on pulmonary function, quality of life or frequency of AECB (354).

Long-acting beta-agonists have been shown to be beneficial in some patients with COPD. Some evidence exists that salmeterol is effective in reducing damage to the epithelium caused by $H$ influenzae or $P$ aeruginosa in vitro $(355,356)$. Theoretically, this may lead to less epithelial damage caused by bacteria and reduce the frequency or severity of AECB. There is some early clinical evidence that this may be true with patients on salmeterol having a longer time to first AECB compared to placebo or ipratropium (357). A similar delay in time to next exacerbation has recently been demonstrated in patients prescribed tiotropium $(358,359)$. Further investigations will be necessary before long-acting betaagonists or long-acting anticholinergics can be recommended for this purpose.

A meta-analysis published in 1998 suggested that oral mucolytic agents such as $\mathrm{N}$-acetylcysteine or iodinated glycerol reduced the frequency of AECB, disability days and antibiotic use (360). The greatest effects were seen in patients who had a large number of exacerbations. Oral mucolytic agents reduced exacerbations by $22 \%$ in patients who had an average of 5.5 exacerbations per year. However, a more typical chronic bronchitic patient with two to three exacerbations per year would expect to reduce exacerbations by less than one by taking mucolytic agents daily for two to three years. No effect on rate of decline of $\mathrm{FEV}_{1}$ was seen. A more recent meta-analysis on the effect of oral $\mathrm{N}$-acetylcysteine revealed similar results in terms of a decrease in AECB in patients treated for 12 to 24 weeks (361). In addition, a recently published update of Poole's Cochrane analysis confirmed the beneficial results of $\mathrm{N}$-acetylcysteine and determined that the number of patients needed to treat for one patient to have no exacerbations during the study period was six (362). A study in Switzerland suggested that therapy with $\mathrm{N}$-acetylcysteine was cost effective (363). The mechanism by which $\mathrm{N}$-acetylcysteine reduces AECB is unclear but may be related to enhancing macrophage activity, which would help defend against mucosal infections (364). N-acetylcysteine therapy should be considered in patients with more than five exacerbations per year (Level I evidence).

Hyaluronan is a high molecular weight glycosaminoglycan that is found naturally in the body. It has a role in enhancing neutrophil function. It has been shown to significantly decrease the frequency of $\mathrm{AECB}$ and reduce the need for antibiotics in this group of patients (365). It has to be given by subcutaneous injection weekly, making it somewhat impractical. In addition, cost effectiveness of this form of therapy remains to be proven. At this point, its use cannot be endorsed to prevent AECB (Level III evidence).

Numerous trials dating back to the mid-1950s have been carried out to determine whether antibiotic prophylaxis reduces the frequency of AECB $(93,366,367)$. Murphy and Sethi (93) identified nine prospective, placebo-controlled, randomized trials in each of which at least 25 patients were studied. In five of these trials, no reduction in the frequency of exacerbations was achieved; however, in two of these, significantly less time was lost from work by the antibiotictreated groups $(368,369)$. In four studies, the frequency of AECB was significantly reduced in groups treated with antibiotics compared with those receiving placebo. Similar to studies using other agents that decrease airway inflammation, antibiotic prophylaxis seemed to benefit patients who suffered the largest number of exacerbations over the course of the year. Therefore, patients in group III may benefit from prophylaxis with antibiotic agents to which their colonizing bacteria are sensitive. It should be pointed out that each of these studies regarding antibiotic prophylaxis was done with older generations of antibiotics and there is a need for current studies with newer antibiotics, particularly given the emerging bacterial resistance problems. Nonetheless, the effects of the antibiotics may be anti-inflammatory rather than antimicrobial. This is suggested by a recent study looking at the effects of erythromycin versus placebo in preventing AECB and hospitalizations in patients with COPD. Erythomycin has no significant activity against $H$ influenzae, the most important pathogen in AECB, yet therapy with $200 \mathrm{mg} /$ day to $400 \mathrm{mg}$ /day of erythromycin for one year led to a 4.71 decrease in the relative risk of developing AECB (11\% versus $56 \%$ in the placebo group) and a significant decrease in hospitalizations due to AECB (370).

Overall, there is evidence to support antibiotic prophylaxis in patients with frequent exacerbations (Level II evidence). However, decisions regarding prophylactic antibiotic treatment should be made on an individual basis.

\section{THE FUTURE}

The past decade has brought with it renewed interest into the pathogenesis of chronic bronchitis and a greater understanding of some of the basic mechanisms of the disease. Paradoxically, these discoveries have brought with them more questions. To improve our therapy of $\mathrm{AECB}$, we need better evidence on which to base future guidelines. The following 


\section{COPYRIGHT PULSUS GROUP ING. - DO NOT COPY}

are the issues most urgently in need of answers in order to make future AECB guidelines more evidence based:

1. We need a better definition of AECB to help guide the design of clinical trials, to allow the results to be generalizable and to better determine the health and economic impact of exacerbations.

2. Antibiotic trials that compare different classes of drugs powered to show superiority of one class over another are desperately needed to make evidence-based recommendations regarding drugs of first choice for AECB.

3. The importance of bacterial eradication in terms of both symptom resolution and determination of remission-free period requires further study.

4. The importance of reducing airway inflammation either with antibiotics with anti-inflammatory effects or with novel anti-inflammatory agents must be studied prospectively in a controlled trial. Ideally, a study looking at the effects of oral steroids alone without concomitant antibiotics should be carried out. This may be ethically difficult to do in patients with Anthonisen type I exacerbations stratified to our groups II or III but would be reasonable for patients with an Anthonisen type II or III exacerbations or for patients in our stratification group I.

5. A study examining the potential role for prophylactic antibiotics for patients in our stratification group III would be welcome.

6. We need better surrogate markers for bacterial infections. A better understanding of the antigenic structures of many of the common bacteria involved in AECB might lead to the development of monoclonal antibodies targeted against these antigens, which may help define acute bacterial infections.

ACKNOWLEDGEMENTS: We gratefully acknowledge the contribution and input in reviewing earlier versions of this manuscript of Dr Michael S Niederman, Winthrop University Hospital, Mineola New York; Dr G Douglas Campbell, LSU Medical Center, Shrevport, Louisiana; Dr Marc Miravitlles, Hospital General Universitarivall d'Hebron, Barcelona, Spain; and Dr Robert Wilson-Royal, Brompton Hospital, London, England. Preparation of this manuscript was coordinated by Core Health Services Inc. This study was sponsored by unrestricted educational grants from Abbott Laboratories Limited, Bayer Inc, BristolMyers Squibb Canada Inc, GlaxoSmithKline, Janssen-Ortho Inc and Pfizer Canada Inc.

\section{Chronic Bronchitis Working Group}

\section{APPENDIX}

Antonio Anzueto MD, University of Texas, San Antonio, Texas, USA; Abraham Born MD, FRCPC, North York General Hospital and University of Toronto, Toronto, Ontario; Jacques Bouchard MD, St-Joseph's Hospital, La Malbaie, Quebec; Nigel JD Duguid MB, FRCPC, Memorial University, Health Care Corporation of St John's, St John's, Newfoundland; Godfrey Harding MD, FACP, FRCPC, University of Manitoba, St Boniface General Hospital, Winnipeg, Manitoba; Marcel Julien MD, FRCPC, Hopital du Sacre-Coeur, Montreal, Quebec; Noel Lampron MD, Université Laval, Laval Hospital, Ste Foy, Quebec; Robert D Levy MD, FRCPC, Univesity of British Columbia, Vancouver General Hospital, Vancouver, British Columbia; James A McSherry MB, ChB, FCFP, FRCGP, FRCP Glasg, FAMB, University of Western Ontario, London Health Sciences Centre, London, Ontario; Karl A Weiss MD, MSc, FRCPC, University of Montreal, Hôpital Maisonneuve-Rosemont, Montreal, Quebec.

\section{REFERENCES}

1. Balter M, Hyland R, Low D. Recommendations on the management of chronic bronchitis: A practical guide for Canadian physicians. Can Med Assoc J 1994;151(Suppl):7-33.

2. Mandell LA, Marrie TJ, Grossman RF, Chow AW, Hyland RH. Canadian guidelines for the initial management of communityacquired pneumonia: An evidence-based update by the Canadian Infectious Diseases Society and the Canadian Thoracic Society. The Canadian Community-Acquired Pneumonia Working Group. Clin Infect Dis 2000;31:383-421.

3. Canadian Lung Association. Lung Facts 1991;3.

4. Siafakas NM, Vermeire P, Pride NB, et al. Optimal assessment and management of chronic obstructive pulmonary disease (COPD). The European Respiratory Society Task Force. Eur Respir J 1995;8:1398-1420.

5. American Thoracic Society. Standards for the diagnosis and care of patients with chronic obstructive pulmonary disease. Am J Respir Crit Care Med 1995;152:S77-121.

6. Definition and classification of chronic bronchitis for clinical and epidemiological purposes. A report to the Medical Research Council by their Committee on the Aetiology of Chronic Bronchitis. Lancet 1965;1:775-9.

7. Oswald NC, Harold JT, Martin WJ. Clinical pattern of chronic bronchitis. Lancet 1953;2265:639-643.

8. Manfreda J, Mao Y, Litven W. Morbidity and mortality from chronic obstructive pulmonary disease. Am Rev Respir Dis 1989;140:S19-26.
9. Lacasse Y, Brooks D, Goldstein RS. Trends in the epidemiology of COPD in Canada, 1980 to 1995. COPD and Rehabilitation Committee of the Canadian Thoracic Society. Chest 1999;116:306-13.

10. Enright PL, Kronmal RA, Higgins MW, Schenker MB, Haponik EF. Prevalence and correlates of respiratory symptoms and disease in the elderly. Cardiovascular Health Study. Chest 1994;106:827-34.

11. US Bureau of the Census. Statistical Abstract of the United States. (14th edn). Washington, DC, US Bureau of the Census, 1994/1995.

12. Woolcock AJ. Epidemiology of chronic airways disease. Chest 1989;96(Suppl 3):302S-6S.

13. Lange P, Groth S, Nyboe J, et al. Chronic obstructive lung disease in Copenhagen: Cross-sectional epidemiological aspects. J Intern Med 1989;226:25-32.

14. Bakke P, Baste V, Hanoa R, Gulsvik A. Prevalence of obstructive lung disease in a general population: Relation to occupational title and exposure to some airborne agent. Thorax 1991;46:863-70.

15. Brotons B, Perez J, Sanchez-Toril F, et al. Prevalencia de la enfermedad obstructiva cronica y el asma: estudio transversal. Arch Bronconeumol 1994;30:149-52.

16. Lundback B, Nystrom L, Rosenhall L, Stjernberg N. Obstructive lung disease in northern Sweden: Respiratory symptoms assessed in a postal survey. Eur Respir J 1991;4:257-66.

17. Ball P, Make B. Acute exacerbations of chronic bronchitis: An international comparison. Chest 1998;113(Suppl):199S-204S. 


\section{COPYRIGHT PULSUS GROUP INC, D DO NOT COPY}

18. Pandey MR. Domestic smoke pollution and chronic bronchitis in a rural community of the Hill Region of Nepal. Thorax 1984;39:337-9.

19. Higgins $M$, Thom T. Incidence, prevalence, and mortality: Intra-and inter-county differences. In: Hensley M, Saunders N, eds. Clinical Epidemiology of Chronic Obstructive Pulmonary Disease. New York: Marcel Dekker, 1990:23-43.

20. U.S. Surgeon General. The Health Consequences of Smoking: Chronic obstructive lung disease. (DHHS Publication No. 8450205). 1994. Washington, DC, U.S. Deparment of Health and Human Services.

21. Sherrill DL, Lebowitz MD, Burrows B. Epidemiology of chronic obstructive pulmonary disease. Clin Chest Med 1990;11:375-87.

22. Buist A. Risk factors for COPD. Eur Resp Rev 1996;6:253-8.

23. Becklake MR. Chronic air flow limitation: Its relationship to work in dusty occupations. Chest 1985;88:608-17.

24. Oxman AD, Muir DC, Shannon HS, Stock SR, Hnizdo E, Lange HJ. Occupational dust exposure and chronic obstructive pulmonary disease: A systematic overview of the evidence. Am Rev Respir Dis 1993;148:38-48.

25. Seersholm N, Kok-Jensen A. Clinical features and prognosis of lifetime non-smokers with severe alpha 1 antirypsin deficiency. Thorax 1998;53:265-8.

26. Cohen BH, Ball WC Jr, Bias WB, et al. A genetic-epidemiologic study of chronic obstructive pulmonary disease. I. Study design and preliminary observations. Johns Hopkins Med J 1975;137:95-104.

27. Tashkin DP, Altose MD, Connett JE, Kanner RE, Lee WW, Wise RA. Methacholine reactivity predicts changes in lung function over time in smokers with early chronic obstructive pulmonary disease. The Lung Health Study Research Group. Am J Respir Crit Care Med 1996;153:1802-11.

28. Postma D, De Vries K, Koeter G, Sluiter H. Independent influence of reversiblity of air-flow obstruction on nonspecific hyperreactivity on the long term course of lung function in chronic air-flow obstruction. Am Rev Respir Dis 1986;134:276-80.

29. Fielding JE, Phenow KJ. Health effects of involuntary smoking. N Engl J Med 1988;319:1452-60.

30. Leuenberger P, Schwartz J, Ackermann-Liebrich U, et al. Passive smoking exposure in adults and chronic respiratory symptoms (SAPALDIA Study). Swiss Study on Air Pollution and Lung Diseases in Adults, SAPALDIA Team. Am J Respir Crit Care Med 1994;150:1222-8.

31. Gold D, Tager I, Weiss S, Tosteson T, Speizer F. Acute lower respiratory illness in childhood as a predictor of lung function and chronic respiratory symptoms. Am Rev Respir Dis 1989;140:877-84.

32. Shaheen S, Barker D, Shiell A, Crocker F, Wield G, Holgate S. The relationship between pneumonia in early childhood and impaired lung function in late adult life. Am J Respir Crit Care Med 1994;149:616-9.

33. Matsuse T, Hayashi S, Kuwano K, Keunecke H, Jefferies WA, Hogg JC. Latent adenoviral infection in the pathogenesis of chronic airways obstruction. Am Rev Respir Dis 1992;146:177-84.

34. Cole P, Wilson R. Host-microbial interrelationships in respiratory infection. Chest 1989;95:217S-21S.

35. Pope CA III, Schwartz J, Ransom MR. Daily mortality and PM10 pollution in Utah Valley. Arch Environ Health 1992;47:211-7.

36. Zemp E, Elsasser S, Schindler C, et al. Long term ambient air pollution and respiratory symptoms in adults (SAPALDIA Study). Am J Crit Care Med 1999;159:1257-66.

37. Dennis RJ, Maldonado D, Norman S, Baena E, Martinez G. Woodsmoke exposure and risk for obstructive airways disease among women. Chest 1996;109:115-9.

38. Prescott E, Bjerg A, Anderson P, Lange P, Vestbo J. Gender differences in smoking effects on lung function and risk of hospitalization for COPD: Results from a Danish longitudinal population study. Eur Respir J 1997;10:822-7.

39. Leynaert B, Bousquet J, Henry C, et al. Is bronchial hyperresponsiveness more frequent in women then in men. Am J Respir Crit Care Med 1997;156:1413-20.

40. Sethi JM, Rochester CL. Smoking and chronic obstructive pulmonary disease. Clin Chest Med 2000;21:67-86.

41. Jeffery PK. Differences and similarities between chronic obstructive pulmonary disease and asthma. Clin Exp Allergy 1999;29(Suppl 2):14-26.

42. Reid L. Measurement of the bronchial mucous gland layer: A diagnostic yardstick in chronic bronchitis. Thorax 1960;15:132-41.

43. Jamal K, Cooney TP, Fleetham JA, Thurlbeck WM. Chronic bronchitis. Correlation of morphologic findings to sputum production and flow rates. Am Rev Respir Dis 1984;129:719-22.

44. Haraguchi M, Shimura S, Shirato K. Morphologic analysis of bronchial cartilage in chronic obstructive pulmonary disease and bronchial asthma. Am J Respir Crit Care Med 1999;159:1005-13.

45. Mullen JB, Wright JL, Wiggs BR, Pare PD, Hogg JC. Reassessment of inflammation of airways in chronic bronchitis. Br Med J (Clin Res Ed) 1985;291:1235-9.

46. Sethi S, Evans N, Grant BJ, Murphy TF. New strains of bacteria and exacerbations of chronic obstructive pulmonary disease. N Engl J Med 2002;347:465-71.

47. Fletcher C, Peto R. The natural history of chronic air flow obstruction. BMJ 1977;1:1645-8.

48. Fletcher C. The Natural History of Chronic Bronchitis and Emphysema: An 8-year Study of Working Men in London. New York: Oxford University Press, 1976.

49. Kauffmann F, Drouet D, Lellouch J, Brille D. Twelve years spirometric changes among Paris area workers. Int J Epidemiol 1979;8:201-12.

50. Higgins MW, Keller JB, Becker M, et al. An index of risk for obstructive airways disease. Am Rev Respir Dis 1982;125:144-51.

51. Kanner R, Renzetti A Jr, Klauber M, Smith C, Golden C. Variables associated with changes in spirometry in patients with obstructive lung diseases. Am J Med 1979;67:44-50.

52. Vestbo J, Prescott E, Lange P. Association of chronic mucus hypersecretion with FEV 1 decline and chronic obstructive pulmonary disease morbidity. Copenhagen City Heart Study Group. Am J Respir Crit Care Med 1996;153:1530-5.

53. Sherman CB, Xu X, Speizer FE, Ferris BG Jr, Weiss ST, Dockery DW. Longitudinal lung function decline in subjects with respiratory symptoms. Am Rev Respir Dis 1992;146:855-9.

54. Lange P, Nyboe J, Appleyard M, Jensen G, Schnohr P. Relation of ventilatory impairment and of chronic mucus hypersecretion to mortality from obstructive lung disease and from all causes. Thorax 1990;45:579-85.

55. Dowson L, Guest P, Stockley R. Longitudinal changes in physiological, radiological, and health status measurements in alphaantitrypsin deficiency and factors associated with decline. Am J Respir Crit Care Med 2001;164:1805-9.

56. Kanner RE, Anthonisen NR, Connett JE, for the Lung Health Study Research Group. Lower respiratory illnesses promote $\mathrm{FEV}_{1}$ decline in current smokers but not ex-smokers with mild chronic obstructive pulmonary disease: Results from the Lung Health Study. Am J Respir Crit Care Med 2001;164:358-64.

57. Niewoehner DE, Kleinerman J, Rice DB. Pathologic changes in the peripheral airways of young cigarette smokers. N Engl J Med 1974;291:755-8.

58. Cosio M, Ghezzo H, Hogg JC, et al. The relations between structural changes in small airways and pulmonary-function tests. N Engl J Med 1978;298:1277-81.

59. Tager IB, Segal MR, Speizer FE, Weiss ST. The natural history of forced expiratory volumes. Effect of cigarette smoking and respiratory symptoms. Am Rev Respir Dis 1988;138:837-49.

60. McClosky SC, Patel BD, Hinchliffe SJ, Reid ED, Wareham NJ, Lomas DA. Siblings of patients with severe chronic obstructive pulmonary disease have a significant risk of air flow obstruction. Crit Care Med 2001;164:1419-24.

61. Silverman EK. Genetics of chronic obstructive pulmonary disease. Novartis Foundation Symposium 2001;234:45-58.

62. Thompson AB, Daughton D, Robbins RA, Ghafouri MA, Oehlerking M, Rennard SI. Intraluminal airway inflammation in chronic bronchitis. Characterization and correlation with clinical parameters. Am Rev Respir Dis 1989;140:1527-37.

63. Richman-Eisenstat JB, Jorens PG, Hebert CA, Ueki I, Nadel JA. Interleukin-8: An important chemoattractant in sputum of patients with chronic inflammatory airway diseases. Am J Physiol 1993;264:L413-8.

64. Riise GC, Ahlstedt S, Larsson S, et al. Bronchial inflammation in chronic bronchitis assessed by measurement of cell products in bronchial lavage fluid. Thorax 1995;50:360-5.

65. Pesci A, Balbi B, Majori M, et al. Inflammatory cells in bronchial lavage of patients with chronic obstructive pulmonary disease. Eur Respir J 1998;12:380-6.

66. Hill AT, Campbell EJ, Hill SL, Bayley DL, Stockley RA. Association between airway bacterial load and markers of airway inflammation in patients with stable chronic bronchitis. Am J Med 2000;109:288-95. 


\section{COPYRIGHT PULSUS GROUP INC, = DO NOT COPY}

67. Stanescu D, Sanna A, Veriter C, et al. Airways obstruction, chronic expectoration, and rapid decline of $\mathrm{FEV}_{1}$ in smokers are associated with increased levels of sputum neutrophils. Thorax 1996;51:267-71.

68. Martin TR, Raghu G, Maunder RJ, Springmeyer SC. The effects of chronic bronchitis and chronic air-flow obstruction on lung cell populations recovered by bronchoalveolar lavage. Am Rev Respir Dis 1985;132:254-60.

69. Keatings VM, Collins PD, Scott DM, Barnes PJ. Differences in interleukin- 8 and tumor necrosis factor-alpha in induced sputum from patients with chronic obstructive pulmonary disease or asthma. Am J Respir Crit Care Med 1996;153:530-4.

70. Fournier M, Lebargy F, Le Roy LF, Lenormand E, Pariente R. Intraepithelial T-lymphocyte subsets in the airways of normal subjects and of patients with chronic bronchitis. Am Rev Respir Dis 1989; 140:737-42.

71. Saetta M, Di Stefano A, Turato G, et al. CD8+ T-lymphocytes in peripheral airways of smokers with chronic obstructive pulmonary disease. Am J Respir Crit Care Med 1998;157:822-6.

72. Lacoste JY, Bousquet J, Chanez P, et al. Eosinophilic and neutrophilic inflammation in asthma, chronic bronchitis, and chronic obstructive pulmonary disease. J Allergy Clin Immunol 1993;92:537-48.

73. Saetta M, Di Stefano A, Maestrelli P, et al. Airway eosinophilia and expression of interleukin- 5 protein in asthma and in exacerbations of chronic bronchitis. Clin Exp Allergy 1996;26:766-74.

74. Balbi B, Bason C, Balleari E, et al. Increased bronchoalveolar granulocytes and granulocyte/macrophage colony-stimulating factor during exacerbations of chronic bronchitis. Eur Respir J 1997; 10:846-50.

75. Crooks SW, Bayley DL, Hill SL, Stockley RA. Bronchial inflammation in acute bacterial exacerbations of chronic bronchitis: The role of leukotriene B4. Eur Respir J 2000;15:274-80.

76. Bhowmik A, Seemungal TA, Sapsford RJ, Wedzicha JA. Relation of sputum inflammatory markers to symptoms and lung function changes in COPD exacerbations. Thorax 2000;55:114-20.

77. Sethi S, Muscarella K, Evans N, Klingman KL, Grant BJ, Murphy TF. Airway inflammation and etiology of acute exacerbations of chronic bronchitis. Chest 2000;118:1557-65.

78. Aaron SD, Angel JB, Lunau M, et al. Granulocyte inflammatory markers and airway infection during acute exacerbation of chronic obstructive pulmonary disease. Am J Respir Crit Care Med 2001;163:349-55.

79. Saetta M, Di Stefano A, Maestrelli P, et al. Airway eosinophilia in chronic bronchitis during exacerbations. Am J Respir Crit Care Med 1994;150:1646-52.

80. Haas H, Morris J, Samson S, Kilbourn J, Kim P. Bacterial flora of the respiratory tract in chronic bronchitis: Comparison of transtracheal, fiberbronchoscopic, and oropharyngeal sampling methods. Am Rev Respir Dis 1977;116:41-7.

81. Hager H, Verghese A, Alvarez S, Berk S. Branhamella catarrhalis respiratory infections. Rev Infect Dis 1987;9:1140-9.

82. Tager I, Speizer F. Role of infection in chronic bronchitis. N Engl J Med 1975;292:563-71.

83. Vishwanath S, Ramphal R. Adherence of Pseudomonas aeruginosa to human tracheobronchial mucin. Infect Immun 1984;45:197-202.

84. Adler K, Hendley D, Davis G. Bacteria associated with obstructive pulmonary disease elaborate extracellular products that stimulate mucin secretion by explants of guinea pig airways. Am J Pathol 1986;125:501-14.

85. Wilson R, Pitt T, Taylor G, et al. Pyocyanin and 1-hydroxyphenazine produced by Pseudomonas aeruginosa inhibit the beating of human respiratory cilia in vitro. J Clin Invest 1987;79:221-9.

86. Wilson R, Cole P. The effect of bacterial products on ciliary function. Am Rev Respir Dis 1988;138:S49-S53.

87. Read R, Wilson R, Rutman A, et al. Interaction of nontypable Haemophilus influenzae with human respiratory mucosa in vitro. J Infect Dis 1991;163:549-58.

88. Wilson R, Tilotson G, Ball P. Clinical studies in chronic bronchitis: A need for better definition and classification of severity. J Antimicrob Chemother 1996;37:205-208.

89. Cosio M, Guerassimov A. Chronic obstructive pulmonary disease. Inflammation of small airways and lung parenchyma. Am J Respir Crit Care Med 1999;160(Suppl):S21-5.
90. Soler N, Ewig S, Torres A, Filella X, Gonzalez J, Zaubet A. Airway inflammation and bronchial microbial patterns in patients with stable chronic obstructive pulmonary disease. Eur Respir J 1999; 14:1015-22.

91. Bresser P, Out T, Van Alphen L, Jansen H, Lutter R. Airway inflammation in nonobstructive and obstructive chronic bronchitis with chronic Haemophilus influenzae airway infection: Comparison with noninfected patients with chronic obstructive pulmonary disease. Am J Respir Crit Care Med 2000;162:947-52.

92. Huang S-L, Su C-H, Chang S-C. Tumor necrosis factor- $\alpha$ gene polymorphism in chronic bronchitis. Am J Respir Crit Care Med 1997;156:1436-9.

93. Murphy T, Sethi S. Bacterial infection in chronic obstructive pulonary disease. Am Respir Dis 1992;146:1067-83.

94. Murphy T, Apicella M. Nontypable Haemophilus influenzae: A review of clinical aspects, surface antigens, and the human immune response to infection. Rev Infect Dis 1987;9:1-15.

95. Cabello H, Torres A, Celis R, et al. Bacterial colonization of distal airways in healthy subjects and chronic lung disease: A bronchoscopic study. Eur Respir J 1997;10:1137-44.

96. Mitchell J, Hill S. Immune response to Haemophilus influenzae in patients with chronic obstructive lung disease. Clin Diagnos Lab Immunol 2000;7:25-30.

97. Zalacain R, Sobradillo V, Amilibia J, et al. Predisposing factors to bacterial colonization in chronic obstructive pulmonary disease. Eur Respir J 1999;13:343-8.

98. Monso E, Rosell A, Bonet G, et al. Risk factors of lower airway bacterial colonization in chronic bronchitis. Eur Respir J 1999; 13:338-42.

99. Eller J, Ede A, Schaberg T, Niederman MS, Mauch H, Lode H. Infective exacerbations of chronic bronchitis: Relation between bacteriologic etiology and lung function. Chest 1998;113:1542-8.

100. Miravitlles M, Espinosa C, Fernandez-Laso E, Martos JA, Maldonado JA, Gallego M. Relationship between bacterial flora in sputum and functional impairment in patients with acute exacerbations of COPD. Study Group of Bacterial Infection in COPD. Chest 1999;116:40-6.

101. Van Schilfgaarde M, Eijk P, Regelink A, et al. Haemophilus influenzae localized in epithelial cell layers is shielded from antibiotics and antibody-mediated bactericidal activity. Microb Pathog 1999;26:249-62.

102. Bandi V, Apicella M, Moson E, et al. Non-typeable Haemophilus influenzae in the lower respiratory tract of patients with chronic bronchitis. Respir Crit Care Med 2001;164:2114-9.

103. Moller L, Timens W, Van Der Bij W, et al. Haemophilus influenzae in lung explants of patients with end-stage pulmonary disease. Am J Respir Crit Care Med 1998;157:950-6.

104. Groenveld K, Van Alphen L, Eijk P, Jansen H, Zanen H. Changes in outer membrane proteins of nontypable Haemophilus influenzae in patients with chronic obstructive pulmonary disease. J Infect Dis 1988;158:360-5.

105. Groeneveld K, Van Alphen L, Voorter C, Eijk P, Jansen H, Zanen H. Antigenic drift of Haemophilus influenzae in patients with chronic obstructive pulmonary disease. Infect Immun 1989;57:3038-44.

106. Fogarty CM, Bettis RB, Griffin TJ, Keyserling CH, Nemeth MA, Tack KJ. Comparison of a 5 day regimen of cefdinar with a 10 day regimen of cefprozil for treatment of acute exacerbations of chronic bronchitis. J Antimicrob Chemother 2000;45:851-8.

107. Wilson R, Kubin I, Deppermann K-M, et al. Five day moxifloxacin therapy compared with 7 day clarithromycin therapy for the treatment of acute exacerbations of chronic bronchitis. J Antimicrob Chemother 1999;44:501-13.

108. Shah PM, Maesen FPV, Dolmann A, Vetter N, Fiss E, Wesch R. Levofloxacin versus cefuroxime axetil in the treatment of acute exacerbations of chronic bronchitis: Results of a randomized, double-blind study. J Antimicrob Chemother 1999;43:529-39.

109. Langan C, Zuck P, Vogel F, et al. Randomized, double-blind study of short-course ( 5 day) grepafloxacin versus 10 day clarithromycin in patients with acute bacterial exacerbations of chronic bronchitis. J Antimicrob Chemother 1999;44:515-23.

110. Georgopoulos A, Borek M, Ridl W, for the Amoxycillin Bronchitis Study Group. Randomized, double-blind, double-dummy study comparing the efficacy and safety of amoxycillin $1 \mathrm{~g}$ bd with amoxycillin $500 \mathrm{mg}$ tds in the treatment of acute exacerbations of chronic bronchitis. J Antimicrob Chemother 2001;47:67-76. 


\section{COPYRIGHT PULSUS GROUP INC. - DO NOT COPY}

111. Habib M, Gentry L, Rodriguez-Gomez G, et al. Multicenter, randomized study comparing efficacy and safety of oral levofloxacin and cefaclor in treatment of acute bacterial exacerbations of chronic bronchitis. Infect Dis Clin Pract 1998;7:101-9.

112. Chodosh S, Lakshminarayan S, Swarz H, Breisch S. Efficacy and safety of a 10-day course of 400 or 600 milligrams of grepafloxacin once daily for treatment of acute bacterial exacerbations of chronic bronchitis: Comparison with a 10-day course of 500 milligrams of ciprofloxacin twice daily. Antimicrob Agents Chemother 1998;42:114-20.

113. DeAbate C, Russell M, McElvaine P, et al. Safety and efficacy of oral levofloxacin versus cefuroxime axetil in acute bacterial exacerbations of chronic bronchitis. Respir Care 1997;42:206-23.

114. Gump DW, Phillips CA, Forsyth BR, McIntosh K, Lamborn KR, Stouch WH. Role of infection in chronic bronchitis. Am Rev Respir Dis 1976;113:465-74.

115. McHardy V, Inglis J, Calder M, et al. A study of infective and other factors in exacerbations of chronic bronchitis. Br J Dis Chest 1980;74:228-38.

116. Fagon J, Chastre J, Trouillet J, et al. Characterization of distal bronchial microflora during acute exacerbation of chronic bronchitis. Am Rev Respir Dis 1990;142:1004-8.

117. Monso E, Ruiz J, Rosell A, et al. Bacterial infection in chronic obstructive pulmonary disease. A study of stable and exacerbated outpatients using the protected specimen brush. Am J Respir Crit Care Med 1995;152:1316-20.

118. Soler N, Torres A, Ewig S, et al. Bronchial microbial patterns in severe exacerbations of chronic obstructive pulmonary disease. Am J Respir Crit Care Med 1998;157:1498-1505.

119. Pela R, Marchesani F, Agostinelli C, et al. Airways microbial flora in COPD patients in stable clinical conditions and during exacerbations: A bronchoscopic investigation. Monaldi Arch Chest Dis 1998;53:262-7.

120. Anthonisen NR, Manfreda J, Warren CP, Hershfield ES, Harding GK, Nelson NA. Antibiotic therapy in exacerbations of chronic obstructive pulmonary disease. Ann Intern Med 1987;106:196-204.

121. Sachs A, Koeter G, Groenier K, Van Der Waaij D, Schiphuis J, Meyboom-de Jong B. Changes in symptoms, peak expiratory flow, and sputum flora during treatment with antibiotics of exacerbations in patients with chronic obstructive pulmonary disease in general practice. Thorax 1995;50:758-63.

122. Stockley R, O'Brien C, Pye A, Hill S. Relationship of sputum color to nature and outpatient management of acute exacerbations of COPD. Chest 2000;117:1638-45.

123. Stockley R, Bayley D, Hill S, Hill A, Crooks S, Campbell E. Assessment of airway neutrophils by sputum colour: Correlation with airways inflammation. Thorax 2001;56:366-72.

124. Gompertz S, Baley D, Hill S, Stockley R. Relationship between airway inflammation and the frequency of exacerbations in patients with smoking related COPD. Thorax 2001;56:36-41.

125. Von Hertzen L, Alakarppa H, Koskinen R, et al. Chlamydia pneumoniae infection in patients with chronic obstructive pulmonary disease. Epidemiol Infect 1997;118:155-64.

126. Buscho R, Saxtan D, Shultz P, Finch E, Mufson M. Infections with viruses and Mycoplasma pneumoniae during exacerbations of chronic bronchitis. J Infect Dis 1978;137:377-83.

127. Smith C, Kanner R, Golden C, Klauber M, Renzetti AJ. Effect of viral infection on pulmonary function in patients with chronic obstructive pulmonary disease. J Infect Dis 1980;141:271-80.

128. Seemungal T, Harper-Owen R, Bhowmik A, et al. Respiratory viruses, symptoms, and inflammatory markers in acute exacerbations and stable chronic obstructive pulmonary disease. Am J Respir Crit Care Med 2001;164:1618-23.

129. Blasi F, Legnani D, Lombardo V, et al. Chlamydia pneumoniae infection in acute exacerbations of COPD. Eur Respir J 1993;6:19-22

130. Beaty C, Grayston J, Wang S-P, Kuo C-C, Reto C, Martin T. Chlamydia pneumoniae, strain TWAR, infection in patients with chronic obstructive pulmonary disease. Am Rev Respir Dis 1991;144:1408-10.

131. Mogulkoc N, Karakurt S, Isalska B, et al. Acute purulent exacerbation of chronic obstructive pulmonary disease and Chlamydia pneumoniae infection. Am J Respir Crit Care Med 1999; 160:349-53.

132. Smith C, Golden C, Klauber M, et al. Interactions between viruses and bacteria in patients with chronic bronchitis. J Infect Dis 1976;134:552-61.

133. Stenhouse A. Rhinovirus infection in acute exacerbation of chronic bronchitis: A controlled prospective study. BM] 1976;3:461-3.

134. Seemungal TA, Donaldson GC, Bhowmik A, Jeffries DJ, Wedzicha JA. Time course and recovery of exacerbations in patients with chronic obstructive pulmonary disease. Am J Respir Crit Care Med 2000;161:1608-13.

135. Seemungal TA, Donaldson GC, Paul EA, Bestall JC, Jeffries DJ, Wedzicha JA. Effect of exacerbation on quality of life in patients with chronic obstructive pulmonary disease. Am J Respir Crit Care Med 1998;157:1418-22.

136. Mushlin AI, Black ER, Connolly CA, Buonaccorso KM, Eberly SW. The necessary length of hospital stay for chronic pulmonary disease. JAMA 1991;266:80-3.

137. Connors AF, Dawson NV, Thomas C, et al. Outcomes following acute exacerbation of severe chronic obstructive lung disease. The SUPPORT investigators (Study to Understand Prognoses and Preferences for Outcomes and Risks of Treatments). Am J Respir Crit Care Med 1996;154:959-67.

138. Burk RH, George RB. Acute respiratory failure in chronic obstructive pulmonary disease. Immediate and long-term prognosis. Arch Intern Med 1973;132:865-8.

139. Seneff MG, Wagner DP, Wagner RP, Zimmerman JE, Knaus WA. Hospital and 1-year survival of patients admitted to intensive care units with acute exacerbation of chronic obstructive pulmonary disease. JAMA 1995;274:1852-7.

140. Cydulka RK, McFadden ER Jr, Emerman CL, Sivinski LD, Pisanelli W, Rimm AA. Patterns of hospitalization in elderly patients with asthma and chronic obstructive pulmonary disease. Am J Resp Crit Care Med 1997;156:1807-12.

141. Osman IM, Godden DJ, Friend JA, Legge JS, Douglas JG. Quality of life and hospital re-admission in patients with chronic obstructive pulmonary disease. Thorax 1997;52:67-71.

142. Peach H, Pathy MS. Follow-up study of disability among elderly patients discharged from hospital with exacerbations of chronic bronchitis. Thorax 1981;36:585-9.

143. Hagedorn SD. Acute exacerbations of COPD. How to evaluate severity and treat the underlying cause. Postgrad Med 1992;91:105-7.

144. Emerman CL, Cydulka RK. Evaluation of high-yield criteria for chest radiography in acute exacerbation of chronic obstructive pulmonary disease. Ann Emerg Med 1993;22:680-4.

145. Tsai TW, Gallagher EJ, Lombardi G, Gennis P, Carter W. Guidelines for the selective ordering of admission chest radiography in adult obstructive airway disease. Ann Emerg Med 1993;22:1854-8.

146. Sherman S, Skoney JA, Ravikrishnan KP. Routine chest radiographs in exacerbations of chronic obstructive pulmonary disease. Diagnostic value. Arch Intern Med 1989;149:2493-6.

147. Wolkove N, Dajczman E, Colacone A, Kreisman H. The relationship between pulmonary function and dyspnea in obstructive lung disease. Chest 1989;96:1247-51.

148. Peto R, Speizer F, Cochrane A, et al. The relevance in adults of airflow obstruction but not of mucus hypersecretion, to morality from chronic lung disease. Results from 20 years of prospective observation. Am Rev Respir Dis 1983;128:491-500.

149. Hodgkin JE. Prognosis in chronic obstructive pulmonary disease. Clin Chest Med 1990;11:555-69.

150. Vitacca M, Clini E, Porta R, Foglio K, Ambrosino N. Acute exacerbations in patients with COPD: Predictors of need for mechanical ventilation. Eur Respir J 1996;9:1487-93.

151. Niewoehner D, Collins D, Erbland M. Relation to FEV 1 to clinical outcomes during exacerbations of chronic obstuctive pulmonary disease. The Department of Veterans Affairs Cooperative Study Group. Am J Respir Crit Care Med 2000;161:1201-5.

152. Mannino DM, Etzel RA, Flanders WD. Do the medical history and physical examination predict low lung function? Arch Intern Med 1993;153:1892-7.

153. Kesten S, Chapman K. Physician perceptions and management of COPD. Chest 1993;104:254-8.

154. Renwick DS, Connolly MJ. Prevalence and treatment of chronic airways obstruction in adults over the age of 45 . Thorax 1996;51:164-8.

155. Kuhl DA, Agiri OA, Mauro LS. Beta-agonists in the treatment of 


\section{COPYRIGHT PULSUS GROUP INC, D DO NOT COPY}

acute exacerbation of chronic obstructive pulmonary disease. Ann Pharmacother 1994;28:1379-88.

156. Emerman CL, Cydulka RK. Effect of different albuterol dosing regimens in the treatment of acute exacerbation of chronic obstructive pulmonary disease. Ann Emerg Med 1997;29:474-8.

157. O'Driscoll BR, Taylor RJ, Horsley MG, Chambers DK, Bernstein A. Nebulised salbutamol with and without ipratropium bromide in acute air flow obstruction. Lancet 1989;1(8652):1418-20.

158. Backman R, Helstrom P. Fenoterol and ipratropium bromide for treatment of patients with chronic bronchitis. Curr Ther Res 1985;38:135-40.

159. Karpel JP, Pesin J, Greenberg D, Gentry E. A comparison of the effects of ipratropium bromide and metaproterenol sulfate in acute exacerbations of COPD. Chest 1990;98:835-9.

160. Rebuck AS, Chapman KR, Abboud R, et al. Nebulized anticholinergic and sympathomimetic treatment of asthma and chronic obstructive airways disease in the emergency room. Am J Med 1987;82:59-64.

161. Moayyedi P, Congleton J, Page RL, Pearson SB, Muers MF. Comparison of nebulised salbutamol and ipratropium bromide with salbutamol alone in the treatment of chronic obstructive pulmonary disease. Thorax 1995;50:834-7.

162. Patrick DM, Dales RE, Stark RM, Laliberte G, Dickinson G. Severe exacerbations of COPD and asthma. Incremental benefit of adding ipratropium to usual therapy. Chest 1990;98:295-7.

163. Cydulka RK, Emerman CL. Effects of combined treatment with glycopyrrolate and albuterol in acute exacerbation of chronic obstructive pulmonary disease. Ann Emerg Med 1995;25:470-3.

164. Shrestha M, O'Brien T, Haddox R, Gourlay HS, Reed G. Decreased duration of emergency department treatment of chronic obstructive pulmonary disease exacerbations with the addition of ipratropium bromide to beta-agonist therapy. Ann Emerg Med 1991;20:1206-9.

165. Turner M, Patel A, Ginsburg S, FitzGerald J. Bronchodilator delivery in acute air flow obstruction. A meta-analysis. Arch Intern Med 1997;157:1736-44.

166. Rice KL, Leatherman JW, Duane PG, et al. Aminophylline for acute exacerbations of chronic obstructive pulmonary disease. A controlled trial. Ann Intern Med 1987;107:305-9.

167. Seidenfeld JJ, Jones WN, Moss RE, Tremper J. Intravenous aminophylline in the treatment of acute bronchospastic exacerbations of chronic obstructive pulmonary disease. Ann Emerg Med 1984;13:248-52.

168. Schmidt GA, Hall JB. Acute or chronic respiratory failure. Assessment and management of patients with COPD in the emergency setting. JAMA 1989;261:3444-53.

169. Bone R, Pierce A, Johnson RJ. Controlled oxygen administration in acute respiratory failure in chronic obstructive pulmonary disease: A reappraisal. Am J Med 1978;65:896-902.

170. Rosen RL. Acute respiratory failure and chronic obstructive lung disease. Med Clin North Am 1986;70:895-907.

171. Derenne JP, Fleury B, Pariente R. Acute respiratory failure of chronic obstructive pulmonary disease. Am Rev Repir Dis 1988;138:1006-33.

172. Weinberger SE, Schwartzstein RM, Weiss JW. Hypercapnia. N Engl J Med 1989;321:1223-31.

173. Stradling JR. Hypercapnia during oxygen therapy in airways obstruction: A reappraisal. Thorax 1986;41:897-902.

174. Levi-Valensi P, Weitzenblum E, Pedinielli JL, Racineux JL, Duwoos H. Three-month follow-up of arterial blood gas determinations in candidates for long-term oxygen therapy. A multicentric study. Am Rev Respir Dis 1986;133:547-51.

175. Anonymous. Recommendations for long term oxygen therapy (LTOT), European society of Pneumology Task Group. Eur Respir J $1992 ; 2: 160-4$

176. Timms RM, Kvale PA, Anthonisen NR, et al. Selection of patients with chronic obstructive pulmonary disease for long-term oxygen therapy. JAMA 1981;245:2514-5.

177. Finiguerra M, Conti P, Figura I, Legnani W, Morandini G. Clinical study on an antibiotic and mucolytic association (amoxicillin and domiodal) in hypersecretory chronic bronchopulmonary diseases. Current Ther Res 1982;31:895-905.

178. Langlands JH. Double-blind clinical trial of bromhexine as a mucolytic drug in chronic bronchitis. Lancet 1970;1(7644):448-50.

179. Aylward M. A between-patient, double-blind comparison of S-carboxymethylcysteine and bromhexine in chronic obstructive bronchitis. Curr Med Res Opin 1973;1:219-27.
180. Anthonisen P, Riis P, Sogaard-Anderson T. The value of lung physiotheraphy in the treatment of acute exacerbations in chronic bronchitis. Acta Med Scand 1964;175:715-9.

181. Newton DA, Bevans HG. Physiotherapy and intermittent positivepressure ventilation of chronic bronchitis. BMJ 1978;2:1525-8.

182. Campbell AH, O'Connell JM, Wilson F. The effect of chest physiotherapy upon the $\mathrm{FEV}_{1}$ in chronic bronchitis. Med J Aust 1975;1:33-5.

183. Connors AF, Hammon WE, Martin RJ, Rogers RM. Chest physical therapy. The immediate effect on oxygenation in acutely ill patients. Chest 1980;78:559-64.

184. Plant PK, Owen JL, Elliott MW. Early use of non-invasive ventilation for acute exacerbations of chronic obstructive pulmonary disease on general respiratory wards: A multicentre randomised controlled trial. Lancet 2000;355:1931-5.

185. Keenan SP, Kernerman PD, Cook DJ, Martin CM, McCormack D, Sibbald WJ. Effect of noninvasive positive pressure ventilation on mortality in patients admitted with acute respiratory failure: A meta-analysis. Crit Care Med 1997;25:1685-92.

186. Mehta S, Hill NS. Noninvasive ventilation. Am J Respir Crit Care Med 2001;163:540-77.

187. Anton A, Guell R, Gomex J, et al. Predicting the result of noninvasive ventilation in severe acute exacerbations of patients with chronic air flow limitation. Chest 2000;117:828-33.

188. Ambrosino N, Foglio K, Rubini F, Clini E, Nava S, Vitacca M. Non-invasive mechanical ventilation in acute respiratory failure due to chronic obstructive pulmonary disease: Correlates for success. Thorax 1995;50:755-7.

189. Meduri G, Turner R, Abou-Shala N, Wunderink R, Tolley E. Noninvasive positive pressure ventilation via face mask. First-line intervention in patients with hypercapnic and hypoxemic respiratory failure. Chest 1996;109:179-93.

190. Emerman C, Connors A, Lukens T, May M, Effron D. A randomized controlled trial of methylprednisolone in the emergency treatment of acute exacerbations of COPD. Chest 1989;95:563-7.

191. Thompson W, Nielson C, Carvalho P, Charan N, Crowley J. Controlled trial of oral prednisone in outpatients with acute COPD exacerbation. Am J Respir Crit Care Med 1996;154:407-12.

192. Davies L, Angus R, Calverley P. Oral corticosteroids in patients admitted to hospital with exacerbations of chronic obstructive pulmonary disease: A prospective randomised controlled trial. Lancet 1999;354:456-60.

193. Niewoehner D, Erbland M, Deupree R, et al. Effect of systemic glucocorticoids on exacerbations of chronic obstructive pulmonary disease. Department of Veterans Affairs Cooperative Study Group. N Engl J Med 1999;340:1941-7.

194. Murata G, Gorby M, Chick T, Halperin A. Intravenous and oral corticosteroids for the prevention of relapse after treatment for decompensated COPD: Effect on patients with a history of multiple relapses. Chest 1990;98:845-9.

195. Abbinante-Nissen J, Simpson L, Leikauf G. Corticosteroids increase secretory leukocyte protease inhibitor transcript levels in airway epithelial cells. Am J Physiol 1995;268:L601-6.

196. Llewellyn-Jones C, Harris T, Stockley R. Effect of fluticasone propionate on sputum of patients with chronic bronchitis and emphysema. Am J Resp Crit Care Med 1996;153:616-21.

197. Tomee J, Koeter G, Hiemstra P, Kauffman H. Secretory leukoprotease inhibitor: A native antimicrobial protein presenting a new therapeutic option? Thorax 1998;53:114-6.

198. Sayiner A, Aytemur ZA, Cirit M, Unsal I. Systemic glucorticoids in severe exacerbations of COPD. Chest 2001;119:726-30.

199. Decramer M, Gosselink R, Troosters T, Verschueren M, Evers G. Muscle weakness is related to utilization of health care resources in COPD. Eur Respir J 1997;10:417-23.

200. Woolhouse C, Hill S, Stockley R. Symptom resolution assessed using a patient directed diary card during treatment of acute exacerbations of chronic bronchitis. Thorax 2001;56:947-53.

201. Maltais F, Ostinelli J, Bourbeau J, Tonnel A, Jacquemet N, Haddon J. Comparison of nebulized budesonide and oral prednisolone with placebo in the treatment of acute exacerbations of chronic obstructive pulmonary disease: A randomized controlled trial. Am J Respir Crit Care Med 2002;165:698-703.

202. Elmes P, Fletcher C, Dutton A. Prophylactic use of oxytetracycline for exacerbations of chronic bronchitis. Br Med J 1957;2:1272-5.

203. Berry D, Fry J, Hindley C, et al. Exacerbations of chronic bronchitis treatment with oxytetracycline. Lancet 1960;1:137-9. 


\section{COPYRIGHT PULSUS GROUP INC, DO NOT COPY}

204. Elmes P, King T, Langlands J, et al. Value of ampicillin in the hospital treatment of exacerbations of chronic bronchitis. Br Med J 1965;5467:904-8.

205. Peterson E, Esmann V, Honcke P, Munkner C. A controlled study of the effect of treatment on chronic bronchitis: an evaluation using pulmonary function tests. Acta Med Scand 1967;182:293-305.

206. Pines A, Raafat H, Greenfield J, Linsell W, Solari M. Antibiotic regimens in moderately ill patients with purulent exacerbations of chronic bronchitis. Br J Dis Chest 1972;66:107-15.

207. Nicotra MB, Rivera M, Awe RJ. Antibiotic therapy of acute exacerbations of chronic bronchitis. A controlled study using tetracycline. Ann Intern Med 1982;97:18-21.

208. Allegra L, Grasi E, Pozzi E. Pruolo degli antibiotici nel trattamento delle riacutizza della bronchite cronica. Ital J Chest Dis 1991;45:138-48.

209. Nouira S, Marghli S, Belghith M, Besbes L, Elatrous S, Abroug F. Once daily oral ofloxacin in chronic obstructive pulmonary disease exacerbation requiring mechanical ventilation: A randomized placebo-controlled trial. Lancet 2001;358:2020-35.

210. Sethi S, Paluri R, Grant E, Murphy T. Prediction models for the etiology of acute exacerbations of COPD. Am J Resp Crit Care Med 1999;159:A819. (Abst)

211. Saint S, Bent S, Vittinghoff E, Grady D. Antibiotics in chronic obstructive pulmonary disease exacerbations. A meta-analysis. JAMA 1995;273:957-60

212. Ball P, Harris J, Lowson D, Tillotson G, Wilson R. Acute infective exacerbations of chronic bronchitis. QJM 1995;88:61-8.

213. Macfarlane JT, Colville A, Guion A, Macfarlane RM, Rose DH. Prospective study of aetiology and outcome of adult lowerrespiratory-tract infections in the community. Lancet 1993;341:511-4.

214. Destache CJ, Dewan N, O'Donohue WJ, Campbell JC, Angelillo VA. Clinical and economic considerations in the treatment of acute exacerbations of chronic bronchitis. J Antimicrob Chemother 1999;43(Suppl A):107-13.

215. Doern GV, Brueggemann AB, Pierce G, Holley HP Jr, Rauch A. Antibiotic resistance among clinical isolates of Haemophilus influenzae in the United States in 1994 and 1995 and detection of beta-lactamase-positive strains resistant to amoxicillin-clavulanate: Results of a national multicenter surveillance study. Antimicrob Agents Chemother 1997;41:292-7.

216. Doern G, Pfaller M, Kugler K, Freeman J, Jones R. Prevalence of antimicrobial resistance among respiratory tract isolates of Streptococcus pneumoniae in North America: 1997 Results from the SENTRY Antimicrobial Surveillance Program. Clin Infect Dis 1998;27:764-70.

217. Sportel JH, Koeter GH, van Altena R, Lowenberg A, Boersma WG. Relation between beta-lactamase producing bacteria and patient characteristics in chronic obstructive pulmonary disease (COPD). Thorax 1995;50:249-53.

218. Doern GV, Brueggemann A, Holley HP, Jr, Rauch AM. Antimicrobial resistance of Streptococcus pneumoniae recovered from outpatients in the United States during the winter months of 1994 to 1995: Results of a 30-center national surveillance study. Antimicrob Agents Chemother 1996;40:1208-13.

219. Thornsberry C, Ogilvie P, Kahn J, Mauriz Y. Surveillance of antimicrobial resistance in Streptococcus pneumoniae, Haemophilus influenzae, and Moraxella catarrhalis in the United States in 1996. 1997 respiratory season. The Laboratory Investigator Group. Diagn Microbiol Infect Dis 1997;29:249-57.

220. Moellering R. Meeting the challenges of beta-lactamases. J Antimicrob Chemother 1993;31(Suppl A):1-8.

221. National committee for clinical laboratory standards. Performance standards for antimicrobial susceptibility. Ninth information supplement. Wayne, PA, 1999.

222. Forward K. The epidemiology of penicillin resistance in Streptococcus pneumoniae. Semin Respir Infect 1999;14:243-54.

223. Zhanel G, Karlowsky J, Palatnick L, Vercaigne L, Low D, Hoban D. Prevalence of antimicrobial resistance in respiratory tract isolates of Streptococcus pneumoniae: Results of a Canadian national surveillance study. The Canadian Respiratory Infection Study Group. Antimicrob Agents Chemother 1999;43:2504-9.

224. Thornsberry C, Ogilvie P, Holley HJ, Sahm D. Survey of susceptibilities of Streptococcus pneumoniae, Haemophilus influenzae, and Moraxella catarrhalis isolates to 26 antimicrobial agents: A prospective U.S. study. Antimicrob Agents Chemother $1999 ; 43: 2612-23$
225. Jacobs M, Bajaksouzian S, Zilles A, Lin G, Pankuch G, Appelbaum P. Susceptibilities of Streptococcus pneumoniae and Haemophilus influenzae to 10 oral antimicrobial agents based on pharmacodynamic parameters: 1997 US surveillance study. Antimicrob Agents Chemother 1999;43:1901-8.

226. Marton A, Meszner Z. Epidemiological studies on drug resistance in Streptococcus pneumoniae in Hungary: An update for the 1990s. Microb Drug Resist 1999;5:201-5.

227. Fluit A, Schmitz F, Jones M, Acar J, Gupta R, Verhoef J. Antimicrobial resistance among community-acquired pneumonia isolates in Europe: First results from the SENTRY antimicrobial surveillance program 1997. SENTRY participants group. Int J Infect Dis 1999;3:153-6.

228. Song J, Lee N, Ichiyama S, et al. Spread of drug-resistant Streptococcus pneumoniae in Asian countries: Asian Network for Surveillance of Resistant Pathogens (ANSORP) study. Clin Infect Dis 1999;28:1206-11.

229. Campbell GJ, Silberman R. Drug-resistant Streptococcus pneumoniae. Clin Infect Dis 1998;26:1188-95.

230. Klugman K, Feldman C. Penicillin and cephalosporin-resistant streptococcus pneumonia: Emerging treatment for an emerging problem. Drugs 1999;58:1-4.

231. Dowell S, Butler J, Giebink G, et al. Acute otitis media: Management and surveillance in an era of pneumococcal resistance A report from the Drug-resistant Streptococcus pneumoniae Therapeutic Working Group. Pediatr Infect Dis J 1999;18:1-9.

232. Butler J, Dowell S, Breiman R. Epidemiology of emerging pneumococcal drug resistance: Implications for treatment and prevention. Vaccine 1998;16:1693-7.

233. National committee for clinical laboratory standards. Performance Standards for Antimicrobial Susceptibility Testing. Twelfth informational supplement. M100-S12. 2002. Wayne, PA, 2002.

234. Davidson R. A cross Canada surveillance of antimicrobial resistance in respiratory tract pathogens. Can J Infect Dis $1999 ; 10: 128-33$

235. Jorgensen JH. Update on mechanisms and prevalence of antimicrobial resistance in Haemophilus influenzae. Clin Infect Dis 1992;14:1119-23.

236. Wallace RJ Jr, Nash DR, Steingrube VA. Antibiotic susceptibilities and drug resistance in Moraxella (Branhamella) catarrhalis. Am J Med 1990;88(Suppl 5A):46S-50S.

237. Felmingham D, Washington J. Trends in the antimicrobial susceptibility of bacterial respiratory tract pathogens - findings of the Alexander project 1992-1996. Chemother 1999;11(Suppl 1):5-21.

238. Richter S, Brueggemann A, Huynh H, et al. A 1997-1998 national surveillance study: Moraxella catarrhalis and Haemophilus influenzae antimicrobial resistance in 34 US institutions. Int J Antimicrob Agents 1999;13:99-107.

239. Doern G, Jones R, Pfaller M, Kugler K. Haemophilus influenzae and Moraxella catarrhalis from patients with community-acquired respiratory tract infections: Antimicrobial susceptibility patterns from the SENTRY Antimicrobial Surveillance Program (United States and Canada, 1997). Antimicrob Agents Chemother 1999;43:385-9.

240. Low DE. Quinupristin/dalfopristin: Spectrum of activity, pharmacokinetics, and initial clinical experience. Microb Drug Resist 1995; 1:223-34.

241. Sutcliffe J, Grebe T, Tait-Kamradt A, Wondrack L. Detection of erythromycin-resistant determinants by PCR. Antimicrob Agents Chemother 1996;40:2562-6.

242. Sutcliffe J, Tait-Kamradt A, Wondrack L. Streptococcus pneumoniae and Streptococcus pyogenes resistant to macrolides but sensitive to clindamycin: A common resistance pattern mediated by an efflux system. Antimicrob Agents Chemother 1996;40:1817-24.

243. Peters DH, Friedel HA, McTavish D. Azithromycin. A review of its antimicrobial activity, pharmacokinetic properties and clinical efficacy. Drugs 1992;44:750-99.

244. Johnston NJ, De Azavedo JC, Kellner JD, Low DE. Prevalence and characterization of the mechanisms of macrolide, lincosamide, and streptogramin resistance in isolates of Streptococcus pneumoniae. Antimicrob Agents Chemother 1998;42:2425-6.

245. Shortridge VD, Doern GV, Brueggemann AB, Beyer JM, Flamm RK. Prevalence of macrolide resistance mechanisms in Streptococcus pneumoniae isolates from a multicenter antibiotic resistance surveillance study conducted in the United States in 1994-1995. Clin Infect Dis 1999;29:1186-8. 


\section{COPYRIGHT PULSUS GROUP INC, = DO NOT COPY}

246. Nishijima T, Saito Y, Aoki A, Toriya M, Toyonaga Y, Fujii R. Distribution of mefE and ermB genes in macrolide-resistant strains of Streptococcus pneumoniae and their variable susceptibility to various antibiotics. J Antimicrob Chemother 1999;43:637-43.

247. Eady EA, Ross JI, Tipper JL, Walters CE, Cove JH, Noble WC. Distribution of genes encoding erythromycin ribosomal methylases and an erythromycin efflux pump in epidemiologically distinct groups of staphylococci. J Antimicrob Chemother 1993;31:211-7.

248. Leclercq R, Courvalin P. Intrinsic and unusual resistance to macrolide, lincosamide, and streptogramin antibiotics in bacteria. Antimicrob Agents Chemother 1991;35:1273-6.

249. Ross JI, Farrell AM, Eady EA, Cove JH, Cunliffe WJ. Characterisation and molecular cloning of the novel macrolidestreptogramin B resistance determinant from Staphylococcus epidermidis. J Antimicrob Chem 1989;24:851-62.

250. Musher DM, Dowell ME, Shortridge VD, et al. Emergence of macrolide resistance during treatment of pneumococcal pneumonia. N Engl J Med 2002;346:630-1.

251. Doern GV, Brueggemann AB, Huynh H, Wingert E. Antimicrobial resistance with Streptococcus pneumoniae in the United States, 1997-98. Emerg Infect Dis 1999;5:757-65.

252. Amsden GW. Pneumococcal macrolide resistance - Myth or reality? J Antimicrob Chemother 1999;44:1-6.

253. Lynch JI, Martinez F. Clinical relevance of macrolide-resistant streptococcus pneumoniae for community-acquired pneumonia. Clin Infect Dis 2002;34:S27-S46.

254. Patel KB, Xuan D, Tessier PR, Russomanno JH, Quintiliani R, Nightingale $\mathrm{CH}$. Comparison of bronchopulmonary pharmacokinetics of clarithromycin and azithromycin. Antimicrob Agents Chemother 1996;40:2375-9.

255. Varon E, Janoir C, Kitzis MD, Gutmann L. ParC and GyrA may be interchangeable initial targets of some fluoroquinolones in Streptococcus pneumoniae. Antimicrob Agents Chemother 1999;43:302-6.

256. Ferrero L, Cameron B, Manse B, et al. Cloning and primary structure of Staphylococcus aureus DNA topoisomerase IV: A primary target of fluoroquinolones. Mol Microbiol 1994;13:641-53.

257. Janoir C, Zeller V, Kitzis MD, Moreau NJ, Gutmann L. High-level fluoroquinolone resistance in Streptococcus pneumoniae requires mutations in parC and gyrA. Antimicrob Agents Chemother 1996;40:2760-4.

258. Munoz R, De La Campa AG. ParC subunit of DNA topoisomerase IV of Streptococcus pneumoniae is a primary target of fluoroquinolones and cooperates with DNA gyrase A subunit in forming resistance phenotype. Antimicrob Agents Chemother 1996;40:2252-7.

259. Pan XS, Ambler J, Mehtar S, Fisher LM. Involvement of topoisomerase IV and DNA gyrase as ciprofloxacin targets in Streptococcus pneumoniae. Antimicrob Agents Chemother 1996;40:2321-6.

260. Aeschlimann JR, Kaatz GW, Rybak MJ. The effects of NorA inhibition on the activities of levofloxacin, ciprofloxacin and norfloxacin against two genetically related strains of Staphylococcus aureus in an in-vitro infection model. J Antimicrob Chemother 1999;44:343-9

261. Chen D, McGeer A, de Azavedo J, Low D. The Canadian bacterial surveillance network. Decreased susceptibility of streptococcus pneumoniae to fluoroquinolones in Canada. N Engl J Med 1999;341:233-9.

262. Vila J, Ruiz J, Sanchez F, et al. Increase in quinolone resistance in a Haemophilus influenzae strain isolated from a patient with recurrent respiratory infections treated with ofloxacin. Antimicrob Agents Chemother 1999;43:161-2.

263. Campos J, Roman F, Georgiou M, et al. Long-term persistence of ciprofloxacin-resistant Haemophilus influenzae in patients with cystic fibrosis. J Infect Dis 1996;174:1345-7.

264. Cunliffe NA, Emmanuel FX, Thomson CJ. Lower respiratory tract infection due to ciprofloxacin resistant Moraxella catarrhalis. J Antimicrob Chemother 1995;36:273-4.

265. DiPersio J, Jones R, Barrett T, Doern G, Pfaller M. Fluoroquinolone-resistant Moraxella catarrhalis in a patient with pneumonia: Report from the SENTRY Antimicrobial Surveillance Program (1998). Diagn Microbiol Infect Dis 1998;32:131-5.

266. Bootsma HJ, Troelstra A, Veen-Rutgers A, Mooi FR, de Neeling AJ, Overbeek BP. Isolation and characterization of a ciprofloxacin-resistant isolate of Haemophilus influenzae from The
Netherlands. J Antimicrob Chemother 1997;39:292-3.

267. Cooper B, Lawlor M. Pneumococcal bacteremia during ciprofloxacin therapy for pneumococcal pneumonia. Am J Med 1989;87:475.

268. Davies BI, Maesen FP, Baur C. Ciprofloxacin in the treatment of acute exacerbations of chronic bronchitis. Eur Clin Microbiol $1986 ; 5: 226-31$.

269. Lee BL, Padula AM, Kimbrough RC, et al. Infectious complications with respiratory pathogens despite ciprofloxacin therapy. $\mathrm{N}$ Engl J Med 1991;325:520-1.

270. Thys JP. Quinolones in the treatment of bronchopulmonary infections. Rev Infect Dis 1988;10(Suppl 1):5212-7.

271. Soman A, Honeybourne D, Andrews J, Jevons G, Wise R. Concentrations of moxifloxacin in serum and pulmonary compartments following a single $400 \mathrm{mg}$ oral dose in patients undergoing fibre-optic bronchoscopy. J Antimicrob Chemother 1999;44:835-8.

272. Birmingham MC, Guarino R, Heller A, et al. Ciprofloxacin concentrations in lung tissue following a single $400 \mathrm{mg}$ intravenous dose. J Antimicrob Chemother 1999;43(Suppl A):43-8.

273. Lacy MK, Lu W, Xu X, et al. Pharmacodynamic comparisons of levofloxacin, ciprofloxacin, and ampicillin against Streptococcus pneumoniae in an in vitro model of infection. Antimicrob Agents Chemother 1999;43:672-7.

274. Lister PD, Sanders CC. Pharmacodynamics of trovafloxacin, ofloxacin, and ciprofloxacin against Streptococcus pneumoniae in an in vitro pharmacokinetic model. Antimicrob Agents Chemother 1999;43:1118-23.

275. Linares J, De La Campa AG, Pallares R. Fluoroquinolone resistance in Streptococcus pneumoniae. N Engl J Med 1999;341:1546-7.

276. Weiss K, Restieri C, Gauthier R, et al. A nosocomial outbreak of fluoroquinolone-resistant Streptococcus pneumoniae. Clin Infect Dis 2001;33:517-22.

277. de Groot R, Sluijter M, de Bruyn A, et al. Genetic characterization of trimethoprim resistance in Haemophilus influenzae. Antimicrob Agents Chemother 1996;40:2131-6.

278. Maskell JP, Sefton AM, Hall LM. Mechanism of sulfonamide resistance in clinical isolates of Streptococcus pneumoniae. Antimicrob Agents Chemother 1997;41:2121-6.

279. Adrian P, Klugman K. Mutations in the dihydrofolate reductase gene of trimethoprim-resistant isolates of Streptococcus pneumoniae. Antimicrob Agents Chemother 1997;41:2406-13.

280. Dale G, Broger C, D'Arcy A, et al. A single amino acid substitution in Staphylococcus aureus dihyrofolate reductase determines trimethoprim resistance. J Mol Biol 1997;266:23-30.

281. Widdowson C, Klugman K. Molecular mechanisms of resistance to commonly used non-betalactam drugs in Streptococcus pneumoniae. Semin Respir Infect 1999;14:255-68.

282. Speer B, Shoemaker N, Salyers A. Bacterial resistance to tetracycline: Mechanisms, transfer, and clinical significance. Clin Microbiol Rev 1992;5:387-99.

283. Widdowson C, Klugman K. The molecular mechanisms of tetracycline resistance in the pneumococcus. Microb Drug Resist 1998;4:79-84.

284. Dewan NA, Rafique S, Kanwar B, et al. Acute exacerbation of COPD: Factors associated with poor treatment outcome. Chest 2000;117:662-71.

285. Miravitlles M, Murio C, Guerrero T, on behalf of the DAFNE study group. Factors associated with relapse after ambulatory treatment of acute exacerbations of chronic bronchitis. Eur Respir J 2001;17:928-33.

286. Adams S, Melo J, Luther M, Anzueto A. Antibiotics are associated with lower relapse rates in outpatients with acute exacerbations of COPD. Chest 2000;117:1345-52.

287. Grossman R, Mukherjee J, Vaughan D, et al, for the Canadian Ciprofloxacin Health Economic Study Group. A 1-year community-based health economic study of ciprofloxacin vs usual antibiotic treatment in acute exacerbations of chronic bronchitis. Chest 1998;113:131-41.

288. Kessler R, Faller M, Fourgaut G, Nennevier B, Weitsenblum E. Predictive factors of hospitalization for acute exacerbation in a series of 64 patients with chronic obstructive pulmonary disease. Am J Crit Care Med 1999;159:158-64.

289. Garcia-Aymerich J, Monso E, Marrales R, et al. Risk factors for a chronic obstructive pulmonary disease exacerbation. Am J Respir Crit Care Med 2001;164:1002-7. 
290. Miravitlles M, Guerrero T, Mayordomo C, Sanchez-Agudo L, Nicolau F, Segu JL. Factors associated with increased risk of exacerbation and hospital admission in a cohort of ambulatory COPD patients: A multiple logistic regression analysis. The EOLO Study Group. Respiration 2000;67:495-501.

291. Antonelli-Incalzi A, Fuso L, De Rosa M, et al. Co-morbidity contributes to predict mortality of patients with chronic obstructive pulmonary disease. Eur Respir J 1997;10:2794-800.

292. Niederman MS, McCombs JS, Unger AN, Kumar A, Popovian R. Treatment cost of acute exacerbations of chronic bronchitis. Clin Ther 1999;21:576-91.

293. Miravitlles M, Murio C, Guerrero T, Gisbert R. Pharmacoeconomic evaluation of acute exacerbations of chronic bronchitis and COPD. Chest 2002;121:1449-55.

294. Fahey T, Stocks N, Thomas T. Quantitative systematic review of randomised controlled trials comparing antibiotic with placebo for acute cough in adults. Br Med J 1998;316:906-10.

295. Smucny J, Becker L, Glazier R, McIsaac W. Are antibiotics effective treatment for acute bronchitis? A meta-analysis. J Fam Pract 1998;47:453-60.

296. Bent S, Saint S, Vittinghoff E, Grady D. Antibiotics in acute bronchitis: A meta-analysis. Am J Med 1999;107:62-7.

297. Gonzales R, Sande M. Uncomplicated acute bronchities. Ann Intern Med 2000;133:981-91.

298. Macfarlane J, Holmes W, Gard P, Thornhill D, Macfarlane R, Hubbard R. Reducing antibiotic use for acute bronchitis in primary care: Blinded, randomised conrolled trial of patient information leaflet. Br Med J 2002;324:91-4.

299. Backhouse R, Shakespeare A, Hutton J. Economic evaluation of alternative antibiotic regimens in the management of acute exacerbations of chronic bronchitis. Br J Med Econ 1995;8:11-25.

300. Wool C, Cerutti R, Garbagna N, Grossi E. A cost-effectiveness study of four different antibiotics in the treatment of acute exacerbations of chronic obstructive pulmonary disease. Br J Med Econ 1996;10:159-68.

301. van Barlingen HJJ, Nuijten MJC, Volmer T. Model to evaluate the cost-effectiveness of different antibiotics in the management of acute bacterial exacerbation of chronic bronchitis in Germany. J Med Econ 1998;1:210-8.

302. Pechere JC, Lacey L. Optimizing economic outcomes in antibiotic therapy of patients with acute bacterial exacerbations of chronic bronchitis. J Antimicrob Chemother 2000;45:19-24.

303. LeLorier J, Derderian F. Effect of listing ciprofloxacin in provincial formularies in hospitalizations for bronchitis and pyelonephritis. Can J Clin Pharmacol 1998;5:133-7.

304. Sin DD, Tu JV. Outpatient antibiotic therapy and short term mortality in elderly patients with chronic obstructive pulmonary disease. Can Respir J 2000;7:466-71.

305. Allegra L, Blasi F, deBernardi B, Cosentini R, Tarsia P. Antibiotic treatment and baseline severity of disease in acute exacerbations of chronic bronchitis: A re-evaluation of previously published data of a placebo controlled randomized study. Pulm Pharmacol Ther 2001;14:149-55.

306. Torrance G, Walker V, Grossman R. Economic evaluation of ciprofloxacin compared with usual antibacterial care for the treatment of acute exacerbations of chronic bronchitis in patients followed for 1 year. Pharmacoeconomics 1999;16:499-520.

307. Chodosh S. Treatment of acute exacerbations of chronic bronchitis: State of the art. Am J Med 1991;91(6A):87S-92S.

308. Chodosh S, Schreurs A, Siami G, et al. Efficacy of oral ciprofloxacin versus clarithromycin for treatment of acute bacterial exacerbations of chronic bronchitis. The Bronchitis Study Group. Clin Infect Dis 1998;27:730-8.

309. Wilson R, Schentag J, Ball P, Mandell L, 068 Study Group. A comparison of gemifloxacin and clarithromycin in acute exacerbations of chronic bronchitis and long-term clinical outcomes. Clin Ther 2002;24:639-52.

310. Wilson R, Jones P, Schaberg T, et al. A clinical and outcomes assessment of the management of acute exacerbations of chronic bronchitis (AECB): The Mosaic Study. 12th ERS Annual Congress Stockholm, Sweden, 2002.

311. Ho P, Tse W, Tsang K, Ng T, Cheng V, Chan R. Risk factors for acquisition of levofloxacin-resistant Streptococcus pneumoniae: A case-control study. Clin Infect Dis 2001;32:701-7.

312. Canadian Lung Association, Health Canada, Statistics Canada, Canadian Institute for Health Information. Tobacco use.

\section{INC, DO NOT COPY}

Respiratory disease in Canada. Ottawa, Canada: Health Canada, 2001:11-7.

313. Anthonisen N, Connett J, Kiley J, et al. Effects of smoking intervention and the use of an inhaled anticholinergic bronchodilator on the rate of decline of $\mathrm{FEV}_{1}$ : The Lung Health Study. JAMA 1994;272:1497-505.

314. Higgins M, Enright P, Kronmal R, Schenker M, Anton-Culver H, Lyles M. Smoking and lung function in elderly men and women. The cardiovascular health study. JAMA 1993;269:2741-8.

315. Postma D, Sluiter H. Prognosis of chronic obstructive pulmonary disease: the Dutch experience. Am Rev Respir Dis 1989;140:S100-5.

316. Wynder E, Kaufman P, Lesser R. A short-term follow-up study on ex-cigarete smokers. With special emphasis on persistent cough and weight gain. Am Rev Respir Dis 1967;96:645-55.

317. Rutgers S, Postma D, ten Hacken N, et al. Ongoing airway inflammation in patients with COPD who do not currently smoke. Thorax 2000;55:12-8.

318. Turato G, Di Stefano A, Maestrelli P, et al. Effect of smoking cessation on airway inflammation in chronic bronchitis. Am J Respir Crit Care Med 1995;152:1262-7.

319. Fiore M. US public health service clinical practice guidelines: Treating tobacco use and dependence. Respir Care 2000;45:1200-62.

320. Jorenby D, Leischow S, Nides M, et al. A controlled trial of sustained-release bupropion, a nicotine patch, or both for smoking cessation. N Engl J Med 1999;340:685-91.

321. Carilli A, Gohd R, Gordon W. A virologic study of chronic bronchitis. N Engl J Med 1964;270:123-7.

322. Lamy M, Ponthier-Simon F, Debacker-Williame E. Respiratory viral infections in hospital patients with chronic bronchitis. Chest 1973;63:336-41.

323. Walsh E, Falsey A, Hennessey P. Respiratory syncytial and other virus infections in persons with chronic cardiopulmonary disease. Am J Respir Crit Care Med 1999;160:791-5.

324. Nichol K, Margolis K, Wuorenma J, Von Sternberg T. The efficacy and cost effectiveness of vaccination against influenza among elderly persons living in the community. N Engl J Med 1994;331:778-84.

325. Nichol K, Baken L, Nelson A. Relation between influenza vaccination and outpatient visits, hospitalizations and mortality among elderly patients with chronic lung disease. Ann Intern Med 1999; 130:397-403.

326. Fine M, Smith M, Carson C, et al. Efficacy of pneumococcal vaccination in adults. A meta-analysis of randomized controlled trials. Arch Intern Med 1994;154:2666-77.

327. Hutchison B, Oxman A, Shannon H, Lloyd S. Clinical effectivenes of pneumococcal vaccines: Meta-analysis. Can Fam Physician 1999;45:2381-93.

328. Nichol K, Baken L, Wuorenma J, Nelson A. The health and economic benefits associated with pneumococcal vaccination of elderly patients with chronic lung disease. Arch Intern Med 1999; 159:2437-42.

329. Butler J, Breiman R, Campbell J, Lipman H, Broome C, Facklam R. Pneumococcal polysaccharide vaccine efficacy: An evaluation of current recommendations. JAMA 1993;270:1826-31.

330. Centre for disease control and prevention. Prevention of pneumococcal disease. 46 (RR-8), 1-24. 1997. MMWR Morb Mortal Wkly Rep. Prevention of pneumococcal disease: recommendations of the Advisory Committee on Immunization Practices (ACIP). MMWR Recomm Rep. 1997 Apr 4;46(RR-8):1-24.

331. Clancy R, Cripps A, Gebski V. Protection against recurrent acute bronchitis after oral immunization with killed Haemophilus influenzae. Med J Aust 1990;152:413-6.

332. Foxwell A, Cripps A. Haemophilus influenzae oral vaccination against accute bronchitis. Cochrane Database Syst S Rev 2000;(2): CD001958.

333. Orcel B, Delclaux B, Baud M, Derenne J. Oral immunization with bacterial extracts for protection against acute bronchitis in elderly institutionlized patients with chronic bronchitis. Eur Respir J 1994;7:446-52.

334. Collett J, Shapiro S, Ernst P, Renzi T, Ducruet T, Robinson A. Effects of an immunostimulating agent on acute exacerbations and hospitalizations in patients with chronic obstructive pulmonary disease.The PARI-IS Study Steering Committee and Research Group. Prevention of Acute Respiratory Infection by an Immunostimulant. Am J Respir Crit Care Med 1997;156:1719-24.

335. Collett J, Ducruet T, Haider S, et al. Economic impact of using an 
immunostimulating agent to prevent severe acute exacerbations in patients with chronic obstructive pulmonary disease. Can Respir J 2001;8:27-33.

336. Thompson A, Mueller M, Heires A, et al. Aerosolized beclomethasone in chronic bronchitis. Improved pulmonary function and diminished airway inflammation. Am Rev Respir Dis 1992;146:389-95.

337. Confalonieri M, Mainardi E, Della Porta R, et al. Inhaled corticosteroids reduce neutrophilic bronchial inflamation in patients with chronic obstructive pulmonary disease. Thorax 1998;53:583-5.

338. Balbi B, Majori M, Bertacco S, et al. Inhaled corticosteroids in stable COPD patients: Do they have effects on cells and molecular mediators of airway inflammation. Chest 2000;117:1633-7.

339. Cox G, Whitehead L, Dolovich M, Jordanna M, Gauldie J, Newhouse M. A randomized controlled trial on the effect of inhaled corticosteroids on airways inflammation in adult cigarette smokers. Chest 1999;115:1271-7.

340. Culpitt SV, Maziak W, Loukidis S, Nightingale JA, Matthews JL, Barnes PJ. Effect of high dose inhaled steroid on cells, cytokines, and proteases in induced sputum in chronic obstructive pulmonary disease. Am J Respir Crit Care Med 1999;160:1635-9.

341. Loppow D, Schleiss MB, Kanniess F, Taube C, Jorres RA, Magnussen $H$. In patients with chronic bronchitis a four week trial with inhaled steroids does not attenuate airway inflammation. Respir Med 2001;95:115-21.

342. Pauwels RA, Lofdahl CG, Laitinen LA, et al. Long-term treatment with inhaled budesonide in persons with mild chronic obstructive pulmonary disease who continue smoking. European Respiratory Society Study on Chronic Obstructive Pulmonary Disease. N Engl J Med 1999;340:1948-53.

343. Vestbo J, Sorensen T, Lange P, Brix A, Torre P, Viskum K. Longterm effect of inhaled budesonide in mild and moderate chronic obstructive pulmonary disease: A randomised controlled trial. Lancet 1999;353:1819-23.

344. Burge PS, Calverley PM, Jones PW, Spencer S, Anderson JA, Maslen TK. Randomised, double blind, placebo controlled study of fluticasone propionate in patients with moderate to severe chronic obstructive pulmonary disease: The ISOLDE trial. Br Med J 2000;320:1297-303.

345. The Lung Health Study Research Group. Effect of inhaled triamcinolone on the decline in pulmonary function in chronic obstructive pulmonary disease. N Engl J Med 2000;343:1902-9.

346. Paggiaro PL, Dahle R, Bakran I, Frith L, Hollingworth K, Efthimiou J. Multicentre randomised placebo-controlled trial of inhaled fluticasone propionate in patients with chronic obstructive pulmonary disease. International COPD Study Group. Lancet 1998;351:773-80.

347. Sin DD, Tu JV. Inhaled corticosteroids and the risk of mortality and readmission in elderly patients with chronic obstructive pulmonary disease. Am J Resp Crit Care Med 2001;164:580-4.

348. Postma DS, Steenhuis EJ, van der Weele LT, Sluiter HJ. Severe chronic air flow obstruction: Can corticosteroids slow down progression? Eur J Respir Dis 1985;67:56-64.

349. Postma DS, Peters I, Steenhuis EJ, Sluiter HJ. Moderately severe chronic air flow obstruction. Can corticosteroids slow down obstruction? Eur Respir J 1988;1:22-6.

350. Renkema TE, Schouten JP, Koeter GH, Postma DS. Effects of longterm treatment with corticosteroids in COPD. Chest 1996;109:1156-62.

351. McEvoy CE, Niewoehner DE. Adverse effects of corticosteroid therapy for COPD. A critical review. Chest 1997;111:732-43.

352. McEvoy CE, Ensrud KE, Bender E, et al. Association between corticosteroid use and vertebral fractures in older men with chronic obstructive pulmonary disease. Am J Respir Crit Care Med 1998;157:704-9.

353. Schols A, Wesseling G, Kester A, et al. Dose dependent increased mortality risk in COPD patients treated with oral glucocorticoids. Eur Respir J 2001;17:337-42.

354. Rice KL, Rubins JB, Lebahn F, et al. Withdrawal of chronic systemic corticosteroids in patients with COPD: A randomized trial. Am J Respir Crit Care Med 2000;162:174-8.

355. Dowling RB, Rayner CF, Rutman A, et al. Effect of salmeterol on Pseudomonas aeruginosa infection of respiratory mucosa. Am J Respir Crit Care Med 1997;155:327-36.

356. Dowling RB, Johnson M, Cole PJ, Wilson R. Effect of salmeterol on Haemophilus influenzae infection of respiratory mucosa in vitro. Eur Respir J 1998;11:86-90.

357. Mahler DA, Donohue JF, Barbee RA, et al. Efficacy of salmeterol xinafoate in the treatment of COPD. Chest 1999;115:957-65.

358. Vincken W, van Noord J, Greefhorst A, et al. Improved health outcomes in patients with COPD during 1 yr's treatment with tiotropium. Eur Respir J 2002;19:209-16.

359. Casaburi R, Mahler D, Jones P, Wanner A, San Pedro G, ZuWallack R. A long-term evaulation of once-daily inhaled tiotropium in chronic obstructive pulmonary disease. Eur Respir J 2002;19:217-24.

360. Poole P, Black P. The effect of mucolytic agents on exacerbation frequency in chronic bronchitis. The Cochrane Library. Oxford: Update software, 1998.

361. Stey C, Steurer J, Bachmann S, Medici T, Tramer N. The effects of oral N-acetylcysteine in chronic bronchitis: A quantitative systemic review. Eur Respir J 2000;16:253-62.

362. Poole PJ, Black PN. Oral mucolytic drugs for exacerbating of chronic obstructive pulmonary disease: A systemic review. Br Med J 2001;322:1271-4.

363. Grandjean E, Berthet P, Ruffman R, Lenberger P. Cost-effectiveness analysis of oral $\mathrm{N}$-acetylcysteine as a preventive treatment in chronic bronchitis. Pharmacol Res 2000;42:39-50.

364. Vecchiarelli A, Dottorini M, Pietrella D, et al. Macrophage activation by $\mathrm{N}$-acetyl-cysteine in COPD patients. Chest 1994;105:806-11.

365. Venger P, Pederson B, Hahansson L, Hallgren R, Lindblad G, Dahl R. Subcutaneous administration of hyaluronan reduces the number of infectious exacerbations in patients with chronic bronchitis. Am J Respir Crit Care Med 1996;153:312-6.

366. Ruben F. Prophylactic treatment of chronic bronchitis. Sem Respir Infec 1988;3:72-80.

367. Liippo K, Pelliniemi T-T, Lehto H. Trimethoprim prophylaxis of acute exacerbations in chronic obstructive pulmonary disease. Acta Med Scand 1987;21:455-9.

368. Value of chemoprophylaxis and chemotherapy in early chronic bronchitis. A report to the Medical Research Council by their working party on the trials of chemotherapy in early chronic bronchitis. Br Med J 1966;5499:317-22.

369. Francis R, Spicer C. Chemotherapy in chronic bronchitis: Influence of daily penicillin and tetracycline on exacerbations and their cost. Br Med J 1960;1:297-303.

370. Suzuki T, Yanai M, Yamaya M, et al. Erythromycin and common cold in COPD. Chest 2001;120:730-3.

371. Albert R, Martin T, Lewis S. Controlled clinical trial of methylprednisolone in patients with chronic bronchitis and acute respiratory insufficiency. Ann Intern Med 1980;92:753-8.

372. Low DE, de Azavedo J, Weiss K, et al. Antimicrobial resistance among clinical isolates of Streptococcus pneumoniae in Canada during 2000. Antimicrob Agents Chemother 2002;46:1295-301. 


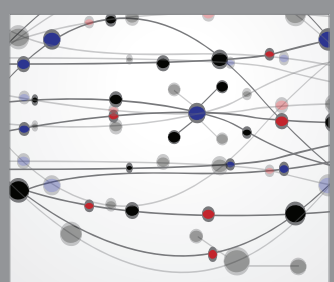

The Scientific World Journal
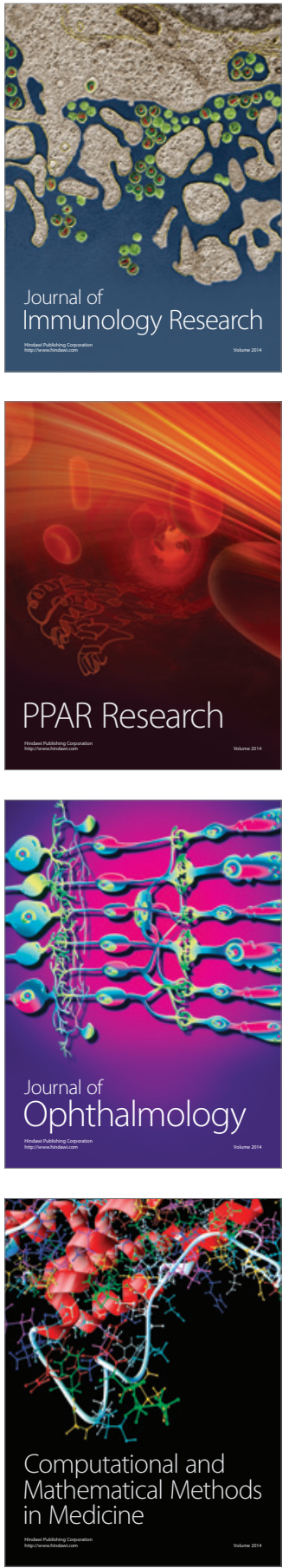

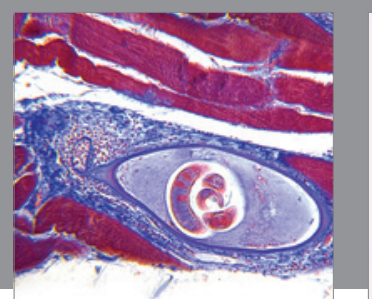

Gastroenterology Research and Practice

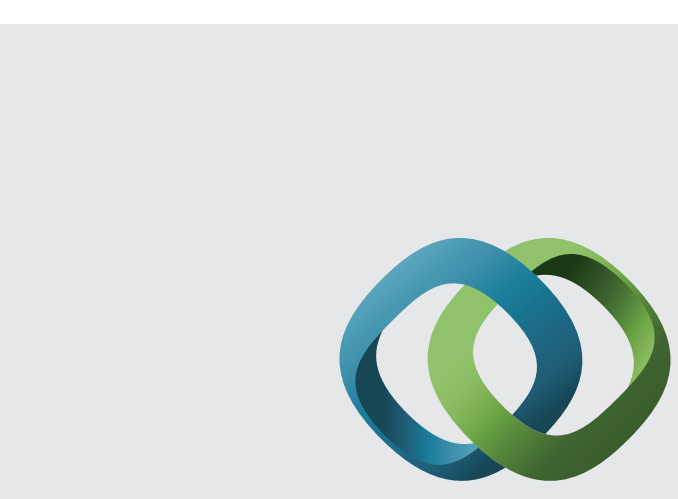

\section{Hindawi}

Submit your manuscripts at

http://www.hindawi.com
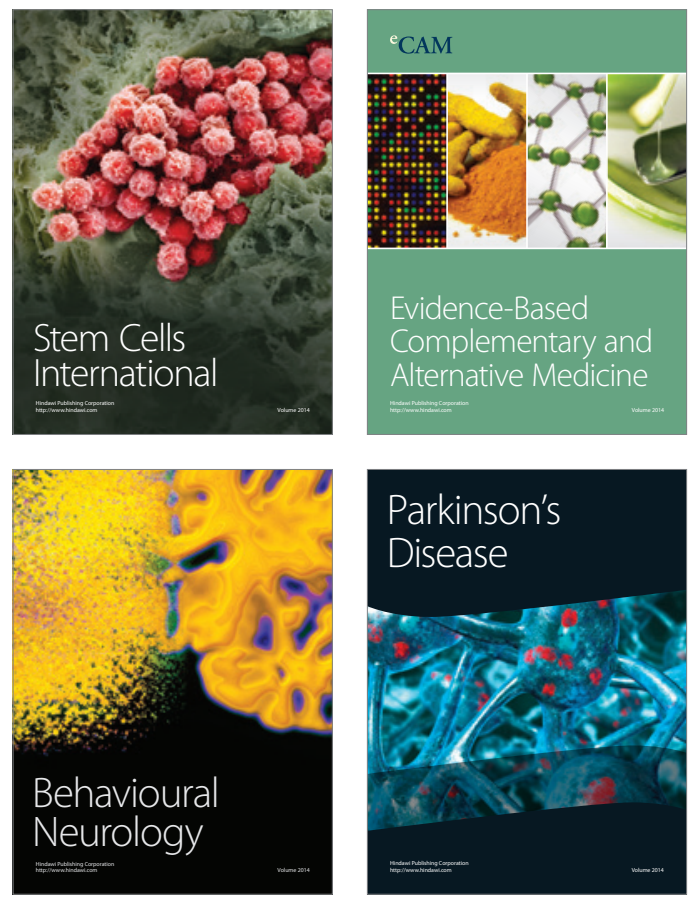
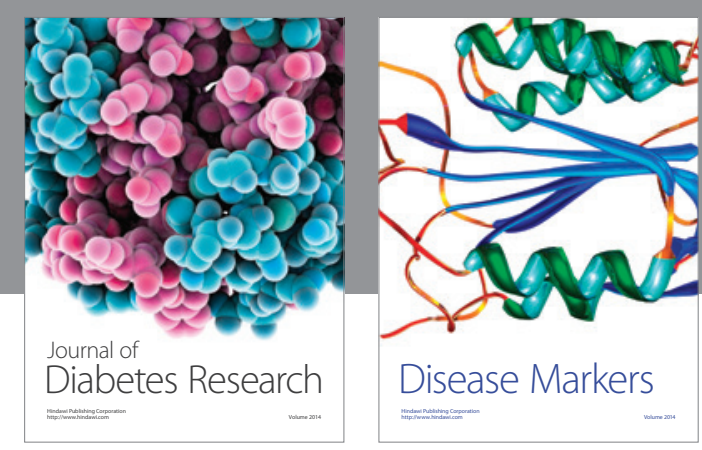

Disease Markers
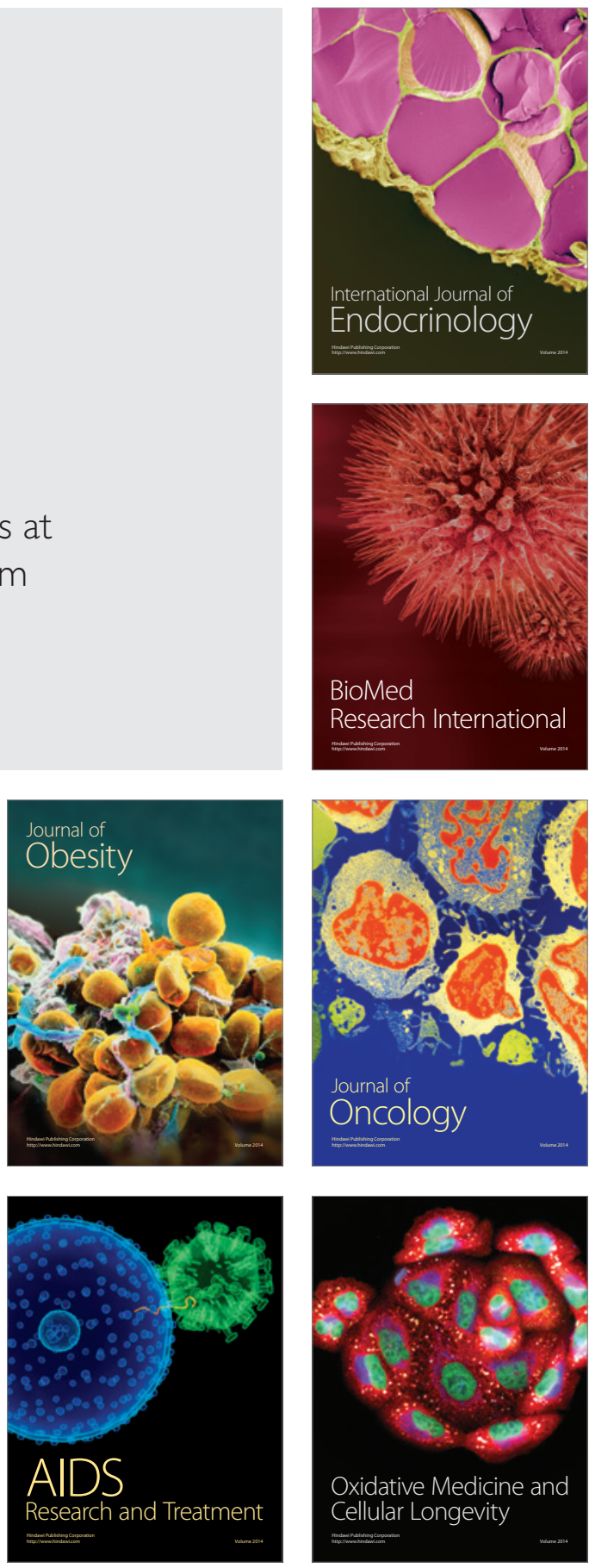